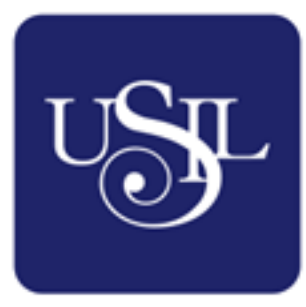

UNIVERSIDAD

SAN IGNACIO

DE LOYOLA

FACULTAD DE CIENCIAS EMPRESARIALES

Carrera de Administración

\title{
RELACIÓN DE LA RESPONSABILIDAD SOCIAL CORPORATIVA Y LA LEALTAD DE CLIENTES EN EL HOTEL PALMETTO DE SAN BORJA 2020
}

Tesis para optar el Título Profesional de Licenciado en Administración

\section{VICTOR ENRIQUE CALDERON REYNA WALTHER JORGINHO CHICO LOPEZ}

Asesora:

PhD. Frida Rosa Coaquira Nina

Lima - Perú

2020 


\section{Índice}

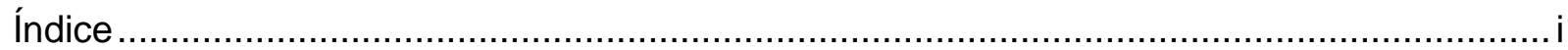

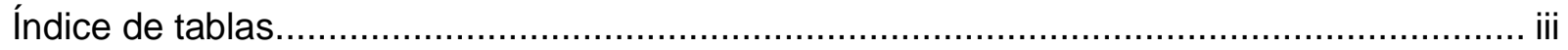

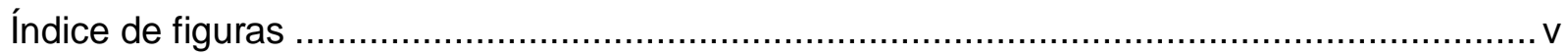

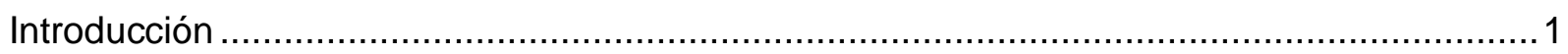

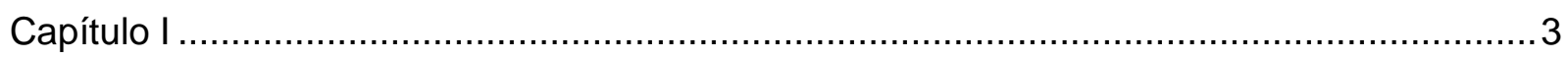

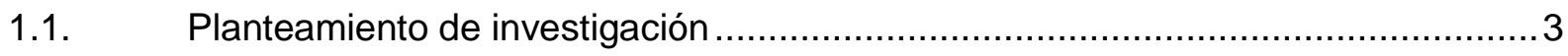

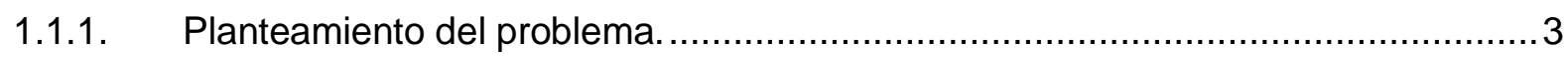

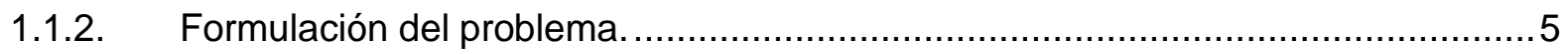

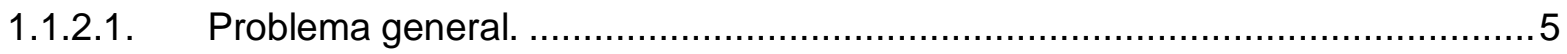

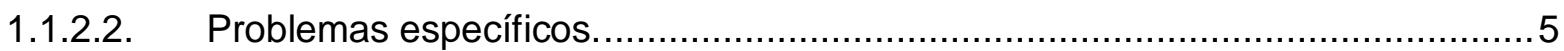

1.1.3. Justificación de la investigación.................................................................

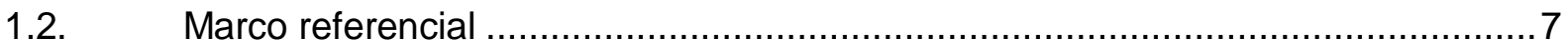

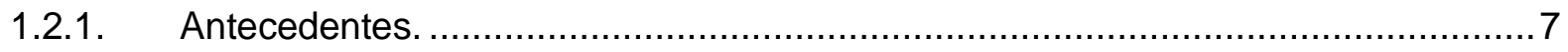

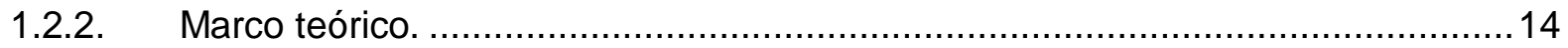

1.2.2.1. Responsabilidad social corporativa (RSC) .............................................. 15

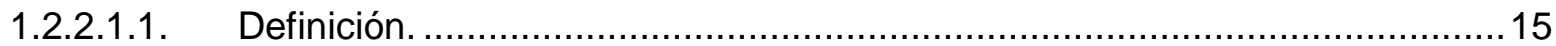

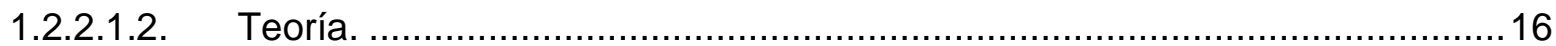

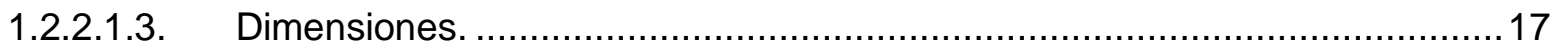

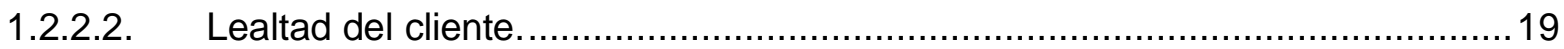

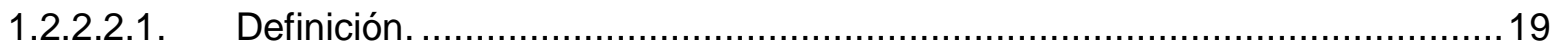

1.2.2.2.2. ¿Cuál es el beneficio de la lealtad del cliente? ..........................................19

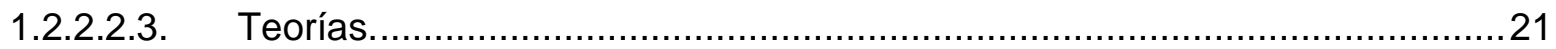

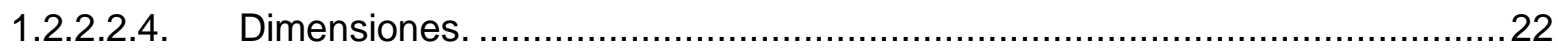

1.2.2.3. Responsabilidad social corporativa y lealtad del cliente................................23

1.2.2.4. Responsabilidad social corporativa e industria hotelera................................24

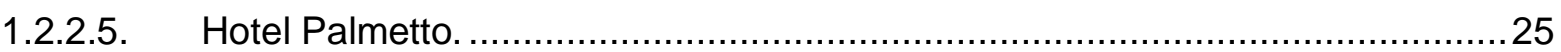

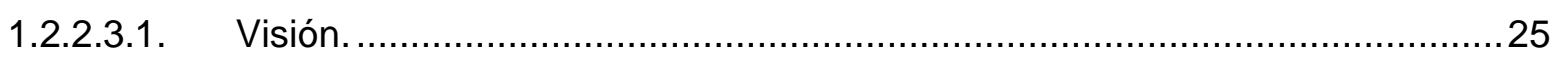

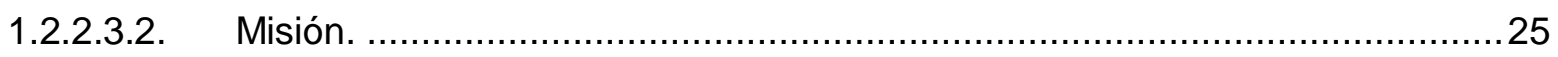

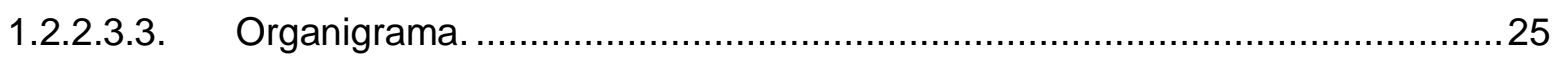

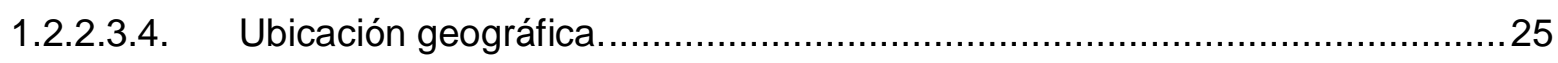

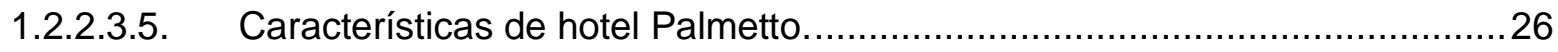

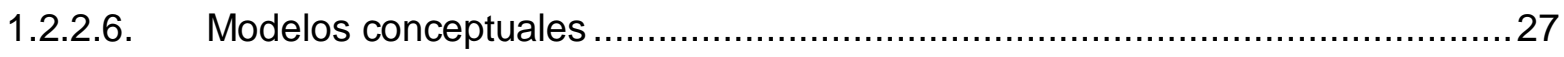






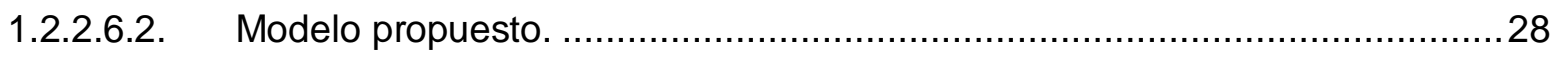

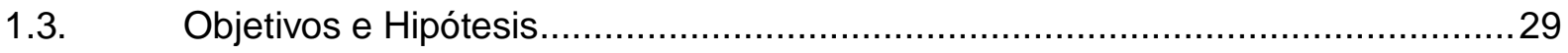

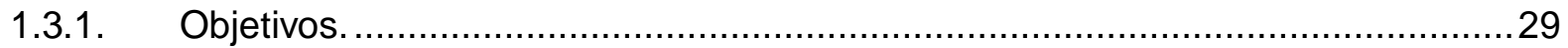

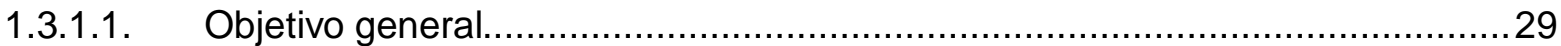

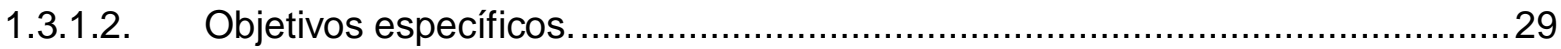

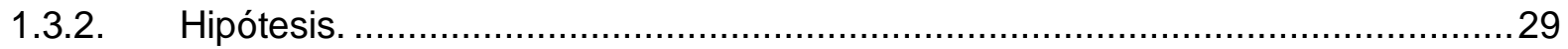

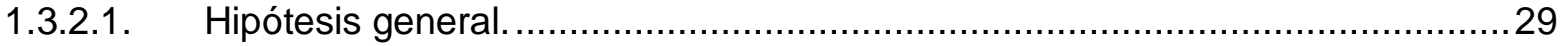

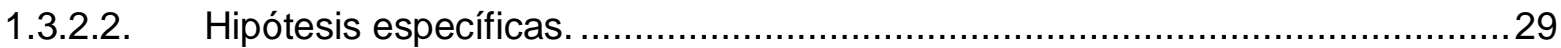

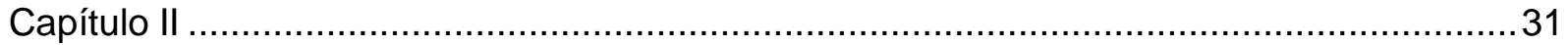

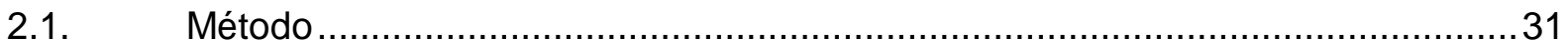

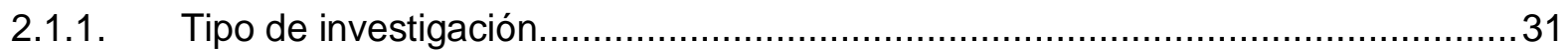

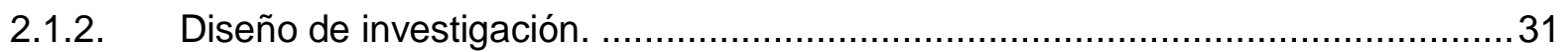

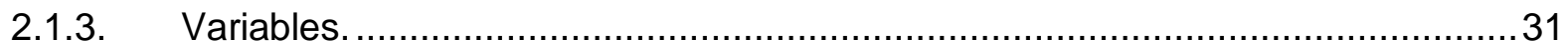



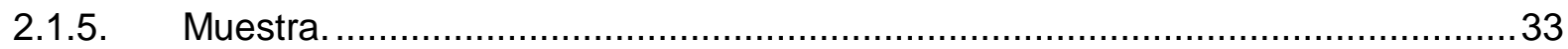

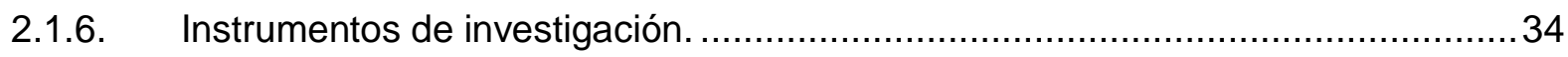

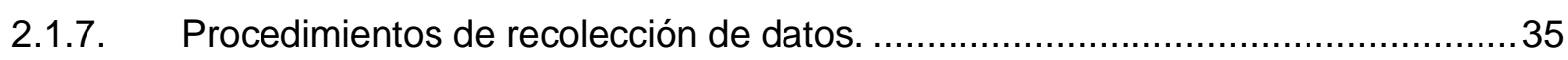

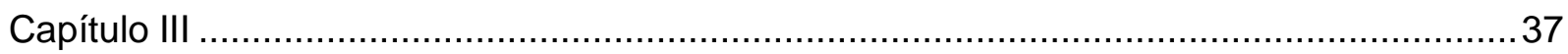

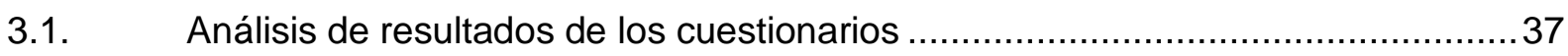

3.1.1. Análisis de los resultados de responsabilidad social corporativa .........................37

3.1.2. Análisis de los resultados de lealtad del cliente .............................................4

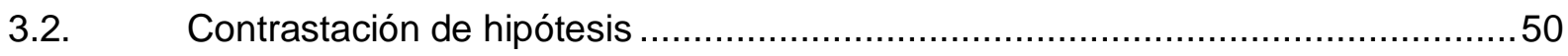

3.2.1. Prueba de normalidad de Kolmogorov-Smirnov ................................................ 50

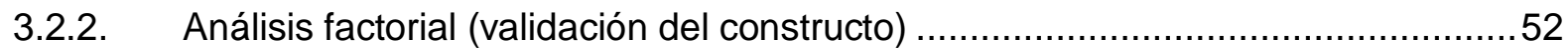

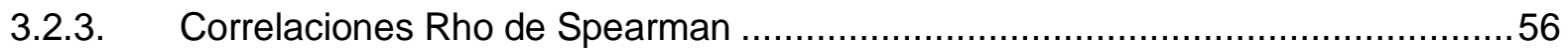

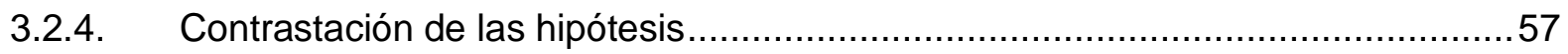

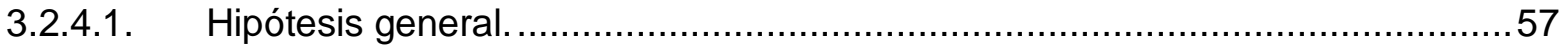

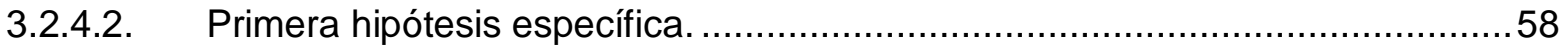

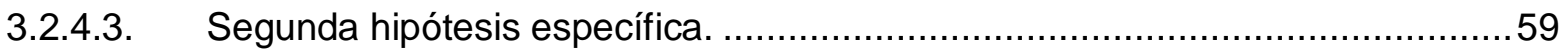

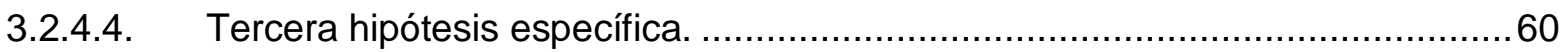

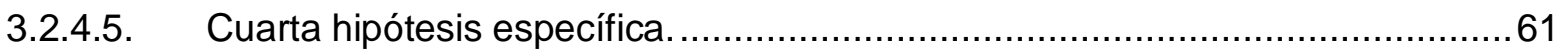

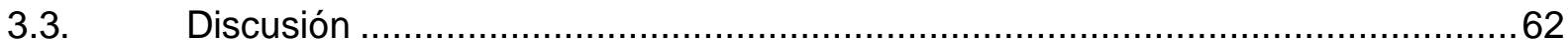




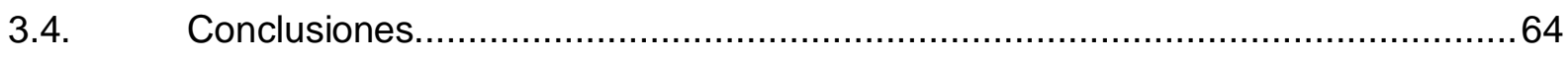

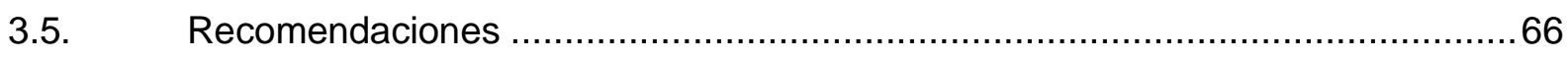

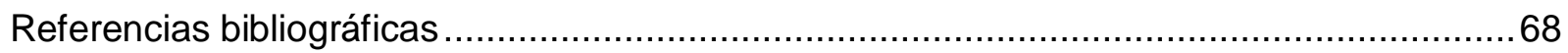



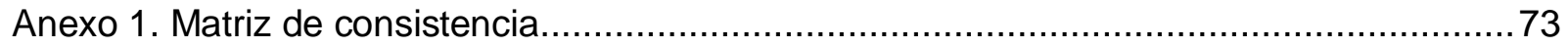

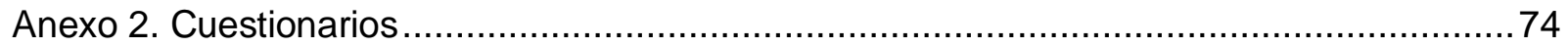

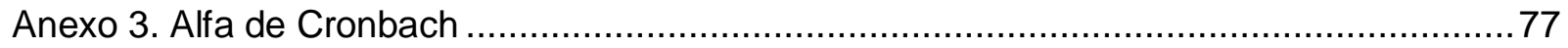

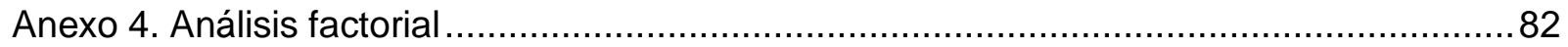

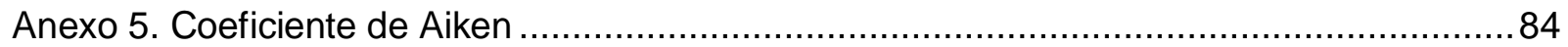

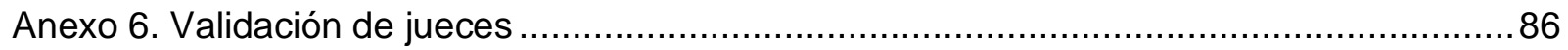



\section{Índice de tablas}

Tabla 1: Dimensiones de responsabilidad social corporativa ............................................17

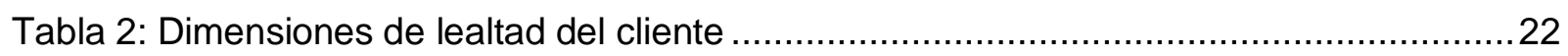

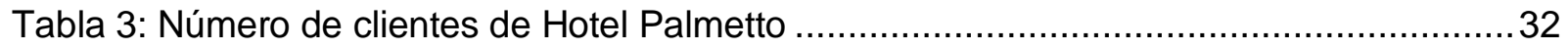

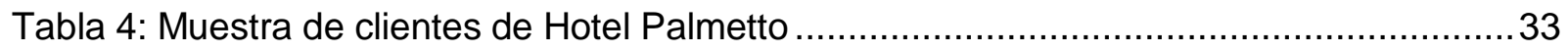

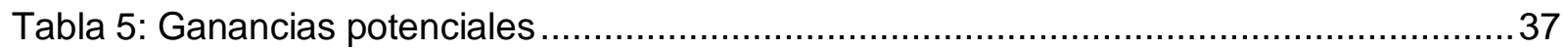

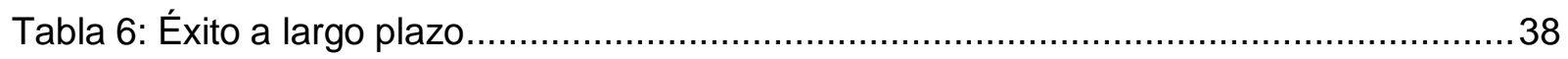

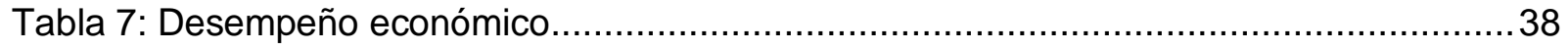

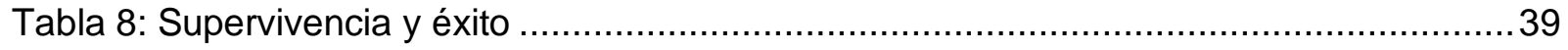

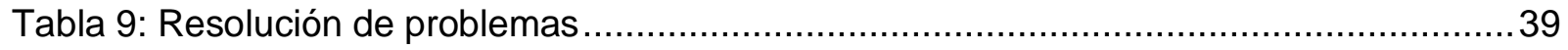

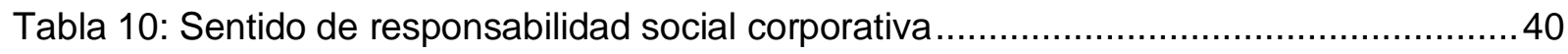

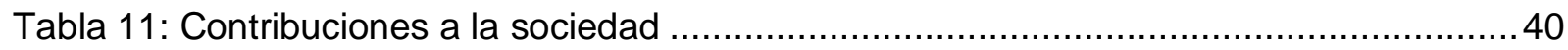

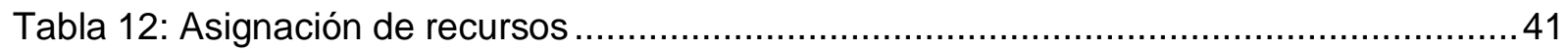

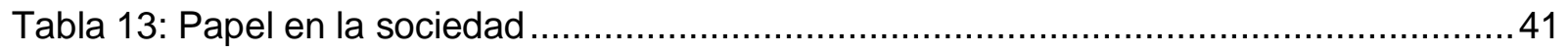

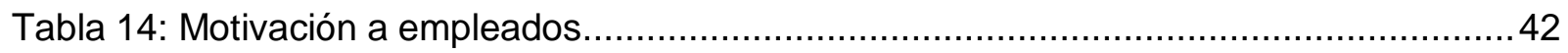

Tabla 15: Importancia de la responsabilidad social corporativa............................................. 42

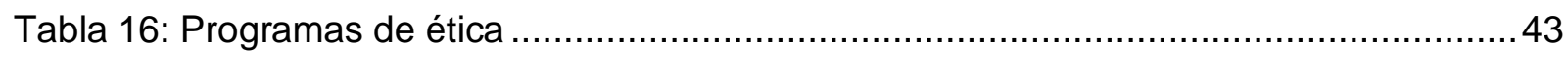



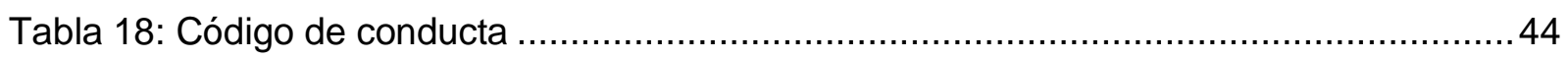

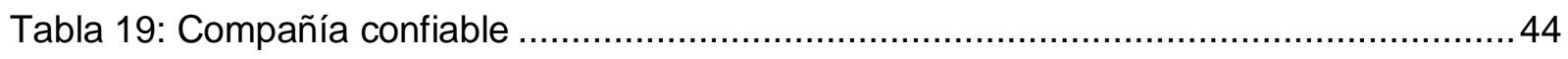

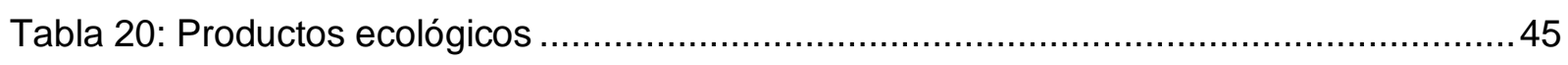




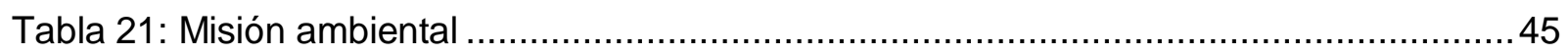

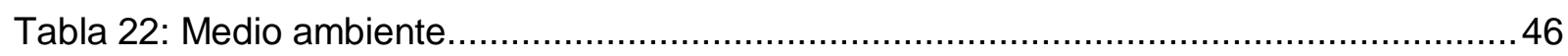

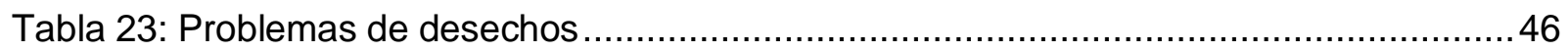

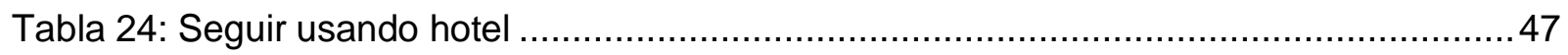



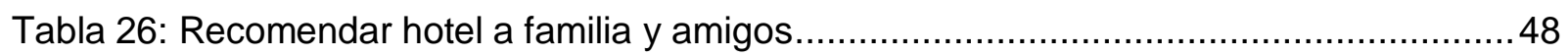

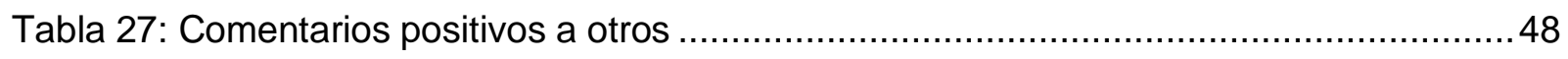

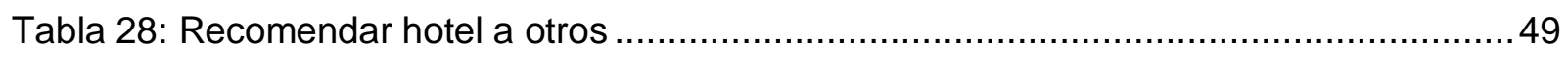

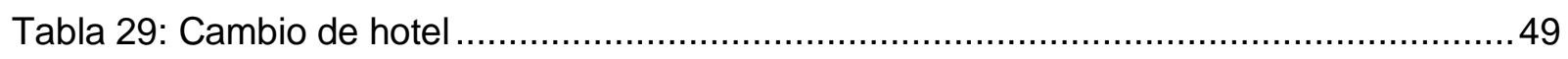

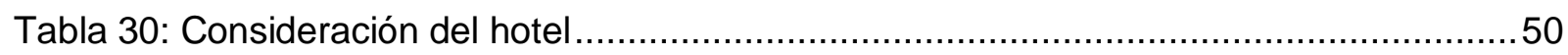

Tabla 31: Prueba de normalidad Kolmogorov-Smirnov RSC ...........................................50

Tabla 32: Prueba de normalidad Kolmogorov-Smirnov Lealtad del cliente ...........................52

Tabla 33: Prueba de KMO, Bartlett y método de extracción .................................................52

Tabla 34: Varianza total explicada - Responsabilidad social corporativa ..............................53

Tabla 35: Matriz de componente rotado de gestión del conocimiento - Método de rotación

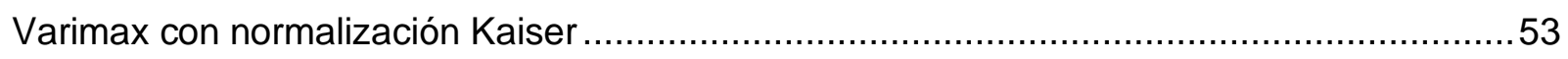

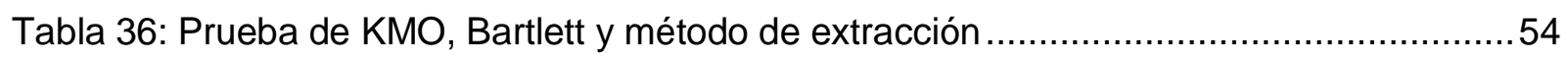

Tabla 37: Varianza total explicada - Lealtad del cliente …….............................................5

Tabla 38: Matriz de componente - Lealtad del cliente …...............................................5

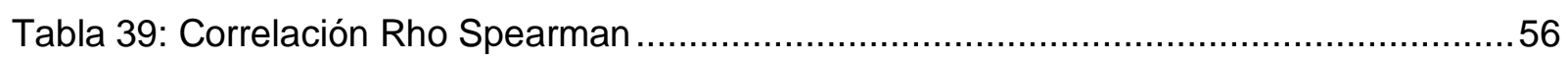

Tabla 40: Resultado de Rho de Spearman - Hipótesis general ..........................................57

Tabla 41: Resultado de Rho de Spearman - Primera hipótesis específica …........................58

Tabla 42: Resultado de Rho de Spearman - Segunda hipótesis específica ..........................59

Tabla 43: Resultado de Rho de Spearman - Tercera hipótesis específica ............................60

Tabla 44: Resultado de Rho de Spearman - Cuarta hipótesis específica ..............................61

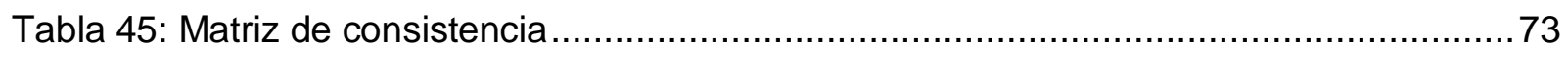

Tabla 46: Cuestionario responsabilidad social corporativa............................................. 74

Tabla 47: Cuestionario lealtad del cliente .................................................................... 


\section{Índice de figuras}

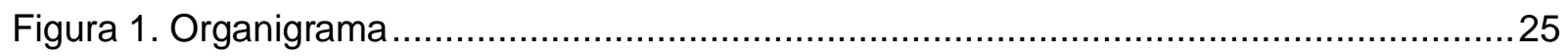

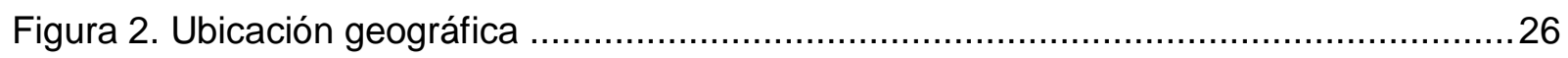

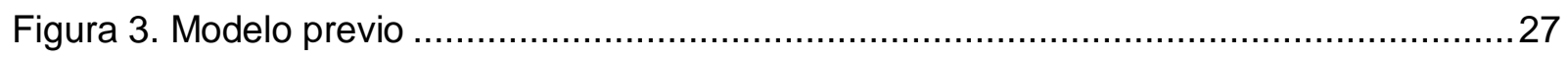

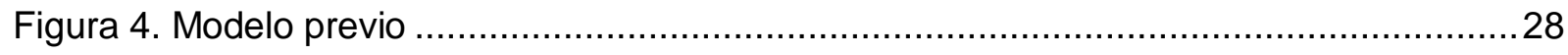

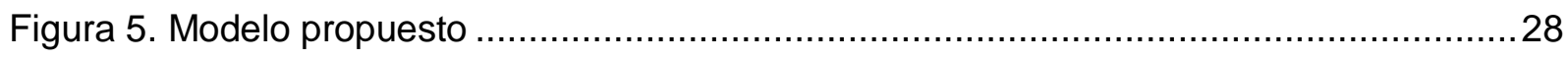




\section{Introducción}

La responsabilidad social corporativa (RSC) incluye aspectos sociales, económicos y medioambientales. Las empresas que deciden asumir la responsabilidad social corporativa en su gestión diaria modifican aspectos de su gestión al tener en cuenta por una parte a sus grupos de interés (clientes, personal contratado, proveedores, accionistas, administración pública, comunidad en la que operan, medios de comunicación, entre otros) y por otra la necesidad de medir y reducir sus impactos medioambientales. La RSC constituye, por tanto, una herramienta de creación de valor para los grupos de interés de la organización, consiguiendo la generación de efectos positivos a través del diálogo y la transparencia con accionistas, políticas de recursos humanos, participación de la comunidad local, al mismo tiempo que constituye una estrategia de gestión de los impactos que genera la organización en el entorno en el que opera.

Los clientes que se consideran habituales (aquellos que suelen reincidir sus prácticas en un mismo servicio) son los encargados de generar mayor rentabilidad para las empresas, por lo cual se puede afirmar que mantener el vínculo con un cliente conocido es más rentable que atraer un cliente nuevo. Los clientes leales realizan compras regularmente y producen tasas de conversión más altas, lo que genera un mayor número de ganancias. La lealtad de cliente permite a las organizaciones a pronosticar el crecimiento de manera eficaz, lo que contribuye en una planificación financiera, la lealtad es considerada como la sensación de afinidad que siente los clientes con los productos o servicios.

Es por esta razón que el objetivo principal de esta investigación es la de determinar si existe o no relación alguna entre la responsabilidad social corporativa y la lealtad de los clientes en un hotel en San Borja.

En el primer capítulo, se identifica y se plantea la problemática, con la intención de reconocer los puntos críticos y proponer diferentes recomendaciones, de igual manera se mencionará los antecedentes que servirán de apoyo para desarrollar la presente investigación, así mismo el objetivo e hipótesis, los cuales servirán para poder ratificar las hipótesis planteadas.

En el segundo capítulo, se detalla la metodología que se utiliza, haciendo hincapié en el tipo y diseño de investigación, así como las variables tomadas en consideración, también se hace mención hacia quienes está dirigida esta investigación. De igual manera se da la explicación pertinente de los cuestionarios se utiliza y el procedimiento de recolección de datos. 
En el tercer capítulo, se presentan los análisis de resultados de los cuestionarios, la contrastación de las hipótesis, donde se desarrolla la prueba de normalidad, el análisis factorial exploratorio, las correlaciones Rho de Spearman y la contrastación de la hipótesis general y específicas, así mismo la discusión, las conclusiones y las recomendaciones. Concluyendo con las referencias bibliográficas y los anexos (cuestionarios), que son elementos primordiales para obtener los datos que se necesitan. 


\section{Capítulo I}

\subsection{Planteamiento de investigación}

\subsubsection{Planteamiento del problema.}

La responsabilidad social corporativa (RSC) y su grado de ejecución son, en la actualidad, una de las formas de medir el desempeño general de las empresas además de tener un impacto característico en el desempeño como empresa y en la aceptación de propietarios, inversores, la comunidad financiera y patrocinadores. La RSC no es un tema difícil para las empresas, por lo contrario, es un tema que se encuentra al alcance de todo hotel, que le podría dejar grandes beneficios que se puedan medir, tanto para los trabajadores como para la empresa, la sociedad en general y los consumidores (De Bracamonte, M., Moran, R., \& Levis, K., 2016).

Los hoteles brindan muchas opciones para elaborar estratégicas nuevas (plan de acción semi-informal para lograr las metas del periodo a mediano y largo plazo) de RSC, en todas sus áreas. Si el período de proceso de la RSC es estratégico, es esencial que se identifique cuáles son los puntos en donde se interceptan los negocios y las sociedades, así como el reconocer cual es la problemática que aqueja a la sociedad (De Bracamonte, M., Moran, R., \& Levis, K., 2016).

De acuerdo con Ventura, J. (2019), profesor de ESAN y autor del libro "Responsabilidad Social y sostenibilidad empresarial", la dirección no crea relaciones con entes de la localidad que tengan la misma visión con los hoteles y muchos menos que impacten positivamente con el comercio del destino; las áreas de recursos humanos no desarrollan dinámicas que junten a los empleados al ambiente social, no empiezan proyectos para mejorar la cohesión, el clima laboral, el trabajo en equipo y la formación de todos los empleados, lo que impacta claramente en el grado de compromiso del empleado con la empresa; la administración puede afianzar el beneficio fiscal de donaciones, aportaciones voluntarias, y fortalecer el funcionamiento ético y la transparencia de la empresa.

De acuerdo con Hernández, J. (2019), docente de la Facultad de Ciencias Económicas y Empresariales de la UDEP, las áreas de marketing y ventas no apuestan por acciones de promoción o comerciales que ayuden a causas medioambientales o sociales, no participan en programas de la comunidad o ayudan con las iniciativas locales; los encargados de 
operaciones no diseñan estrategias que sean responsables en la gestión de los recursos como gestión de residuos, la energía y el agua, no participan en los programas para la prueba de equipos nuevos o estrategias más eficaces; el área de bebidas y alimentación no impulsan a que se utilicen los productos de la localidad y que no tengan sustancias peligrosas para el medio ambiente y el consumidor, no elaboran programas de alimentación saludable ni aportan al bancos de alimentos con donaciones y otras iniciativas similares; mientras que los encargados de comunicación y relaciones públicas no ayudan a las acciones de promoción de bienes educativos, culturales, y que sean interesantes para los turistas por medio de actividades, o con acciones de sensibilización e información. Estos puntos afectan directamente a la lealtad de los clientes dado que les genera una mala impresión en como los hoteles son realmente responsables ante la sociedad.

De igual manera de acuerdo con Peralta, J. B., Rossi, E. L., \& Álvarez, M. N. (2019) los hoteles no ofrecen oportunidades para desarrollar iniciativas reactivas y estratégicas en RSC en sus diferentes áreas de negocios que se enfoquen a que sus clientes les sean leales, dado que la fase de desarrollo de la RSC sea reactiva o estratégica, es fundamental identificar los puntos de intersección entre el negocio y la sociedad y saber escoger qué problema social se debe abordar. Estos puntos y actuaciones pueden ser genéricos, pero deben tener relación con la cadena de valor o con una dimensión social de contexto competitivo.

Así mismo se observa que en el Hotel Palmetto no se involucra a las distintas áreas de la empresa en la implementación de la responsabilidad social corporativa, ni tienen un área que se encargue exclusivamente de la responsabilidad social corporativa, y por ende no tienen políticas en gestión responsable. Igualmente, el Hotel Palmetto no invierten en la implementación de sistemas informáticos para integrar procesos e informaciones de la empresa, y no tienen una actitud para contribuir al desarrollo social así como a mejorar el medioambiente, dado que no crean programas que fomenten a disminuir la huella ambiental.

Dentro de las temporadas altas donde se da un incremento significativo de la demanda de reservas de huéspedes dentro del Hotel Palmetto, los colaboradores se ven afectados ya que existe la necesidad por parte del hotel de que realicen horas extras o hasta jornadas dobles, con lo cual algunas veces los colaboradores no están satisfechos ya que no siempre esperan un beneficio económico, sino contar con las herramientas necesarias para cumplir de mejor manera su labor y ser más productivos; lo cual muchas veces trae como consecuencia un incremento en la rotación del personal. Esta falta de compromiso con sus colaboradores 
ocasiona una inversión económica por parte del hotel para volver a realizar nuevos procesos de reclutamiento y selección, además del efecto que esto puede generar en los huéspedes. Por otro lado, el aumento de demanda no se traduce en la rentabilidad que el hotel debería generar.

Por otro lado, el hotel Palmetto no realiza campañas sociales, tampoco tiene políticas y normas de responsabilidad social lo cual afecta la imagen de la empresa; debido a que, con el pasar de los años y los efectos que han ocurrido, la sociedad ha concientizado el cuidado del medio ambiente, disminuyendo los excesos comunes.

\subsubsection{Formulación del problema.}

\subsubsection{Problema general.}

¿Existe relación entre la responsabilidad social corporativa y la lealtad de los clientes en el hotel Palmetto en San Borja 2020?

\subsubsection{Problemas específicos.}

¿Existe relación entre las responsabilidades económicas y la lealtad de los clientes en el hotel Palmetto en San Borja 2020?

¿Existe relación entre las responsabilidades filantrópicas y la lealtad de los clientes en el hotel Palmetto en San Borja 2020?

¿Existe relación entre las responsabilidades éticas y la lealtad de los clientes en el hotel Palmetto en San Borja 2020?

¿Existe relación entre las responsabilidades ambientales y la lealtad de los clientes en el hotel Palmetto en San Borja 2020?

\subsubsection{Justificación de la investigación.}

Palmetto hoteles, es una innovadora cadena hotelera categorizada como hoteles 3 estrellas, pero con un servicio de 4 estrellas y se encuentra dirigida al sector corporativo, moderno, seguro, confortable y con un servicio impecable; enfocado en brindar a los clientes una estancia agradable y que supere sus expectativas. En Palmetto Hoteles se distingue la vocación de servicio de los empleados y la búsqueda permanente por la lealtad de los clientes a través de los servicios y ambientes. Así mismo el hotel ubicado en el distrito de San Borja es 
la sede más moderna y grande, constantemente se invierte en innovación y tecnología y cuenta con 2 salas de auditoria de 80 y 120 personas, un salón ideal para directores, conferencias, workshops, eventos empresariales entre otros. $\mathrm{Y}$ se encuentra ubicado estratégicamente en el distrito de San Borja, cerca de centro empresariales, comerciales y financieros (Palmetto, 2019)

Es por esto que la presente investigación tiene como enfoque teórico la evaluación de la relación entre la responsabilidad social corporativa y la lealtad de los clientes en un hotel en San Borja, igualmente se intentará determinar la relación de las dimensiones de la responsabilidad social corporativa (responsabilidades económicas, responsabilidades filantrópicas, responsabilidades éticas y responsabilidades ambientales) y la lealtad de los clientes en el mismo hotel.

Al momento de concluir esta investigación, se obtendrán datos importantes para el hotel en San Borja, así como para las demás empresas dedicadas al mismo rubro dentro del mismo distrito, las cuales podrán usar esta información de manera referencial. Es un elemento clave que el hotel en San Borja sepa cómo es que la responsabilidad social corporativa pueda darle grandes beneficios, con la intención de que la lealtad de sus clientes sea mayor, y por tal motivo se beneficie la empresa misma.

De acuerdo con las relaciones obtenidas entre responsabilidad social corporativa y la lealtad de los clientes, se está en la capacidad de elaborar diferentes recomendaciones que le brinde mejoras al desempeño del hotel, con la finalidad de que las personas encargadas del hotel tomen las medidas oportunas para ser más responsables socialmente.

Uno de los beneficiados con la presente investigación será el mismo hotel ubicado en San Borja, puesto que el personal encargado, así como los dueños en base a los resultados que se lleguen a obtener en la presente investigación podrán estar en la capacidad de tomar conocimiento de cuáles son los puntos clave de la responsabilidad social corporativa que le puedan dar la lealtad que deseen por parte de sus clientes. Igualmente, los clientes mismos serán beneficiados, puesto que el personal encargado y los dueños llegarán a emplear las mejoras correspondientes con la intención de que sean leales al hotel.

Los dueños, así como el personal encargado del hotel ubicado en San Borja podrán estar en una situación favorable para realizar nuevas estrategias basándose en los resultados que se obtengan en la presente investigación, en relación a cómo deben ser responsables 
socialmente como corporación y así generar la lealtad necesaria de sus clientes. Igualmente, se espera que la presente investigación sea de utilidad para la elaboración de futuras investigaciones que tomen en cuenta a la responsabilidad social corporativa y la lealtad del cliente. Así mismo se espera que este trabajo de investigación sirva como referente teórico practico de futuras investigaciones que tomen la decisión de estudiar las variables en estudio, dado que contiene información que será beneficioso, así sea para empresas que pertenecen al mismo sector o ya sea para empresas en general que decidan realizar mejoras en la responsabilidad social corporativa, en post de aumentar la lealtad del cliente. De igual manera esta investigación es de utilidad para cubrir la brecha académica que existe en la literatura concerniente a las dos variables en estudio.

Por los consiguiente, existe la necesidad de investigar más sobre la lealtad del cliente en la empresa de servicio de alojamiento - PALMETTO HOTEL, que estrategias utilizar y como mantener la lealtad del cliente. Actualmente existe una brecha de investigación entre la responsabilidad social corporativa y lealtad del cliente en el rubro de hospedaje. Los clientes no satisfechos, sin duda alguna están más propensos de no alojarse en el hotel por optar por otras opciones. El problema es la incertidumbre si existe relación entre la responsabilidad social corporativa y la lealtad del cliente.

\subsection{Marco referencial}

\subsubsection{Antecedentes.}

Tras una exhausta búsqueda en libros, google académico, tesis en repositorios y artículos académicos, que se llegó a usar para este trabajo de investigación en relación a las variables de responsabilidad social corporativa y la lealtad del cliente, se pudo determinar que, en el Perú, así como en Latinoamérica existen pocos estudios de investigación que relacionen ambas variables en estudio en el sector.

\section{Antecedentes internacionales}

De acuerdo con Martínez, P. \& del Bosque, I. R. (2013) en su investigación "CSR and customer loyalty: The roles of trust, customer identification with the company and satisfaction.", donde se afirma que la responsabilidad social corporativa (RSC) se ha convertido en una construcción crucial en las empresas de hostelería. Una de las razones principales se debe a la idea de que la RSC influye en la lealtad del consumidor. Este documento presenta un modelo 
de influencia de la lealtad del cliente de RSC en el hotel al incluir simultáneamente la confianza, la identificación del cliente con la compañía y la satisfacción como mediadores al mostrar los efectos directos e indirectos entre estos constructos. El método cuantitativo utilizado para probar las hipótesis de investigación incluyó el desarrollo de un cuestionario de encuesta para medir las percepciones de los clientes de las empresas hoteleras españolas, se realizaron encuestas personales a los clientes del hotel. La recopilación de datos se desarrolló en colaboración con estudiantes universitarios de la Universidad de Cantabria que cursan su último año académico. De los 400 cuestionarios, se devolvieron 382 cuestionarios utilizables. En el modelo propuesto, la lealtad se ve indirectamente afectada por la RSC percibida, a través de la mediación de la confianza, la identificación y la satisfacción. Las pruebas empíricas que utilizan una encuesta de consumidores hoteleros españoles confirman la mayoría de los efectos hipotéticos, excepto el efecto de la confianza del cliente en la identificación del cliente con la empresa. Finalmente, se discuten las implicaciones administrativas y las limitaciones de los hallazgos.

La investigación de Kim, S. B. \& Kim, D. Y. (2016) denominada "The impacts of corporate social responsibility, service quality, and transparency on relationship quality and customer loyalty in the hotel industry.", tuvo como propósito el evaluar cómo las percepciones de los clientes potenciales sobre las actividades de responsabilidad social corporativa, la calidad del servicio y la transparencia de un hotel afectan las construcciones de calidad de la relación, como la confianza, la satisfacción y la lealtad del cliente. El diseño de investigación consistió en utilizar una encuesta de conveniencia a 487 clientes estadounidenses potenciales de hoteles. Luego se siguió un enfoque de dos pasos, proyectando un modelo de medición y luego analizando un modelo estructural para probar las relaciones teóricas entre los constructos. Los siguientes hallazgos en el contexto de los hoteles de EE. UU. muestran que: La responsabilidad social corporativa y la reputación tuvieron relaciones positivas con la confianza y la satisfacción, mientras que la calidad del servicio tuvo un efecto directo en la lealtad del cliente. Además, la transparencia tuvo una influencia significativa en la confianza del cliente. La confianza del cliente tuvo una influencia significativamente positiva en la lealtad del cliente. La influencia de la satisfacción en la lealtad del cliente está mediada por la confianza. Esta investigación contribuirá a debates académicos y gerenciales.

Kim, S. B., \& Kim, D. Y. (2016) en su investigación "The influence of corporate social responsibility, ability, reputation, and transparency on hotel customer loyalty in the US: a 
gender-based approach.", exploró un marco conceptual que incorpora interrelaciones entre la responsabilidad social corporativa (RSC), la capacidad corporativa, la reputación corporativa y la transparencia relacionada con la RSC sobre la lealtad del cliente dentro del contexto del hotel. En este estudio, también se analiza la propensión de los consumidores a apoyar iniciativas de RSC a través del indicador sociodemográfico de género. Utilizando la prueba t de muestra independiente y el análisis de regresión múltiple para probar hipótesis basadas en 487 respuestas de participantes estadounidenses. Cuatro antecedentes exhibieron efectos favorables en la lealtad del cliente. Entre estos cuatro factores, las iniciativas de RSC percibidas positivamente tuvieron un mayor impacto en la lealtad del cliente. Además, según los hallazgos, las participantes femeninas tenían más probabilidades de tener una percepción positiva de los cuatro antecedentes que los hombres.

De acuerdo con la investigación de Singal, M. \& Rhou, Y. (2017) denominada "Corporate Social Responsibility in the Hospitality Sector.", existe un consenso general de que las empresas desempeñan un papel cada vez más importante en la sociedad y la responsabilidad de una empresa va más allá de solo obtener ganancias. Sin embargo, el concepto de responsabilidad social corporativa (RSC) ha evolucionado desde la comprensión de que una empresa debe cuidar no solo a sus inversores y clientes, sino también a sus empleados, a la sociedad y la comunidad en general, e incluso al medio ambiente, dando lugar al triple fondo enfoque en línea para mejorar las ganancias, las personas y el planeta. La industria hotelera, dada su gran huella tanto en términos de empleo (empleó a 6 millones de trabajadores estadounidenses en 2015), y el consumo de recursos naturales como alimentos, agua y energía a menudo ha estado a la vanguardia de la implementación de prácticas orientadas a minimizar lo negativo impactos de su negocio en el medio ambiente. Estos incluyen intentos de aumentar la eficiencia del combustible en las aerolíneas, la reducción del desperdicio de alimentos en los restaurantes y el ahorro de agua y energía en los hoteles. Sin limitarse a las preocupaciones ambientales, la industria también abarca otros problemas sociales y las principales compañías hoteleras han implementado iniciativas de RSC relacionadas con el desarrollo comunitario, fomentando la diversidad entre su fuerza laboral y prácticas de empleo progresivas, con el resultado de que varias de ellas, como Marriott International, Kimpton Hotels (ahora fusionada con IHG), Hyatt Hotels, Hilton Worldwide y Wyndham Worldwide, se han incluido en listas como las mejores compañías para trabajar de Fortune y las compañías más admiradas del mundo. 
La investigación de Gürlek, M., Düzgün, E., \& Meydan, S. (2017) titulada "How does corporate social responsibility create customer loyalty? The role of corporate image.", tuvo como objetivo investigar si la imagen corporativa tiene un efecto mediador sobre la influencia de la responsabilidad social corporativa (RSC) en la lealtad del cliente en hoteles independientes. Se recopilaron datos de clientes de hoteles de cinco estrellas ubicados en Estambul, Turquía. El modelo teórico se probó con 404 datos utilizables. Los resultados se analizaron mediante el uso de modelos de ecuaciones estructurales (SEM). Los resultados muestran que la RSC crea lealtad del cliente parcialmente a través de la imagen corporativa en los hoteles independientes. Además, se encontró que los hoteles incluidos en el estudio llevaron a cabo un nivel moderado de actividades de RSC. El modelo de investigación se probó en hoteles independientes de cinco estrellas. Se podrían realizar más estudios utilizando diferentes empresas de hospitalidad independientes. Además, la investigación se realizó en una muestra limitada, ya que los gerentes de los hoteles no estaban dispuestos a permitir el contacto directo con los clientes. Se podrían realizar más estudios en muestras más grandes. Este estudio recomienda que los hoteles independientes realicen más actividades de RSC en temas sociales y ambientales. Además, el efecto directo de la RSC en la lealtad del cliente es menor que su efecto indirecto a través de la imagen corporativa. Por lo tanto, si las empresas desean crear lealtad de los clientes a través de la RSC, deben presentar sus actividades de RSC a los clientes a través de herramientas de comunicación (sitio web, medios de comunicación. Este estudio examina la RSC en términos de desarrollo sostenible en los hoteles independientes. Además, explica las relaciones entre la RSC y la imagen corporativa y la lealtad del cliente a través del principio de reciprocidad generalizada especificado en la teoría del cambio social.

Según la investigación de Marium, M., \& Younas, S. (2017) titulada "The Impact of corporate social responsibility (CSR) and relationship marketing on relationship maintainer and customer loyalty by mediating role of customer satisfaction.", la RSC se ha convertido en uno de los implementos imprescindibles para satisfacer a los clientes. Lo imparcial de esta investigación es calcular la RSC, el marketing relacional y la satisfacción del cliente. No hay más estudios acompañados en Pakistán para cuantificar el efecto de la RSC y el marketing relacional sobre el mantenedor de la relación y la lealtad del cliente. Para averiguar el enfoque deductivo y el método de encuesta se utiliza como enfoque de investigación y estrategia de investigación, respectivamente. Este diseño de investigación es un estudio descriptivo y cuantitativo. Para los datos, se adopta el método de cuestionario de recolección con escala diferencial semántica 
y escalas de siete puntos. Los datos se han recopilado adoptando la técnica de conveniencia de no probabilidad como técnica de muestreo y el tamaño de la muestra es de 400. Para el análisis factorial confirmatorio de factores, el modelo de ecuaciones estructurales y el análisis de medicamentos, se utilizó el software de análisis de regresión Amos. La evidencia empírica sólida respalda que la percepción del cliente del rendimiento de la RSC está altamente influenciada por los valores.

De acuerdo con Irshad, A., Rahim, A., Khan, M. F., \& Khan, M. M. (2017) en su investigación titulada "The impact of corporate social responsibility on customer satisfaction and customer loyalty, moderating effect of corporate image.", a medida que las empresas crecen muy rápido hoy en día, existen diferentes técnicas y herramientas para hacer que el lugar en la mente de los clientes y el concepto de Responsabilidad Social Corporativa sea el área más prominente en la literatura desde el punto de vista del cliente, en las últimas dos décadas se encontró RSC muy eficaz para atraer a los poseedores de la pila especialmente a los clientes. Esta revisión examina cómo los factores de RSC influyen en la satisfacción y lealtad de los clientes en presencia de la imagen corporativa como moderador en la economía de Pakistán. El estudio basado en el método de investigación cualitativa y el cuestionario se extendió en 370 personas objetivo, y se recibieron 236 de esos 219 se encontraron confiables para la prueba. Se generaron seis hipótesis y los datos se ejecutaron en SPSS y todos fueron compatibles. Finalmente, los resultados generales se encontraron con un efecto positivo de la Responsabilidad Social Corporativa en la Satisfacción y Lealtad de los Clientes y el efecto moderador de la alta imagen corporativa resulta en una relación más fuerte entre RSC y Satisfacción del Cliente y Lealtad del Cliente. Debería haber necesidad de implicación en el mercado de esto e investigaciones en aria más amplia con la maximización de los recursos.

Según a los investigadores Shahril, A., Ashaari, N., Hamid, R., Bachok, S. \& Baba, N. (2017) en su trabajo "The Effect of Perceived Corporate Social Responsibility Initiatives Towards Loyalty Intention Among Four and Five Star Hotels in Malaysia: The Mediating Effect of Brand Preference.", los hoteles están interesados en implementar programas de RSC porque enfrentan una competencia intensa en la industria y por la idea de que la RSC influye en la intención de lealtad entre los consumidores. En un mundo ideal, una suposición común es que las empresas motivadas interna o externamente actuarán de manera socialmente responsable. En el contexto de Malasia, todavía hay relativamente pocas investigaciones adecuadas sobre los programas de RSC y su influencia en la lealtad del cliente en hoteles de 
cuatro y cinco estrellas en este país. Este estudio intenta explorar la relación entre las iniciativas de RSC percibidas, la preferencia de marca y la intención de lealtad haciendo una encuesta en hoteles de cuatro y cinco estrellas en Kuala Lumpur. Se distribuyeron 300 conjuntos de cuestionarios a los huéspedes de estos hoteles y los datos se analizaron utilizando el Paquete Estadístico para Ciencias Sociales (SPSS) versión 21.0. Se analizaron 236 datos útiles y los resultados de esta encuesta obtenidos se discutieron en forma de tablas. Los resultados indican que existe una relación significativa y positiva entre las iniciativas de percepción de RSC y la preferencia de marca, la relación significativa y positiva entre la preferencia de marca y la intención de lealtad, la relación significativa y positiva entre las iniciativas de RSC percibidas y la preferencia de marca y la preferencia de marca median parcialmente la relación entre la RSC percibida iniciativas e intenciones de fidelización. Las implicaciones del estudio serán útiles para que los gerentes de hoteles y los encargados de formular políticas diseñen un programa adecuado de RSC en la organización e improvisen sus esfuerzos actuales de RSC para ganar una buena reputación de marca.

Para Puriwat, W. \& Tripopsakul, S. (2018) en su investigación "The Impact of Corporate Social Responsibility on Customer Satisfaction and Loyalty: A Case Study of the Hotel Industry in Thailand.", la responsabilidad social corporativa (RSC) es actualmente uno de los problemas corporativos más vitales. Desde un punto de vista estratégico, se ha discutido la RSC con respecto a cómo las empresas responden a las demandas de los interesados externos e internos. Estudios anteriores han revelado que la RSC mejora el rendimiento corporativo. Según Bonini, Gorner y Jones (2010), aproximadamente el 80\% de los altos directivos creen que la RSC contribuye positivamente al valor de una empresa a largo plazo; aproximadamente el $60 \%$ está de acuerdo en que esta sostenibilidad ayuda a sus empresas a establecer una reputación. Para la recopilación de datos, se realizó una encuesta en línea a través de correo electrónico y sitios de redes sociales. Los datos se recopilaron mediante un cuestionario en línea entre julio de 2017 y septiembre de 2017. Se pidió a los encuestados que recordaran su estadía en el hotel más reciente en los últimos 12 meses. El cuestionario también solicitó que incluyeran el nombre del hotel. La encuesta en línea se dispersó a 500 muestras. Se recogieron un total de 225 respuestas utilizables de las 500 muestras, una tasa de respuesta del $45 \%$. Esta investigación tenía algunas limitaciones. Primero, los datos para este estudio se obtuvieron mediante un método de estudio retrospectivo, que incurre en algún efecto de sesgo. Por esa razón, se recomiendan otras metodologías de investigación, como el método experimental, para superar esta situación. En segundo lugar, el modelo conceptual utilizado 
en este estudio fue examinado por una encuesta auto administrada, que puede haber influido en los resultados. Se recomienda la investigación futura para utilizar métodos mixtos, como los métodos cualitativos y cuantitativos para recopilar datos de otros grupos de encuestados para ampliar la generalización de los resultados. En tercer lugar, la recopilación de datos se limitó a los clientes de los hoteles en Tailandia. Por lo tanto, los resultados deben generalizarse cuidadosamente para las industrias hoteleras de otros países. Finalmente, este estudio utilizó análisis cuantitativo para representar los hallazgos. Otros estudios deberían incluir otros factores y la investigación de metodología mixta.

\section{Antecedentes nacionales}

La investigación referencial de Camayo, J. (2015) titulada "Responsabilidad social corporativa de las empresas de la Región Callao en el año 2014.", tuvo como objetivo reconocer cual es el impacto de la responsabilidad social corporativa de las empresas de la región callao en la comunidad, y se tuvo una metodología hipotético deductivo cualicuantitativo, usando las entrevistas y los cuestionarios como técnica, procedimiento e instrumento para recolectar datos, y una muestra de 100 empresas de la región callao. Donde se concluyó que la responsabilidad social corporativa de las empresas del callao tiene poco impacto en la comunidad de la región.

De Bracamonte, M., Moran, R., \& Levis, K. (2016) en su investigación referencial titulada "La Responsabilidad Social corporativa en la Empresa Hotelera SUNSET BAY COLAN SCRL y su contribución al desarrollo Turístico sostenible en el Distrito de Colán de la Provincia de Paita del Departamento de Piura en el año 2016.", tuvieron como objetivo relacionar la responsabilidad social corporativa con la sostenibilidad y con el turismo en el hotel SUNSET BAY COLAN SCRL, utilizando un diseño no experimental y descriptivo, teniendo como muestra a 155 clientes y se utilizó la encuesta y el análisis documental como técnica para recolectar datos. Llegando a la conclusión que la responsabilidad social corporativa del hotel ayuda a que el turismo se desarrolle sosteniblemente mediante campañas de promoción para conservar el medio ambiente, donaciones, programas para limpieza de las playas.

La investigación referencial de Coila, D. (2014) titulada "Responsabilidad social en la sociedad stakeholders en agencias de viajes y turismo de la ciudad de Puno 2012.", tuvo como principal objetivo determinar la perspectiva de la responsabilidad social en los stakeholders, utilizando un tipo descriptivo con un diseño explicativo, y una muestra de 45 agencias de viajes 
y turismo en la ciudad de Puno. Utilizando la entrevista como técnica de recolección de datos. Según los resultados logrados en la investigación se puede estimar que la perspectiva de responsabilidad social en gran proporción las agencias de viajes y turismo tienen perspectivas de generar impacto en la sociedad stakeholders

Vásquez López, A. M., \& Maldonado Fernández, P. F. (2017) en su investigación referencial denominada "Responsabilidad social interna y ventaja competitiva del capital humano en el sector hotelero de 3 y 4 estrellas de la ciudad de Cajamarca.", tuvo como objetivo diagnosticar en nivel de responsabilidad social interna de los hoteles 3 y 4 estrellas en Cajamarca, teniendo como muestra a 349 empleados de 24 hoteles, aplicando un cuestionario de 16 ítems, y se utilizó un diseño no experimental, y una temporalidad transversal o transeccional. Llegando a la conclusión que la responsabilidad social interna y la ventaja competitiva se relacionan positivamente.

\subsubsection{Marco teórico.}

El marco teórico empieza con la explicación de la primera variable, responsabilidad social corporativa, sus definiciones, teorías, y sus dimensiones, tomando en cuenta a investigadores como, latridis, K. (2011), Bruns, A. S. (2017), Puriwat, W. \& Tripopsakul, S. (2018), siguiendo con la segunda variable, lealtad del cliente, sus definiciones, beneficios y dimensiones, comando en cuenta a investigadores como, Khadka, K., \& Maharjan, S. (2017), Seyedhossein N., Harihodin B., Rasimah Ch. y Mohsen M. (2017), Srivastava, M., \& Kaul, D. (2016).

La responsabilidad social empresarial (RSE) cambia la mentalidad de las empresas y para esto es necesario unir esfuerzos entre los stakeholders y las empresas involucradas para que se pueda obtener una armonía entre estos y obtener beneficios económicos, sociales y medioambientales. Es de suma importancia que los lideres trabajen en equipo para obtener que se cambie de manera efectiva a la sociedad moderna que existe en la actualidad. La RSE trata de crear valor en diferentes grupos de interés que concurren en la actividad empresarial, evaluando los resultados en términos de ventas, cuotas de mercado y satisfacción, llegando a generar un interés claro en los accionistas y en los gestores (Cubillos, C. H., Montealegre, J. V., \& Delgado, A., 2016).

La responsabilidad social corporativa (RSC) parte de la idea de empresa como sujeto moral o ciudadano corporativo que genera, para la sociedad y el entorno, externalidades positivas que es necesario maximizar y negativas que hay que minimizar. Es precisamente de la 
sociedad de quien depende en sus relaciones económicas y sociales, por lo que cualquier actuación en materia social y medioambiental debe realizarse acorde a las expectativas del entorno y en constante comunicación y diálogo con los agentes implicados. Empresas responsables son aquellas que controlan y evalúan las condiciones del entorno y que se centran en las demandas de varios stakeholders, definidos como todos aquellos agentes que tienen que ver y se relacionan con la compañía (Fraile, E. B., 2018)

En el caso de la presente investigación se hace referencia a la corporación, dado que no existe un solo hotel, e inclusive existen hoteles que pertenecen a la corporación que están pronto por inaugurar.

\subsubsection{Responsabilidad social corporativa (RSC).}

\subsection{Definición.}

De acuerdo con latridis, K. (2011) la responsabilidad social corporativa se define como la integración de las operaciones y los valores comerciales, mediante la cual los intereses de todas las partes interesadas, incluidos los inversores, clientes, empleados y el medio ambiente, se reflejan en las políticas y acciones de la empresa.

Carroll, A. B. (2015) definió la responsabilidad social corporativa como las actividades y el estado de una empresa en relación con sus obligaciones sociales o de partes interesadas percibidas.

Bruns, A. S. (2017) define la responsabilidad social corporativa como las acciones que parecen promover algún bien social, más allá de los intereses de la empresa y lo que exige la ley.

Puriwat, W. \& Tripopsakul, S. (2018) definieron la responsabilidad social corporativa como el compromiso continuo de las empresas de comportarse éticamente y contribuir al desarrollo económico al tiempo que mejora la calidad de vida de la fuerza laboral y sus familias, así como de la comunidad local y la sociedad en general.

Según Abbas, J., et. al (2019) la responsabilidad social corporativa se define como las organizaciones comprometidas con valores, procedimientos, políticas y contribuciones específicos para ser una responsabilidad para la sociedad. 


\subsection{Teoría.}

\section{Teoría del triple resultado final}

Elkington acuñó el término triple resultado a mediados de la década de 1990. El término se presta a un marco, que fue desarrollado para medir la sostenibilidad. Abarca no solo el aspecto económico de las cosas, sino que también incorpora los impactos sociales y ambientales de las actividades de la empresa. Las dimensiones de la línea de base triple se conocen como 3P, por sus siglas en inglés, (Beneficio, Planeta y Gente).

\section{Sostenibilidad Económica}

Las empresas deben valorar las ganancias a largo plazo sobre las ganancias arriesgadas y a corto plazo. Las corporaciones más grandes tienen la responsabilidad hacia la sociedad de elaborar planes de negocios que permitan inversiones y acciones estables.

\section{Sostenibilidad social}

Las empresas deben valorar el equilibrio entre la forma de hacer negocios y la forma en que sus negocios afectan la vida de las personas en la sociedad. Para que una empresa sea estable a largo plazo, las oportunidades y la riqueza deben extenderse para abarcar a un gran número de la sociedad. La responsabilidad social no solo termina con el dinero distribuido o redistribuido, sino que también tiene que ver con la forma en que las personas son tratadas y respetadas. El movimiento de comercio justo es un buen ejemplo de la ejecución de la sostenibilidad social.

\section{Sostenibilidad del medio ambiente}

La mayoría de los recursos naturales a nuestra disposición para crear riqueza son finitos y eventualmente se agotarán. Si la tasa de agotamiento es alta, no se permitirá que las futuras generaciones disfruten de la misma calidad de vida que nosotros. Por lo tanto, se ha convertido en parte de la responsabilidad de una empresa operar de tal manera que el impacto que tiene en el medio ambiente sea mínimo y que funcione en las esferas del proteccionismo ambiental.

\section{La teoría de las partes interesadas}

La teoría de las partes interesadas es una de las teorías más utilizadas por los estudiosos de la responsabilidad social corporativa. Según latridis, K. (2011), las empresas deben 
satisfacer a una serie de componentes, incluidos los empleados, los clientes, las organizaciones comunitarias locales, que pueden influir en los resultados de la empresa.

Sostiene que, además de tratar de maximizar los rendimientos para sus accionistas, las empresas deben tener en cuenta a otros grupos no financieros porque los rendimientos de tal comportamiento pueden ser significativos. Además, la teoría sugiere que al aplicar una serie de políticas de responsabilidad social corporativa para satisfacer a los grupos no financieros, la empresa gana la aceptación y el apoyo de estos grupos y, por lo tanto, puede continuar sus operaciones sin enfrentar objeciones (latridis, K., 2011).

\subsubsection{Dimensiones.}

Tabla 1:

Dimensiones de responsabilidad social corporativa

Autores Dimensiones

Amponsah, M. Preocupaciones ambientales,

Participación en asistencia social o caridad,

Participación de la comunidad,

Productos o servicios y

Problemas relacionados con desastres

naturales.

Puriwat, W., \& Tripopsakul, S. Responsabilidades económicas

Responsabilidades filantrópicas

Responsabilidades éticas, y

Responsabilidades ambientales.

Fuente: Amponsah, M. (2015); Puriwat, W., \& Tripopsakul, S. (2018).

Elaboración: Calderón y Chico (2020) - Extraído del SPSS (2020)

En la presente investigación se utilizará la versión de los investigadores Puriwat, W., \& Tripopsakul, S. (2018).

\section{Responsabilidades económicas}

La responsabilidad básica de cualquier negocio es la responsabilidad económica, lo que significa la maximización de la riqueza y las ganancias y el desarrollo del crecimiento económico, desde el principio, la organización empresarial fue la unidad económica básica en las comunidades. El papel principal de las empresas era producir bienes y servicios que los consumidores necesitaban y entregaban para obtener un beneficio aceptable. Otras responsabilidades de los negocios son seguidas por la responsabilidad económica de la empresa, porque sin ella las demás pierden sentido. 


\section{Responsabilidades filantrópicas}

Las responsabilidades de filantropía son acciones o políticas hacia la humanidad y la caridad, en respuesta a las expectativas sociales y comunitarias de que las empresas son buenos ciudadanos corporativos. Las responsabilidades filantrópicas son compartir voluntariamente los negocios para el desarrollo de la sociedad y la contribución a la educación o la comunidad. Las responsabilidades éticas son componentes que se esperan en un sentido ético o moral y la filantropía es una parte voluntaria de un negocio para la sociedad. El componente filantrópico es la voluntad de contribuir en las expectativas caritativas de la sociedad y los proyectos que mejoran la calidad de vida de una comunidad.

\section{Responsabilidades éticas}

A pesar de las responsabilidades económicas y legales seguidas de las normas éticas y el valor de la sociedad y la comunidad. Las responsabilidades éticas encarnan aquellos estándares, normas o expectativas que reflejan una preocupación por lo que los consumidores, empleados, accionistas y la comunidad consideran justos, justos o de acuerdo con el respeto o la protección de los derechos morales de las partes interesadas. Las responsabilidades éticas son los valores estratégicos de los gerentes sobre el comportamiento comercial correcto e incorrecto. La ética o los valores están procediendo al establecimiento de la ley de acuerdo con las normas de la comunidad. La ética es la fuerza impulsora detrás de la creación de leyes o reglamentos.

\section{Responsabilidades ambientales}

El impacto de las corporaciones en el medio ambiente se ha convertido en uno de los componentes más importantes de la RSC. Con la reciente preocupación por el calentamiento global, se ha puesto aún más presión sobre las corporaciones para disminuir su huella ambiental. Estas presiones son una de las principales razones por las cuales las corporaciones están preocupadas por su impacto en el medio ambiente. Hay una variedad de prácticas en las que las empresas se comprometen a hacer su parte para mejorar las condiciones ambientales y disminuir los impactos negativos sobre el medio ambiente. Dichos programas y prácticas pueden ser tan simples como colocar contenedores de reciclaje en los negocios reales y fomentar el reciclaje. Otras iniciativas más elaboradas pueden incluir una reestructuración completa de un plan de negocios, como la estación de esquí The Grand Targhee en Jackson Hole Wyoming y la estación de esquí Aspen Highlands, ambas utilizan 
energía 100\% renovable, lo que evita que se expulsen unos 430 millones de libras de dióxido de carbono a la atmósfera.

\subsubsection{Lealtad del cliente.}

\subsection{Definición.}

Loo, C. (2015) definió como el comportamiento del cliente que realiza compras repetidas siempre que sea posible y al mismo tiempo continúa recomendando y manteniendo una actitud positiva.

De acuerdo con Khadka, K., \& Maharjan, S. (2017) la lealtad del cliente es definida como la fuerza de la relación entre la actitud relativa de un individuo y el re-patrocinio.

Según Seyedhossein N., Harihodin B., Rasimah Ch. y Mohsen M. (2017) la lealtad del cliente es definida como la probabilidad de que un cliente vuelva a comprar en la misma empresa.

Abu-Alhaija, A. S., Yusof, R. N. R., Hashim, H., \& Jaharuddin, N. S. (2018) definieron la lealtad del cliente como un compromiso arraigado para recomprar o volver a patrocinar un producto/servicio preferido de manera consistente en el futuro, causando compras repetitivas de la misma marca o del mismo conjunto de marca.

Según Puriwat, W., \& Tripopsakul, S. (2018) la lealtad del cliente se define como la intención o predisposición del cliente a comprar productos o servicios de las mismas empresas o proveedores de servicios.

\subsubsection{2. ¿Cuál es el beneficio de la lealtad del cliente?}

Desde la perspectiva tradicional, la cuota de mercado es el determinante más importante de las ganancias de las empresas. Muchas empresas han participado en fusiones y adquisiciones para que puedan obtener economías de escala. De esta manera, pueden reducir los costos y aumentar las ganancias. Sin embargo, también hay algunas compañías para ser excepciones. Según Hill y Alexander (2000), algunas empresas que no tienen la mayor participación de mercado son más rentables que aquellas con una mayor participación. La razón de esto es que descubrieron que la lealtad del cliente es más rentable que la participación en el mercado. 
Desde la perspectiva de las empresas, la implementación de la estrategia de fidelización de clientes es útil para el beneficio de las empresas. Se afirma que un aumento del $5 \%$ en la retención de clientes conduce a un aumento de las ganancias del 25\% al 95\%. La estrategia de fidelización de clientes puede ayudar a las empresas a ahorrar dinero en una variedad de costos, por ejemplo:

- Costos de publicidad para atraer nuevos clientes;

- Costos del esfuerzo personal de venta a nuevos prospectos;

- Costos de configurar nuevas cuentas para nuevos clientes;

- Costos de explicar los procedimientos comerciales a nuevos clientes;

- Costos de comportamiento ineficiente durante el proceso de aprendizaje de los clientes.

Además, en el libro de Nykamp (2001), menciona que la estrategia de fidelización de los clientes tiene otras ventajas. La primera es que las empresas tendrán clientes de su lado. El segundo es que la gestión exitosa de clientes diferentes es la clave del éxito en los negocios modernos. Además de eso, en el artículo de Duffy (2003), también menciona que una estrategia de fidelización de clientes puede ahorrar dinero para las empresas. Además, hay cinco beneficios más de la estrategia de fidelización de clientes.

El primero es "referencias". Significa que los clientes que se familiaricen con su marca no dudarán en recomendar la marca a amigos y vecinos.

El segundo es "quejarse en lugar de defecto". Significa que el cliente fiel verá la marca como suya. Cuando hay problemas, por lo tanto, se pondrán en contacto con la empresa para asegurarse de que los problemas se resuelvan, pero no que tengan defectos.

El tercero es "Migración de canales". Significa que los clientes leales están más dispuestos a comprar una marca a través de múltiples canales, por ejemplo, Internet. Hacer esto puede aumentar su consumo total y reducir el costo de hacer negocios con ellos.

El cuarto es "Conciencia sin ayuda". Significa que los clientes leales tienen muchas más probabilidades de tener en mente su marca. también ayuda con "referencias" y ayuda a atraer a otros clientes a su marca.

El quinto es "una mayor conciencia de los activos de la marca". Significa que los clientes leales tienden a ser más conscientes de algunos de los beneficios auxiliares que ofrece una 
marca. Una mayor conciencia del cliente tiene impacto en retener la lealtad del cliente. Estos clientes tendían a quedarse con la marca más tiempo porque sentían que recibían un mejor valor.

\subsection{Teorías.}

\section{La teoría del comportamiento del consumidor}

La teoría del comportamiento del consumidor en situaciones deterministas como la expusieron, Debreu (1959) o Uzawa (1960) es una cosa de gran belleza estética, una joya engastada en una vitrina. Producto de un largo proceso de refinamiento desde los teóricos de la utilidad del siglo XIX a través de Slutsky y Hicks-Allen hasta los economistas de los últimos veinticinco años, se ha despojado de todos los postulados irrelevantes, de modo que ahora se erige como un ejemplo de cómo extraer el mínimo de resultados a partir del mínimo de supuestos. Al proceso de cortar con la navaja de Occam, el autor hizo una pequeña contribución (1957). Esto provocó una respuesta de Johnson (1958) que sugería, un tanto irónicamente, que la determinación del signo del efecto sustitución (el único resultado sustantivo de la teoría del comportamiento del consumidor) podría derivarse de la proposición de que los bienes son bienes.

Se presume que el consumo es una actividad en la que los bienes, solos o en combinación, son insumos y en la que la salida es una colección de características. Y que los ordenamientos de utilidad o preferencia clasifican colecciones de características y solo clasifican colecciones de bienes indirectamente a través de las características que poseen. Una comida (tratada como un solo bien) posee características nutricionales pero también posee características estéticas, y diferentes comidas poseerán estas características en diferentes proporciones relativas. Además, una cena, una combinación de dos bienes, una comida y un entorno social, puede poseer características nutricionales, estéticas y quizás intelectuales diferentes de la combinación que se obtiene de una comida y una reunión social consumidas por separado.

\section{Teoría de la actitud}

Tras un breve flirteo con la teoría del comportamiento (Doob, 1947; Fishbein, 1963; Staats \& Staats, 1958), la investigación sobre la formación y el cambio de actitudes pronto estuvo dominada por la perspectiva del procesamiento de la información presentada por Carl Hovland y sus asociados en la Universidad de Yale (Hovland, Janis, \& Kelley, 1953). Implícito en su 
enfoque estaba el supuesto de que las actitudes se basan en información sobre el objeto de la actitud y que, por lo tanto, las actitudes pueden cambiarse impartiendo nueva información en forma de comunicación persuasiva. La recepción y aceptación de esta nueva información conduciría a un cambio de actitud. Aunque este enfoque guió la teoría y la investigación durante muchos años, ahora sabemos que se trata de una visión demasiado simplificada del proceso de persuasión (Ajzen, 1992; Petty \& Cacioppo, 1986).

\subsection{Dimensiones.}

Tabla 2:

Dimensiones de lealtad del cliente

\begin{tabular}{cl}
\hline Autores & \multicolumn{1}{c}{ Dimensiones } \\
\hline Srivastava, M., \& Kaul, D. & Lealtad de comportamiento, y \\
& Lealtad de actitud. \\
$\begin{array}{c}\text { Seyedhossein N., Harihodin B., Rasimah } \\
\text { Ch. y Mohsen M. }\end{array}$ & Lealtad del cliente
\end{tabular}

Fuente: Srivastava, M., \& Kaul, D. (2016); Seyedhossein N., Harihodin B., Rasimah Ch. y Mohsen M. (2017) Elaboración: Calderón y Chico (2020) - Extraído del SPSS (2020)

Srivastava, M., \& Kaul, D. (2016) definieron la lealtad de comportamiento desde la perspectiva de la lealtad como comportamiento, tal medida solo es válida en la medida en que las intenciones conductuales declaradas se correspondan estrechamente con el comportamiento real (de recompra). Y definieron la lealtad actitudinal en términos del deseo del consumidor de continuar la relación con la organización que vende productos o servicios independientemente de los precios más bajos ofrecidos por los competidores y de recomendar el producto / servicio a otros.

Seyedhossein N., Harihodin B., Rasimah Ch. y Mohsen M. (2017) definen la lealtad como un compromiso profundamente arraigado para reconstruir y volver a patrocinar un producto 0 servicio preferido en el futuro a pesar de las influencias situacionales y los esfuerzos de marketing que tienen el potencial de causar comportamientos cambiantes. La lealtad del cliente es vista como la fortaleza de la relación entre la actitud relativa de un individuo y el repatrocinio. Aunque la satisfacción del cliente es una parte crucial de un negocio, la satisfacción por sí sola no puede llevar a un negocio a un nivel superior. La satisfacción del cliente produce un resultado financiero positivo, especialmente en compras regulares. mercado en el que crear y mantener la lealtad del cliente es más complejo de lo que solía ser en los últimos años. Esto se debe a los avances tecnológicos y al uso generalizado de Internet. La creación de lealtad 
requiere que la empresa enfoque el valor de sus productos y servicios y muestre que le interesa cumplir el deseo o construir la relación con los clientes. Dado lo mencionado se tomara la definición de la lealtad del cliente la versión de los investigadores Seyedhossein N., Harihodin B., Rasimah Ch. y Mohsen M. (2017).

Thomas y Tobe (2013) enfatizan que la lealtad es más rentable. Los gastos para ganar un nuevo cliente son mucho más que retener el existente. Los clientes leales alentarán a otros a comprarle y pensar más de dos veces antes de cambiar de opinión para comprar otros servicios. La lealtad del cliente no se gana por accidente, se construye a través de las decisiones de abastecimiento y diseño. Diseñar para fidelizar al cliente requiere enfoques centrados en el cliente que reconozcan la necesidad e interés del receptor del servicio. La lealtad del cliente se construye con el tiempo en múltiples transacciones.

\subsubsection{Responsabilidad social corporativa y lealtad del cliente.}

Para Gürlek, M., Düzgün, E., \& Meydan Uygur, S. (2017) el concepto de lealtad del cliente se define como un compromiso profundamente arraigado de recomprar o repatriar un producto / servicio preferido de manera consistente en el futuro, causando compras repetitivas de la misma marca o de la misma marca, a pesar de las influencias situacionales y los esfuerzos de marketing que tienen el potencial de causar un cambio de comportamiento. La lealtad del cliente contribuye a disminuir los costos, aumentar la cantidad de ventas y la confianza en el negocio. Las empresas se han asegurado de que la lealtad de sus clientes obtuviera más ventajas en comparación con sus competidores porque la lealtad de los clientes es un componente importante que les permite obtener ganancias y garantizar su sostenibilidad. Este concepto generalmente se examina a través de tres enfoques principales: enfoque conductual, enfoque actitudinal y enfoque integrado (Gürlek, M. et al., 2017).

La lealtad conductual se define como la frecuencia de compra de los clientes. Con el tiempo, los investigadores indicaron que el enfoque conductual no era suficiente para explicar la lealtad del cliente, y prestaron atención a la dimensión actitudinal de la lealtad. El enfoque actitudinal se puede definir como el compromiso psicológico y emocional de los clientes con los productos y servicios de un negocio específico. Los clientes que han adoptado un enfoque de actitud permanecen leales al negocio en términos emocionales. Por último, en un enfoque integrado, la lealtad del cliente puede considerarse como el producto que prefieren los clientes y los servicios de la misma empresa y los recomiendan a su vecindad inmediata (Gürlek, M. et al., 
2017). Si bien Caruana (2002) ha asociado la dimensión actitudinal con un vínculo psicológico entre clientes y productos, ha explicado la dimensión conductual a través de la tasa de compra de un producto y servicio específico.

Algunos investigadores de la industria hotelera solo se centraron en la dimensión actitudinal de la lealtad del cliente. Sin embargo, el hecho de que el cliente tenga una actitud positiva con respecto a un producto en particular no puede llevarlo a volver a comprar el producto. Por lo tanto, los investigadores enfatizan que la lealtad del cliente debe medirse en términos de dimensiones conductuales y actitudinales. La lealtad del cliente es bastante importante en la industria hotelera. A través de la lealtad del cliente, las compañías hoteleras obtienen una ventaja competitiva sostenible. Cada cliente fiel recomienda el hotel a aproximadamente 12 personas a través del marketing de boca en boca. Además, un aumento del 5 por ciento en la lealtad del cliente puede conducir a un aumento del 25-80 por ciento en las ganancias. Las campañas de RSC contribuyen a la fidelización de los clientes. A medida que los clientes piensan que proporcionarán beneficios sociales al comprar los productos y servicios de una empresa, se vuelven más leales al negocio. Por ejemplo, una empresa puede utilizar la RSC como estrategia de marketing al anunciar que donará parte de sus ingresos a organizaciones benéficas y organizaciones medioambientales y luchará por resolver un problema social (Gürlek, M. et al., 2017).

\subsubsection{Responsabilidad social corporativa e industria hotelera.}

Según Gürlek, M. et al. (2017) las empresas hoteleras han comenzado a desempeñar un papel más importante en el turismo debido al hecho de que los turistas viajan a lugares más distantes y permanecen allí por más tiempo. Muchos hoteles están ubicados por recursos naturales y culturales y una gran cantidad de turistas se alojan en estos hoteles. Por lo tanto, la contaminación del aire y el ruido ocurre en las áreas donde se encuentran los hoteles, y esto conduce a la pérdida de biodiversidad y crea contaminación ambiental. Debido a las ventajas económicas que trae consigo el sector turístico, los riesgos ambientales, sociales y culturales pueden ser ignorados. Las actividades de RSC están directamente relacionadas con el desarrollo sostenible. Las empresas de hoteles pueden llevar a cabo actividades de RSC en línea con la sostenibilidad del entorno natural y social. En los últimos 20 años, se ha observado que la industria del turismo se ha centrado en los problemas ambientales, el reciclaje y el uso productivo de la energía. Para minimizar los efectos negativos del turismo, las empresas prestan más atención a las actividades de RSC. Se centran en diferentes actividades de RSC 
según el sector en el que están activas. Como los diferentes sectores tienen objetivos diferentes, adoptan la estrategia de desarrollo sostenible más adecuada y racional.

\subsubsection{Hotel Palmetto.}

\subsection{Visión.}

Ser reconocidos como una de las mejores empresas en el rubro hotelero corporativo en la categoría 3 estrellas a nivel nacional.

\subsection{Misión.}

Ser una empresa con reconocimiento en el rubro de hoteles corporativos, en la categoría 3 estrellas a nivel nacional, logrando el liderazgo y llegar a ser la primera opción para las empresas. Y brindar servicios hoteleros para los ejecutivos de las principales empresas del país a través de un equipo de colaboradores en constante capacitación y comprometidos con la calidad del servicio.

\subsection{Organigrama.}

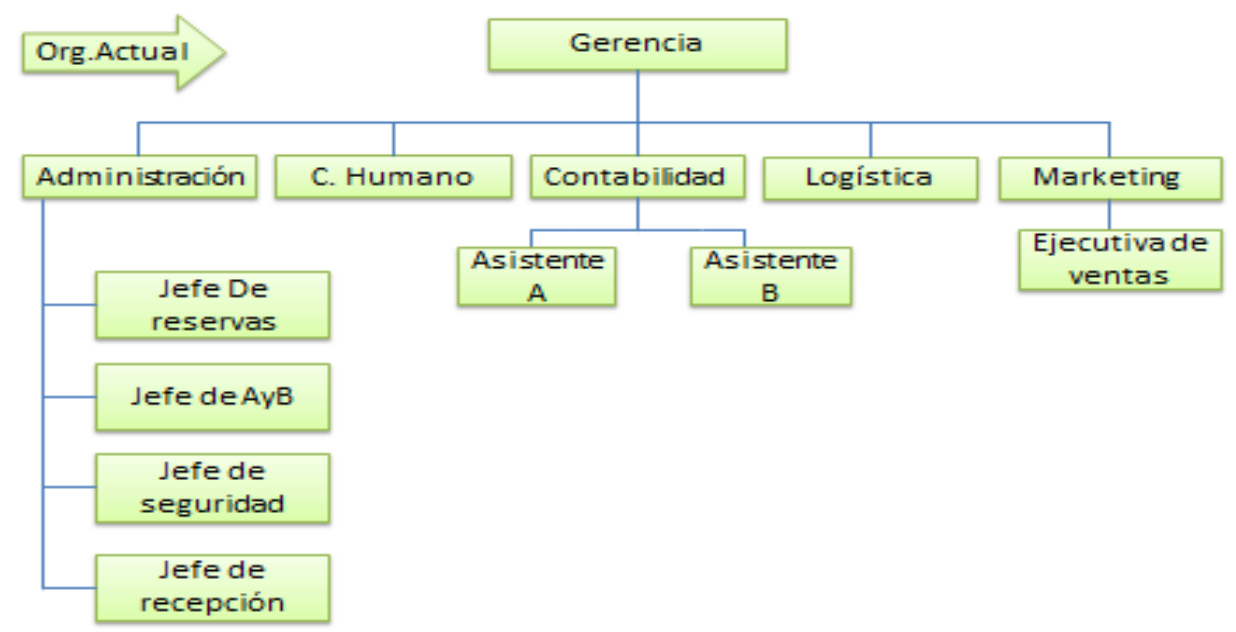

Figura 1. Organigrama

Fuente: Hotel Palmetto (2019)

\subsection{Ubicación geográfica.}

Para efectos de la investigación se estudiará El hotel Palmetto que se encuentra ubicado en la Av. San Borja Sur 415 - San Borja como se muestra a continuación: 


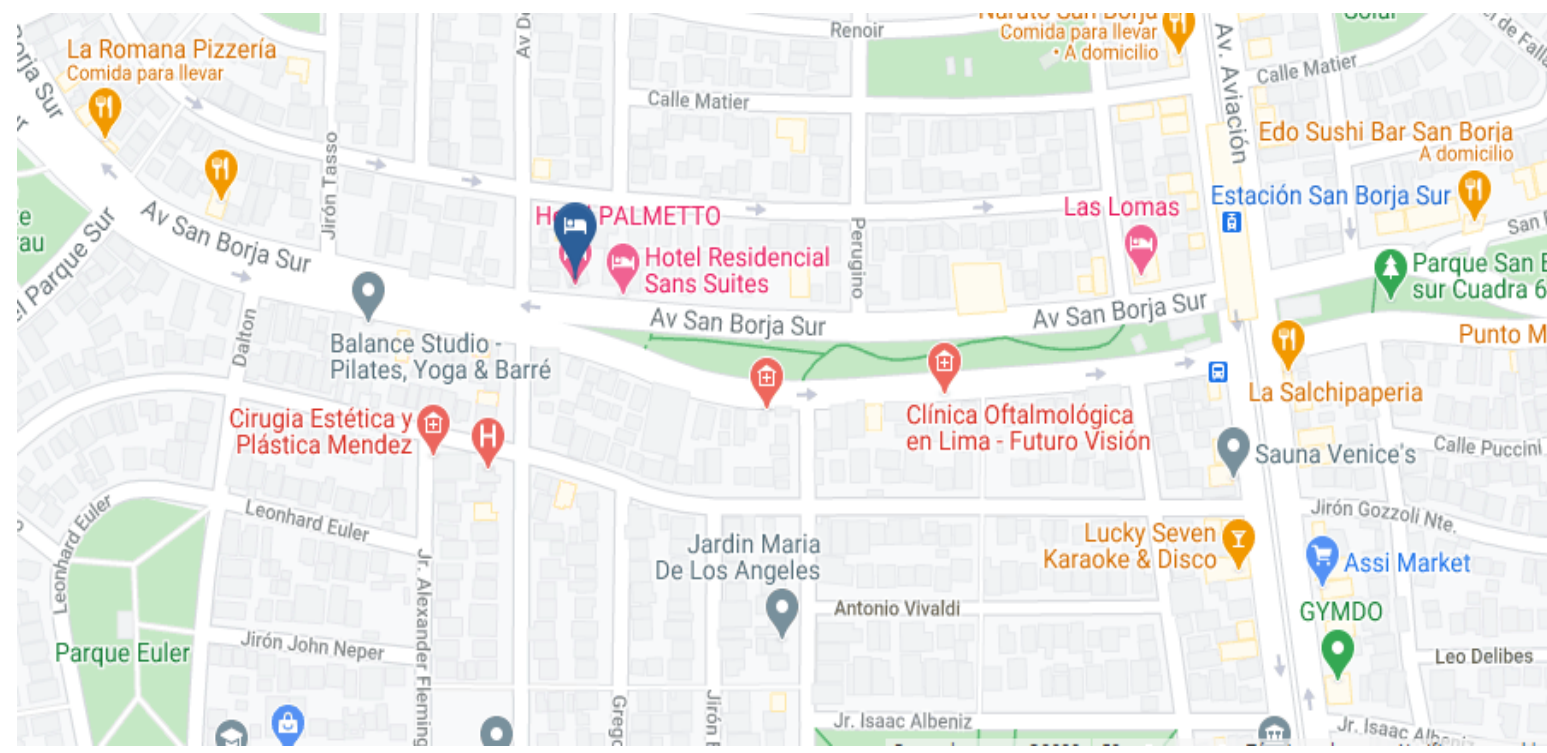

Figura 2. Ubicación geográfica Fuente: Hotel Palmetto (2019)

\subsection{Características de hotel Palmetto.}

Palmetto Hoteles como cadena hotelera, cuenta con tres hoteles ubicados en:

- Av. San Borja Sur 415 - San Borja

- Av. La Marina 3691, San Miguel

- Av. La Marina 1090 - La Perla - Callao

Cada hotel cuenta con un restaurante D' gust en el que se ofrecen exquisitos platos nacionales e internacionales, elaborados con la mejor atención y sabor.

Cuentan con amplias salas de eventos y directorios totalmente equipados para reuniones corporativas y/o educativas que requieran los clientes.

La ubicación estratégica de cada uno de los hoteles hace que sean una gran opción sea cual sea su motivo de viaje, negocio, turismo, diversión, etc. Todas las instalaciones tienen lo que los clientes buscan.

En este trabajo de investigación se estudiará la sede de San Borja, dado que se diferencia de las demás sedes en los siguientes puntos:

- Hotel categorizado de 3 estrellas con servicio de 4 estrellas. 
- Es la sede más moderna y grande, constantemente se invierte en innovación y tecnología.

- Cuenta con APP MOVIL PALMETTO, donde se puede realizar el check in/ out.

- Cuenta con 2 salas de auditoria de 80 y 120 personas, un salón ideal para directores, conferencias, workshops, eventos empresariales entre otros.

- Ubicado estratégicamente en el distrito de San Borja, cerca de centro empresariales, comerciales y financieros.

- Premio A TRAVELLES CHOICE 2020 (TRIPADVISOR)

\subsubsection{Modelos conceptuales}

\subsection{Modelo previo.}

En seguida se presenta los modelos propuestos por los investigadores Puriwat, W., \& Tripopsakul, S. (2018) e Irshad, A., Rahim, A., Khan, M. F., \& Khan, M. M. (2017).

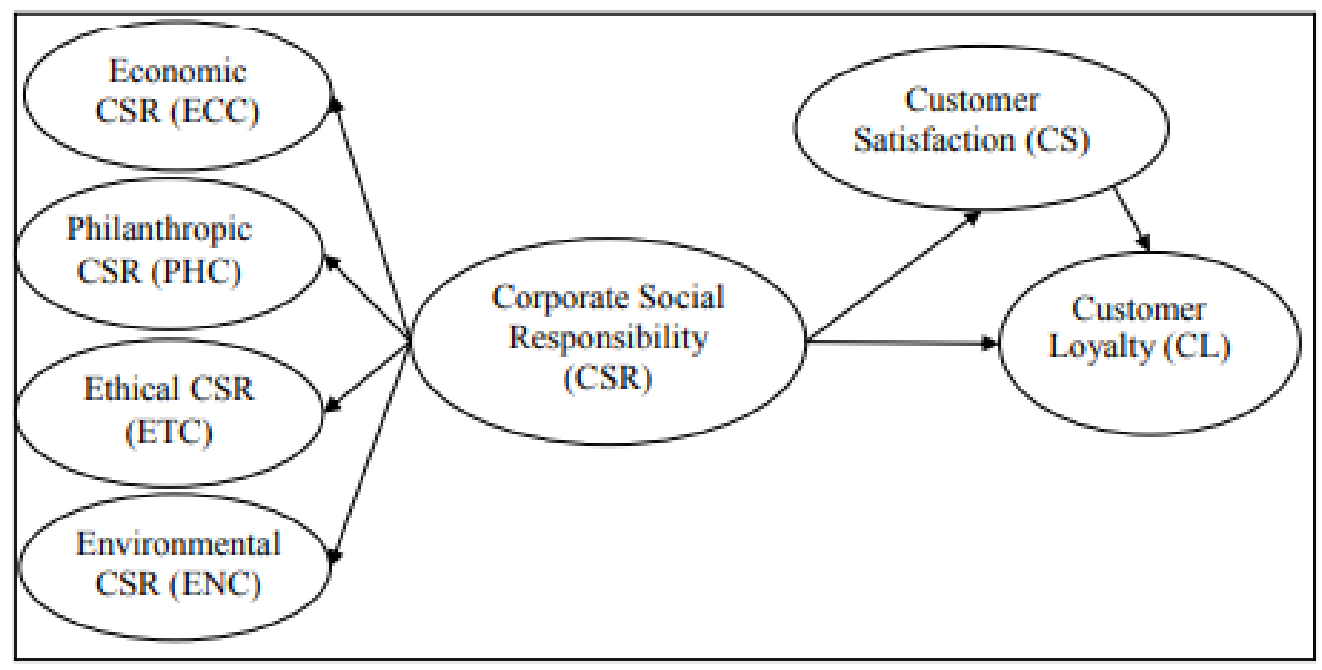

Figura 3. Modelo previo

Fuente: Puriwat, W., \& Tripopsakul, S. (2018) 


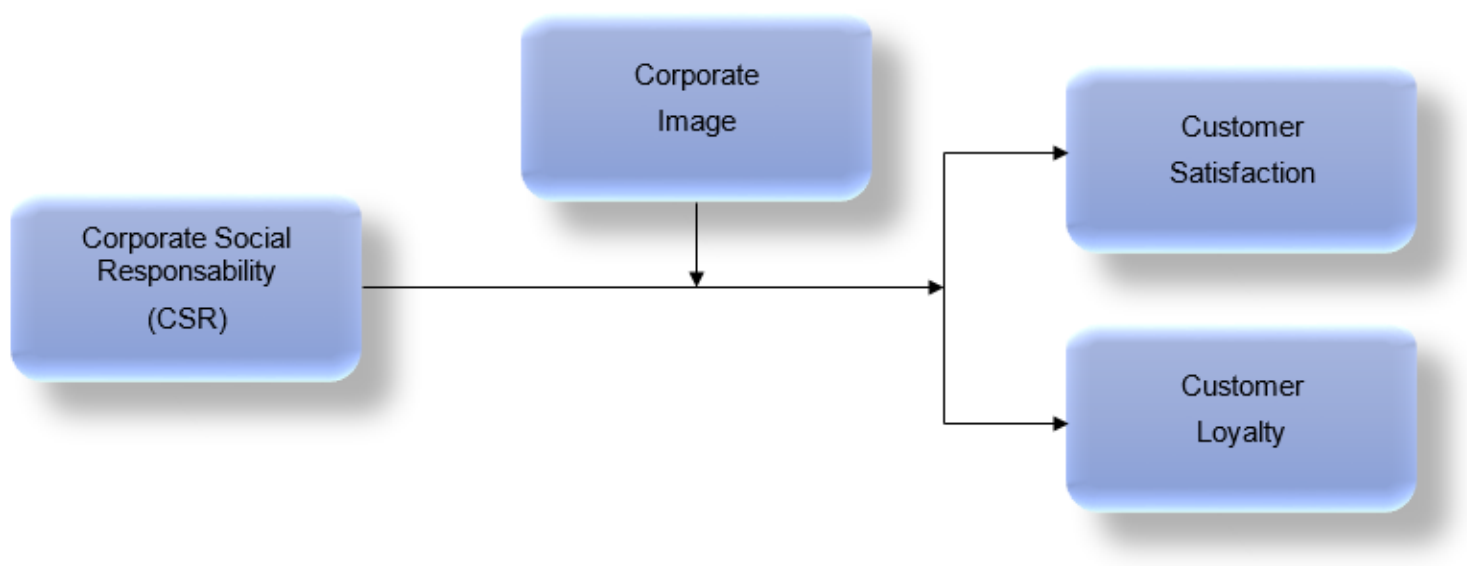

Figura 4. Modelo previo

Fuente: Irshad, A., Rahim, A., Khan, M. F., \& Khan, M. M. (2017)

1.2.2.6.2. Modelo propuesto.

A continuación, se muestra el modelo propuesto para este trabajo de investigación:

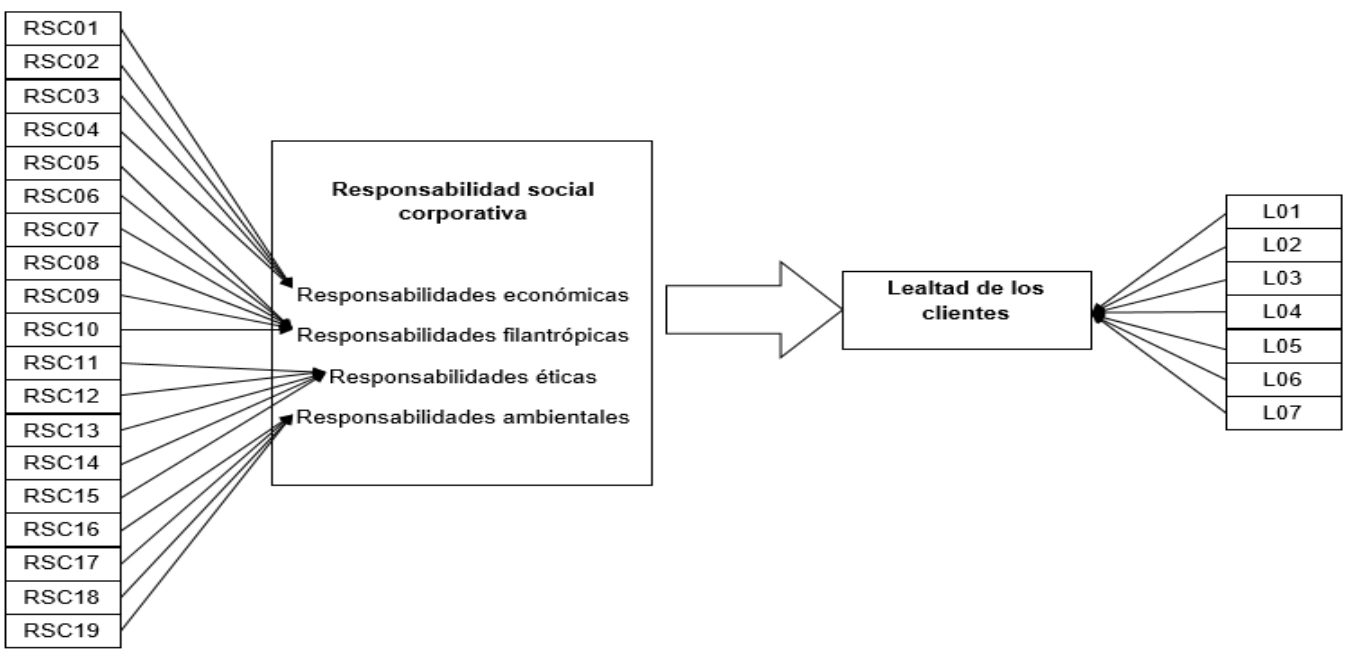

Figura 5. Modelo propuesto

Elaboración: Calderón y Chico (2020) 


\subsection{Objetivos e Hipótesis}

\subsubsection{Objetivos.}

\subsubsection{Objetivo general.}

Analizar si existe relación entre la responsabilidad social corporativa y la lealtad de los clientes en un hotel en San Borja 2020.

\subsubsection{Objetivos específicos.}

Analizar si existe relación entre las responsabilidades económicas y la lealtad de los clientes en el hotel Palmetto en San Borja 2020.

Analizar si existe relación entre las responsabilidades filantrópicas y la lealtad de los clientes en el hotel Palmetto en San Borja 2020.

Analizar si existe relación entre las responsabilidades éticas y la lealtad de los clientes en el hotel Palmetto en San Borja 2020.

Analizar si existe relación entre las responsabilidades ambientales y la lealtad de los clientes en el hotel Palmetto en San Borja 2020.

\subsubsection{Hipótesis.}

\subsubsection{Hipótesis general.}

La responsabilidad social corporativa se relaciona positivamente con la lealtad de los clientes en el hotel Palmetto en San Borja 2020.

\subsubsection{Hipótesis específicas.}

Las responsabilidades económicas se relacionan positivamente con la lealtad de los clientes en el hotel Palmetto en San Borja 2020.

Las responsabilidades filantrópicas se relacionan positivamente con la lealtad de los clientes en el hotel Palmetto en San Borja 2020.

Las responsabilidades éticas se relacionan positivamente con la lealtad de los clientes en el hotel Palmetto en San Borja 2020. 
Las responsabilidades ambientales se relacionan positivamente con la lealtad de los clientes en el hotel Palmetto en San Borja 2020. 


\section{Capítulo II}

\subsection{Método}

Como método en la presente investigación se usó un tipo cuantitativo, puesto que se utilizaron cuestionarios conformados con preguntas estándar, con la intención de que se obtengan resultados que sean cuantificables y así poder ratificar los objetivos formulados y perfeccionarlos.

\subsubsection{Tipo de investigación.}

Como tipo de investigación se empleó el tipo correlacional, que de acuerdo a Hernández, Fernández y Baptista (2014) es el tipo de investigación en donde se recolectan datos con tal de poder demostrar las hipótesis que se plantean, basados en mediciones numéricas y pruebas estadísticas pretendiendo predecir un valor cercano.

\subsubsection{Diseño de investigación.}

Como diseño de esta investigación se empleó un diseño no experimental transversal correlacional, que según Sánchez y Reyes (2000) es el diseño donde no se manejan las variables tomadas en cuenta y se estudian en su estado original.

Según Hernández et al. (2014) la presente investigación fue de corte transversal, puesto que se recolectan datos en un preciso momento, y correlacional ya que se intentó determinar la relación entre dos variables o más, con la intención de entender el comportamiento de las variables consideradas.

\subsubsection{Variables.}

Variable $(\mathrm{X} 1)$ : responsabilidad social corporativa

Puriwat, W. \& Tripopsakul, S. (2018) definieron la responsabilidad social corporativa como el compromiso continuo de las empresas de comportarse éticamente y contribuir al desarrollo económico al tiempo que mejora la calidad de vida de la fuerza laboral y sus familias, así como de la comunidad local y la sociedad en general.

Según Puriwat, W. \& Tripopsakul, S. (2018) la responsabilidad social corporativa está dividida en las siguientes dimensiones: 
- X1A: Responsabilidades económicas

- X1B: Responsabilidades filantrópicas

- X1C: Responsabilidades éticas, y

- X1D: Responsabilidades ambientales.

Variable (X2): lealtad del cliente

Según Seyedhossein N., Harihodin B., Rasimah Ch. y Mohsen M. (2017) la lealtad del cliente es definida como la probabilidad de que un cliente vuelva a comprar a la misma empresa. Y la define como una variable unidimensional.

\subsubsection{Población.}

La población estuvo conformada por 14298 clientes corporativos del hotel Palmetto que asistieron en el 2019 a su sede en San Borja (Palmetto, 2019), los que se encuentran segmentados de la siguiente manera:

Criterios de Inclusión:

- Se incluye a los clientes corporativos del Hotel Palmetto.

- Se incluye a los clientes corporativos del Hotel Palmetto que se hospedan entre 2 y 5 noches.

- Se incluye a los clientes corporativos del Hotel Palmetto mayores a 25 años o más.

Criterios de Exclusión:

- Se excluye a los clientes naturales del Hotel Palmetto

- Se excluye a los clientes del Hotel Palmetto con un número de días de alojamiento menor a 2 noches y mayor a 5 noches

- Se excluye a los clientes corporativos del Hotel Palmetto menores a 25 años

Tabla 3:

Número de clientes de Hotel Palmetto

\begin{tabular}{lc}
\hline \multicolumn{1}{c}{ Tipo de cliente } & Cantidad de clientes \\
\hline Nacional-Lima & 405 \\
Nacional-Provincia & 7490 \\
Internacional & 6403 \\
\hline Total & 14298 \\
\hline Fuente: Palmetto (2019) &
\end{tabular}




\subsubsection{Muestra.}

Para obtener la muestra, se utilizó un tipo de muestreo probabilístico de población finita y estratificado, para esto se usó la fórmula que a continuación se muestra:

$$
n=\frac{\left(\sum_{h=1}^{H} N_{h} \sqrt{p_{h}\left(1-p_{h}\right)}\right)^{2}}{\left(N^{2}\left(\mathcal{E}^{2} / Z^{2}{ }_{1-\frac{\alpha}{2}}\right)+\Sigma_{h=1}^{H} N_{h} P_{h}\left(1-p_{h}\right)\right.}
$$

Datos:

- $\mathrm{n}=$ Tamaño de muestra de los clientes corporativos del Hotel Palmetto.

- $\mathrm{N}=$ Tamaño de población: 14298 clientes corporativos del Hotel Palmetto.

- $\boldsymbol{Z}^{2}{ }_{1-\frac{\alpha}{2}}=1.96$, para un nivel de confianza del $95 \%$

- $\boldsymbol{N}_{\boldsymbol{h}}$ : Cantidad de empresas en el estrato $\mathrm{h}$.

- $\varepsilon=0.05$ : error de estimación máximo.

- $\boldsymbol{p}_{\boldsymbol{h}}=\mathbf{0 . 5}$ : proporción de clientes corporativos del Hotel Palmetto con buen desempeño en el estrato $\mathrm{h}$, se ha considerado un valor de 0.5 .

$$
n=\frac{(405 \sqrt{0.5 \times 0.5}+7490 \sqrt{0.5 \times 0.5}+6403 \sqrt{0.5 \times 05})^{2}}{14298^{2}\left(\frac{0.05^{2}}{1.96^{2}}\right)+(405 \times 0.5 \times 0.5+7490 \times 0.5 \times 0.5+6403 \times 0.5 \times 0.5)}
$$

La muestra que se toma en cuenta es de 375 clientes corporativos del Hotel Palmetto que asistieron en el 2019 y que suelen recomendar a sus empresas que hoteles usar. A continuación, se muestra la estratificación de los clientes según el tipo de cliente corporativo:

$$
\begin{gathered}
n_{1}=\frac{N_{1}}{N} \times n=\frac{405}{14298} \times 375=10.62 \cong 11 \\
n_{2}=\frac{N_{2}}{N} \times n=\frac{7490}{14298} \times 375=196.44 \cong 196 \\
n_{3}=\frac{N_{3}}{N} \times n=\frac{6403}{14298} \times 375=167.93 \cong 168
\end{gathered}
$$

Tabla 4:

Muestra de clientes de Hotel Palmetto

\begin{tabular}{lcccccc}
\hline \multirow{2}{*}{ Tipo de cliente } & $\begin{array}{c}\text { Cantidad de } \\
\text { clientes }\end{array}$ & \multicolumn{2}{c}{ Sexo } & \multicolumn{2}{c}{ Edad } \\
\cline { 3 - 6 } & 11 & 5 & 6 & 8 & 3 \\
\hline Nacional-Lima & 116 & 69 & 127 & 123 & 73 \\
Nacional-Provincia & 196 & 77 & 91 & 121 & 47 \\
Internacional & 168 & 151 & 224 & 252 & 123 \\
\hline Total & 375 & & &
\end{tabular}


Elaboración: Calderón y Chico (2020)

\subsubsection{Instrumentos de investigación.}

Los instrumentos de investigación fueron verificados por el juicio de expertos (anexo 6) mediante el coeficiente de Aiken (responsabilidad social corporativa: 0.90 y lealtad del cliente: 0.93), y se ratificó su fiabilidad por medio del Alfa de Cronbach (responsabilidades económicas: 0.919, responsabilidades filantrópicas: 0.895 , responsabilidades éticas: 0.832 responsabilidades ambientales: 0.937 y lealtad del cliente: 0.978). De igual manera las hipótesis que se plantean se corroboraron mediante la prueba de Rho de Spearman, que según los investigadores Hernández et al. (2014) es la prueba que se usa para contrastar la correlación entre dos variables cuando la muestra tiene distribución no normal y el estudio es de alcance correlacional.

Para calcular el grado de la variable responsabilidad social corporativa se usó un cuestionario comprendido por 19 ítems, con un coeficiente de Aiken igual a 0.90, dividido entre sus cuatro dimensiones: responsabilidades económicas (4 ítems), responsabilidades filantrópicas (6 ítems), responsabilidades éticas (5 ítems) y responsabilidades ambientales (4 ítems), y con una escala de Likert del 1 al 5 en donde 1 es totalmente en desacuerdo, 2 es en desacuerdo, 3 es indiferente, 4 es de acuerdo y 5 es totalmente de acuerdo. Este cuestionario les pertenece a los investigadores Puriwat, W. y Tripopsakul, S. (2018).

- Ficha técnica de cuestionario de responsabilidad social corporativa

\begin{tabular}{ll}
\hline Nombre: & Cuestionario de responsabilidad social corporativa \\
Autor: & Puriwat, W. y Tripopsakul, S. \\
Año: & 2018 \\
Procedencia: & Tailandia \\
Ámbito de aplicación: & Adultos \\
Forma de aplicación: & Individual - Colectivo \\
Edades de aplicación: & Mayores de 18 años \\
Duración: & 15 a 20 minutos \\
Versión: & inglés \\
Cantidad de preguntas: & 19 \\
Confiabilidad: & Alfa de Cronbach $=0.853$
\end{tabular}

Fuente: Puriwat, W. \& Tripopsakul, S. (2018)

Elaboración: Calderón y Chico (2020) 
En tanto que para la variable lealtad del cliente se utilizó un cuestionario con 7 ítems, con un coeficiente de Aiken igual a 0.93, y con una escala de Likert del 1 al 5 en donde 1 es totalmente en desacuerdo, 2 es en desacuerdo, 3 es indiferente, 4 es de acuerdo y 5 es totalmente de acuerdo. Este cuestionario les pertenece a los investigadores Seyedhossein N., Harihodin B., Rasimah Ch. y Mohsen M. (2017).

- Ficha técnica de cuestionario de lealtad del cliente

\begin{tabular}{ll}
\hline Nombre: & Cuestionario de lealtad del cliente \\
Autor: & Seyedhossein N., Harihodin B., Rasimah Ch. y Mohsen M. \\
Año: & 2017 \\
Procedencia: & Malasia \\
Ámbito de aplicación: & Adultos \\
Forma de aplicación: & Individual - Colectivo \\
Edades de aplicación: & Mayores de 18 años \\
Duración: & 15 a 20 minutos \\
Versión: & inglés \\
Cantidad de preguntas: & 7 \\
Confiabilidad: & Alfa de Cronbach $=0.912$ \\
\hline
\end{tabular}
Fuente: Seyedhossein N., Harihodin B., Rasimah Ch. \& Mohsen M. (2017)

Elaboración: Calderón y Chico (2020)

\subsubsection{Procedimientos de recolección de datos.}

El procedimiento de recolección de datos que se tomó en cuenta fueron dos cuestionarios, con la intención de recolectar información precisa y clara. Ambos cuestionarios fueron aplicados a los clientes corporativos del hotel Palmetto en San Borja por medio de correo electrónico que fueron facilitados por el mismo hotel, ambos cuestionarios fueron enviados previa coordinación con los clientes y se envió un consentimiento informado (anexo 7), entre los días 15 de mayo del 2020 y el 19 de junio del 2020, sin que los resultados se hayan visto afectados, y pidiéndoles que sus respuestas se den con la mayor sinceridad que puedan con la finalidad de darle solución a dichos cuestionarios. Es preciso mencionar que se realizó el contacto con los mismos clientes telefónicamente y por correo electrónico para poder efectuar las coordinaciones respectivas y pidiéndoles que los cuestionarios sean desarrollados por los mismos clientes. A continuación, los cuestionarios fueron tabulados mediante el programa SPSS 22, siendo el programa que ayudo con el desarrollo de la investigación, con tal de poder 
estudiar la relación entre las variables tomadas en cuenta, y demostrar dichas relaciones por medio del coeficiente de correlación de Rho de Spearman. 


\section{Capítulo III}

En el capítulo III se muestran los análisis de los resultados de los cuestionarios sobre la responsabilidad social corporativa y la lealtad de los clientes, igualmente se muestra la contrastación de las hipótesis (desarrollando la prueba de normalidad, el análisis factorial exploratorio, la correlación de las hipótesis mediante el coeficiente de correlación Rho Spearman, así como la contrastación de la hipótesis general y específicas), las discusiones, las conclusiones y las recomendaciones.

Cabe mencionar que dentro de toda investigación existe el error (1\% y $5 \%$ ), siendo el error del $5 \%$ el que más comúnmente se da en una investigación. Por tal motivo el nivel de significancia para este trabajo de investigación es del 5\%, por lo que las personas encargadas de desarrollar la investigación tienen $95 \%$ de confianza para la generalización de los resultados sin errar (Hernández, Fernández \& Baptista, 2014).

\subsection{Análisis de resultados de los cuestionarios}

En seguida se presentan los resultados que se han obtenido de los 375 cuestionarios que fueron aplicados a los clientes corporativos del hotel Palmetto en San Borja, de acuerdo a la relación entre la responsabilidad social corporativa y la lealtad de los clientes del mismo hotel.

\subsubsection{Análisis de los resultados de responsabilidad social corporativa}

Tabla 5:

Ganancias potenciales

RSC1. Personalmente creo que el hotel obtiene las mayores ganancias potenciales

\begin{tabular}{llrrrr}
\hline & Frecuencia & Porcentaje & $\begin{array}{c}\text { Porcentaje } \\
\text { válido }\end{array}$ & $\begin{array}{c}\text { Porcentaje } \\
\text { acumulado }\end{array}$ \\
\hline \multirow{2}{*}{ Votalmente en desacuerdo } & & & 4.5 & 4.5 & 29.1 \\
& En desacuerdo & 92 & 24.5 & 24.5 & 64.8 \\
\cline { 2 - 5 } & Indiferente & 174 & 35.7 & 35.7 & 95.5 \\
& De acuerdo & 115 & 30.7 & 30.7 & 100.0 \\
\hline
\end{tabular}

Interpretación: como se observa en la tabla 5, del total de los clientes el 35.2\% se encuentra totalmente de acuerdo y de acuerdo con la afirmación "Personalmente creo que el hotel obtiene las mayores ganancias potenciales", mientras que el $35.7 \%$ se encuentra indiferente, y el 
$29.1 \%$ se encuentra en desacuerdo y en total desacuerdo. Por lo que se llega a la conclusión que la mayoría no sabe si el hotel obtiene las mayores ganancias potenciales.

Tabla 6:

Éxito a largo plazo

RSC2. Personalmente creo que el hotel intenta lograr el éxito a largo plazo.

\begin{tabular}{llrrrr} 
& Frecuencia & Porcentaje & $\begin{array}{c}\text { Porcentaje } \\
\text { válido }\end{array}$ & $\begin{array}{r}\text { Porcentaje } \\
\text { acumulado }\end{array}$ \\
\hline \multirow{2}{*}{ Valido } & & & 2.7 & 2.7 \\
& Totalmente en desacuerdo & 10 & 2.7 & 24.0 & 26.7 \\
& En desacuerdo & 90 & 24.0 & 38.7 & 65.3 \\
& Indiferente & 145 & 38.7 & 31.2 & 96.5 \\
& De acuerdo & 117 & 31.2 & 3.5 & 100.0 \\
\cline { 2 - 6 } & Totalmente de acuerdo & 13 & 3.5 & 100.0 & \\
\hline
\end{tabular}

Interpretación: como se observa en la tabla 6, del total de los clientes el 34.7\% se encuentra totalmente de acuerdo y de acuerdo con la afirmación "Personalmente creo que el hotel intenta lograr el éxito a largo plazo", mientras que el $38.7 \%$ se encuentra indiferente, y el $26.7 \%$ se encuentra en desacuerdo y en total desacuerdo. Por lo que se llega a la conclusión que la mayoría no sabe si el hotel intenta lograr el éxito a largo plazo.

Tabla 7:

Desempeño económico

\section{RSC3. Personalmente creo que el hotel mejora el desempeño económico.}

\begin{tabular}{llrrrr} 
& Frecuencia & Porcentaje & $\begin{array}{c}\text { Porcentaje } \\
\text { válido }\end{array}$ & $\begin{array}{c}\text { Porcentaje } \\
\text { acumulado }\end{array}$ \\
\hline \multirow{2}{*}{ Valido } & & & 24.3 & 24.3 & 24.3 \\
& Totalmente en desacuerdo & 134 & 35.7 & 35.7 & 60.0 \\
& En desacuerdo & 128 & 34.1 & 34.1 & 94.1 \\
& Indiferente & 22 & 5.9 & 5.9 & 100.0 \\
\cline { 2 - 6 } & De acuerdo & 375 & 100.0 & 100.0 & \\
\hline
\end{tabular}

Interpretación: como se observa en la tabla 7, del total de los clientes el $5.9 \%$ se encuentra de acuerdo con la afirmación "Personalmente creo que el hotel mejora el desempeño económico", mientras que el $34.1 \%$ se encuentra indiferente, y el $60 \%$ se encuentra en desacuerdo y en total desacuerdo. Por lo que se llega a la conclusión que la mayoría afirma que el hotel no mejora el desempeño económico. 
Tabla 8:

Supervivencia y éxito

\begin{tabular}{lrrrr}
\hline RSC4.Personalmente creo que el hotel asegura una supervivencia y éxito en \\
el tiempo. \\
\hline & Frecuencia & Porcentaje & $\begin{array}{c}\text { Porcentaje } \\
\text { válido }\end{array}$ & $\begin{array}{r}\text { Porcentaje } \\
\text { acumulado }\end{array}$ \\
\hline \multirow{6}{*}{ Totalmente en desacuerdo } & 6 & 1.6 & 1.6 & 1.6 \\
Valido & 18 & 4.8 & 4.8 & 6.4 \\
En desacuerdo & 101 & 26.9 & 26.9 & 33.3 \\
Indiferente & 128 & 34.1 & 34.1 & 67.5 \\
De acuerdo & 122 & 32.5 & 32.5 & 100.0 \\
\hline Totalmente de acuerdo & 375 & 100.0 & 100.0 & \\
\hline
\end{tabular}

Interpretación: como se observa en la tabla 8, del total de los clientes el $66.6 \%$ se encuentra totalmente de acuerdo y de acuerdo con la afirmación "Personalmente creo que el hotel asegura una supervivencia y éxito en el tiempo", mientras que el $26.9 \%$ se encuentra indiferente, y el $6.4 \%$ se encuentra en desacuerdo y en total desacuerdo. Por lo que se llega a la conclusión que la mayoría afirma que el hotel asegura una supervivencia y éxito en el tiempo.

Tabla 9:

Resolución de problemas

RSC5. Personalmente creo que el hotel ayuda a resolver problemas de la comunidad.

\begin{tabular}{llrrrr}
\hline & Frecuencia & Porcentaje & $\begin{array}{c}\text { Porcentaje } \\
\text { válido }\end{array}$ & $\begin{array}{c}\text { Porcentaje } \\
\text { acumulado }\end{array}$ \\
\hline \multirow{2}{*}{ Valido } & & & 4.5 & 4.5 & 4.5 \\
& Totalmente en desacuerdo & 17 & 36.3 & 36.3 & 40.8 \\
& En desacuerdo & 136 & 47.5 & 47.5 & 88.3 \\
& Indiferente & 178 & 9.3 & 9.3 & 97.6 \\
& De acuerdo & 35 & 2.4 & 2.4 & 100.0 \\
\cline { 2 - 6 } & Totalmente de acuerdo & 9 & 100.0 & 100.0 & \\
\hline
\end{tabular}

Interpretación: como se observa en la tabla 9, del total de los clientes el $11.7 \%$ se encuentra totalmente de acuerdo y de acuerdo con la afirmación "Personalmente creo que el hotel ayuda a resolver problemas de la comunidad", mientras que el $47.5 \%$ se encuentra indiferente, y el $40.8 \%$ se encuentra en desacuerdo y en total desacuerdo. Por lo que se llega a la conclusión que la mayoría no sabe si el hotel ayuda a resolver problemas de la comunidad. 
Tabla 10:

Sentido de responsabilidad social corporativa

RSC6. Personalmente creo que el hotel tiene un fuerte sentido de responsabilidad social corporativa (RSC)

\begin{tabular}{llrrrr}
\hline & Frecuencia & Porcentaje & $\begin{array}{c}\text { Porcentaje } \\
\text { válido }\end{array}$ & $\begin{array}{c}\text { Porcentaje } \\
\text { acumulado }\end{array}$ \\
\hline \multirow{6}{*}{ Valido } & & & 37.3 & 37.3 & 37.3 \\
& Totalmente en desacuerdo & 140 & 46.7 & 46.7 & 84.0 \\
& En desacuerdo & 175 & 11.7 & 11.7 & 95.7 \\
& Indiferente & 44 & 3.2 & 3.2 & 98.9 \\
& De acuerdo & 12 & 1.1 & 1.1 & 100.0 \\
\cline { 2 - 6 } & Totalmente de acuerdo & 4 & 100.0 & 100.0 & \\
\hline
\end{tabular}

Interpretación: como se observa en la tabla 10, del total de los clientes el $4.3 \%$ se encuentra totalmente de acuerdo y de acuerdo con la afirmación "Personalmente creo que el hotel tiene un fuerte sentido de responsabilidad social corporativa (RSC)", mientras que el $11.7 \%$ se encuentra indiferente, y el $84 \%$ se encuentra en desacuerdo y en total desacuerdo. Por lo que se llega a la conclusión que la mayoría afirma que el hotel no tiene un fuerte sentido de responsabilidad social corporativa (RSC).

Tabla 11:

Contribuciones a la sociedad

RSC7. Personalmente creo que el hotel proporciona contribuciones suficientes a las sociedades.

\begin{tabular}{llrrrr}
\hline & Frecuencia & Porcentaje & $\begin{array}{c}\text { Porcentaje } \\
\text { válido }\end{array}$ & $\begin{array}{c}\text { Porcentaje } \\
\text { acumulado }\end{array}$ \\
\hline \multirow{2}{*}{ Valido } & & & 3.2 & 3.2 & 3.2 \\
& Totalmente en desacuerdo & 12 & 36.0 & 36.0 & 39.2 \\
& Indiferente & 135 & 47.5 & 47.5 & 86.7 \\
& De acuerdo & 42 & 11.2 & 11.2 & 97.9 \\
Totalmente de acuerdo & 8 & 2.1 & 2.1 & 100.0 \\
\hline Total & 375 & 100.0 & 100.0 & \\
\hline
\end{tabular}

Interpretación: como se observa en la tabla 11, del total de los clientes el $13.3 \%$ se encuentra totalmente de acuerdo y de acuerdo con la afirmación "Personalmente creo que el hotel proporciona contribuciones suficientes a las sociedades", mientras que el $47.5 \%$ se encuentra indiferente, y el $39.2 \%$ se encuentra en desacuerdo y en total desacuerdo. Por lo que se llega a la conclusión que la mayoría no sabe si el hotel proporciona contribuciones suficientes a las sociedades. 
Tabla 12:

Asignación de recursos

\section{RSC8. Personalmente creo que el hotel asigna recursos a actividades} filantrópicas.

\begin{tabular}{llrrrr}
\hline & Frecuencia & Porcentaje & $\begin{array}{c}\text { Porcentaje } \\
\text { válido }\end{array}$ & $\begin{array}{c}\text { Porcentaje } \\
\text { acumulado }\end{array}$ \\
\hline \multirow{2}{*}{ Valido } & & & 2.1 & 2.1 & 2.1 \\
& Totalmente en desacuerdo & 8 & 9.6 & 9.6 & 11.7 \\
& En desacuerdo & 36 & 34.7 & 34.7 & 46.4 \\
& Indiferente & 130 & 42.1 & 42.1 & 88.5 \\
& De acuerdo & 158 & 11.5 & 11.5 & 100.0 \\
\cline { 2 - 6 } & Totalmente de acuerdo & 43 & 100.0 & 100.0 & \\
\hline
\end{tabular}

Interpretación: como se observa en la tabla 12 , del total de los clientes el $53.6 \%$ se encuentra totalmente de acuerdo y de acuerdo con la afirmación "Personalmente creo que el hotel asigna recursos a actividades filantrópicas", mientras que el $34.7 \%$ se encuentra indiferente, y el $11.7 \%$ se encuentra en desacuerdo y en total desacuerdo. Por lo que se llega a la conclusión que la mayoría afirma que si el hotel si asigna recursos a actividades filantrópicas.

Tabla 13:

Papel en la sociedad

RSC9. Personalmente creo que el hotel tiene un papel en la sociedad que va más allá de la generación de ganancias.

\begin{tabular}{llrrrr}
\hline & Frecuencia & Porcentaje & $\begin{array}{c}\text { Porcentaje } \\
\text { válido }\end{array}$ & $\begin{array}{c}\text { Porcentaje } \\
\text { acumulado }\end{array}$ \\
\hline \multirow{2}{*}{ Valido } & & 4 & 1.1 & 1.1 & 1.1 \\
& Totalmente en desacuerdo & 27 & 7.2 & 7.2 & 8.3 \\
& En desacuerdo & 139 & 37.1 & 37.1 & 45.3 \\
& Indiferente & 166 & 44.3 & 44.3 & 89.6 \\
& De acuerdo & 39 & 10.4 & 10.4 & 100.0 \\
\cline { 2 - 6 } & Totalmente de acuerdo & 375 & 100.0 & 100.0 & \\
\hline
\end{tabular}

Interpretación: como se observa en la tabla 13, del total de los clientes el $54.7 \%$ se encuentra totalmente de acuerdo y de acuerdo con la afirmación "Personalmente creo que el hotel tiene un papel en la sociedad que va más allá de la generación de ganancias", mientras que el $37.1 \%$ se encuentra indiferente, y el $8.3 \%$ se encuentra en desacuerdo y en total desacuerdo. Por lo que se llega a la conclusión que la mayoría afirma que el hotel si tiene un papel en la sociedad que va más allá de la generación de ganancias. 
Tabla 14:

Motivación a empleados

\begin{tabular}{|c|c|c|c|c|c|}
\hline \multicolumn{6}{|c|}{$\begin{array}{l}\text { RSC10. Personalmente creo que el hotel motiva a los empleados a contribuir } \\
\text { en acciones voluntarias. }\end{array}$} \\
\hline & & Frecuencia & Porcentaje & $\begin{array}{l}\text { Porcentaje } \\
\text { válido }\end{array}$ & $\begin{array}{l}\text { Porcentaje } \\
\text { acumulado }\end{array}$ \\
\hline \multirow{5}{*}{ Valido } & Totalmente en desacuerdo & 133 & 35.5 & 35.5 & 35.5 \\
\hline & En desacuerdo & 188 & 50.1 & 50.1 & 85.6 \\
\hline & Indiferente & 46 & 12.3 & 12.3 & 97.9 \\
\hline & De acuerdo & 8 & 2.1 & 2.1 & 100.0 \\
\hline & Total & 375 & 100.0 & 100.0 & \\
\hline
\end{tabular}

Interpretación: como se observa en la tabla 14, del total de los clientes el $2.1 \%$ se encuentra de acuerdo con la afirmación "Personalmente creo que el hotel motiva a los empleados a contribuir en acciones voluntarias", mientras que el $12.3 \%$ se encuentra indiferente, y el $85.6 \%$ se encuentra en desacuerdo y en total desacuerdo. Por lo que se llega a la conclusión que la mayoría afirma que el hotel no motiva a los empleados a contribuir en acciones voluntarias.

Tabla 15:

Importancia de la responsabilidad social corporativa

RSC11. Personalmente creo que el hotel destaca la importancia de la RSC para los empleados

\begin{tabular}{llrrrr}
\hline & Frecuencia & Porcentaje & $\begin{array}{c}\text { Porcentaje } \\
\text { válido }\end{array}$ & $\begin{array}{c}\text { Porcentaje } \\
\text { acumulado }\end{array}$ \\
\hline \multirow{2}{*}{ Valido } & & 15 & 4.0 & 4.0 & 4.0 \\
& Totalmente en desacuerdo & 204 & 54.4 & 54.4 & 58.4 \\
& En desacuerdo & 119 & 31.7 & 31.7 & 90.1 \\
& Indiferente & 25 & 6.7 & 6.7 & 96.8 \\
& De acuerdo & 12 & 3.2 & 3.2 & 100.0 \\
\cline { 2 - 6 } & Totalmente de acuerdo & 375 & 100.0 & 100.0 & \\
\hline
\end{tabular}

Interpretación: como se observa en la tabla 15, del total de los clientes el $9.9 \%$ se encuentra totalmente de acuerdo y de acuerdo con la afirmación "Personalmente creo que el hotel destaca la importancia de la RSC para los empleados", mientras que el $31.7 \%$ se encuentra indiferente, y el $58.4 \%$ se encuentra en desacuerdo y en total desacuerdo. Por lo que se llega a la conclusión que la mayoría afirma que el hotel no destaca la importancia de la RSC para los empleados. 
Tabla 16:

Programas de ética

\begin{tabular}{|c|c|c|c|c|c|}
\hline & & Frecuencia & Porcentaje & $\begin{array}{c}\text { Porcentaje } \\
\text { válido } \\
\end{array}$ & $\begin{array}{l}\text { Porcentaje } \\
\text { acumulado }\end{array}$ \\
\hline \multirow{6}{*}{ Valido } & Totalmente en desacuerdo & 6 & 1.6 & 1.6 & 1.6 \\
\hline & En desacuerdo & 26 & 6.9 & 6.9 & 8.5 \\
\hline & Indiferente & 206 & 54.9 & 54.9 & 63.5 \\
\hline & De acuerdo & 114 & 30.4 & 30.4 & 93.9 \\
\hline & Totalmente de acuerdo & 23 & 6.1 & 6.1 & 100.0 \\
\hline & Total & 375 & 100.0 & 100.0 & \\
\hline
\end{tabular}

Interpretación: como se observa en la tabla 16, del total de los clientes el $36.5 \%$ se encuentra totalmente de acuerdo y de acuerdo con la afirmación "Personalmente creo que el hotel organiza programas de capacitación en ética para empleados", mientras que el 54.9\% se encuentra indiferente, y el $8.5 \%$ se encuentra en desacuerdo y en total desacuerdo. Por lo que se llega a la conclusión que la mayoría no sabe si el hotel organiza programas de capacitación en ética para empleados.

Tabla 17:

Entrega de información a clientes

\begin{tabular}{|c|c|c|c|c|c|}
\hline \multicolumn{6}{|c|}{$\begin{array}{l}\text { RSC13. Personalmente creo que el hotel proporciona información precisa a } \\
\text { todos los clientes. }\end{array}$} \\
\hline & & Frecuencia & Porcentaje & $\begin{array}{l}\text { Porcentaje } \\
\text { válido }\end{array}$ & $\begin{array}{l}\text { Porcentaje } \\
\text { acumulado }\end{array}$ \\
\hline \multirow{6}{*}{ Valido } & Totalmente en desacuerdo & 186 & 49.6 & 49.6 & 49.6 \\
\hline & En desacuerdo & 127 & 33.9 & 33.9 & 83.5 \\
\hline & Indiferente & 32 & 8.5 & 8.5 & 92.0 \\
\hline & De acuerdo & 24 & 6.4 & 6.4 & 98.4 \\
\hline & Totalmente de acuerdo & 6 & 1.6 & 1.6 & 100.0 \\
\hline & Total & 375 & 100.0 & 100.0 & \\
\hline
\end{tabular}

Interpretación: como se observa en la tabla 17, del total de los clientes el $8 \%$ se encuentra totalmente de acuerdo y de acuerdo con la afirmación "Personalmente creo que el hotel proporciona información precisa a todos los clientes", mientras que el $8.5 \%$ se encuentra indiferente, y el $83.5 \%$ se encuentra en desacuerdo y en total desacuerdo. Por lo que se llega a la conclusión que la mayoría afirma que el hotel no proporciona información precisa a todos los clientes. 
Tabla 18:

Código de conducta

RSC14.Personalmente creo que el hotel tiene un código de conducta integral

\begin{tabular}{|c|c|c|c|c|c|}
\hline & & Frecuencia & Porcentaje & $\begin{array}{c}\text { Porcentaje } \\
\text { válido }\end{array}$ & $\begin{array}{l}\text { Porcentaje } \\
\text { acumulado }\end{array}$ \\
\hline \multirow{6}{*}{ Valido } & Totalmente en desacuerdo & 195 & 52.0 & 52.0 & 52.0 \\
\hline & En desacuerdo & 124 & 33.1 & 33.1 & 85.1 \\
\hline & Indiferente & 31 & 8.3 & 8.3 & 93.3 \\
\hline & De acuerdo & 20 & 5.3 & 5.3 & 98.7 \\
\hline & Totalmente de acuerdo & 5 & 1.3 & 1.3 & 100.0 \\
\hline & Total & 375 & 100.0 & 100.0 & \\
\hline
\end{tabular}

Interpretación: como se observa en la tabla 18, del total de los clientes el $6.6 \%$ se encuentra totalmente de acuerdo y de acuerdo con la afirmación "Personalmente creo que el hotel tiene un código de conducta integral", mientras que el $8.3 \%$ se encuentra indiferente, y el $85.1 \%$ se encuentra en desacuerdo y en total desacuerdo. Por lo que se llega a la conclusión que la mayoría afirma que el hotel no tiene un código de conducta integral.

Tabla 19:

Compañía confiable

\begin{tabular}{|c|c|c|c|c|c|}
\hline \multicolumn{6}{|c|}{$\begin{array}{l}\text { RSC15.Personalmente creo que el hotel es reconocido como una compañía } \\
\text { confiable }\end{array}$} \\
\hline & & Frecuencia & Porcentaje & $\begin{array}{l}\text { Porcentaje } \\
\text { válido }\end{array}$ & $\begin{array}{l}\text { Porcentaje } \\
\text { acumulado }\end{array}$ \\
\hline \multirow{6}{*}{ Valido } & Totalmente en desacuerdo & 10 & 2.7 & 2.7 & 2.7 \\
\hline & En desacuerdo & 27 & 7.2 & 7.2 & 9.9 \\
\hline & Indiferente & 202 & 53.9 & 53.9 & 63.7 \\
\hline & De acuerdo & 112 & 29.9 & 29.9 & 93.6 \\
\hline & Totalmente de acuerdo & 24 & 6.4 & 6.4 & 100.0 \\
\hline & Total & 375 & 100.0 & 100.0 & \\
\hline
\end{tabular}

Interpretación: como se observa en la tabla 19, del total de los clientes el $36.3 \%$ se encuentra totalmente de acuerdo y de acuerdo con la afirmación "Personalmente creo que el hotel es reconocido como una compañía confiable", mientras que el $53.9 \%$ se encuentra indiferente, y el $9.9 \%$ se encuentra en desacuerdo y en total desacuerdo. Por lo que se llega a la conclusión que la mayoría no sabe si el hotel es reconocido como una compañía confiable. 
Tabla 20:

Productos ecológicos

\section{RSC16. Personalmente creo que el hotel intenta ofrecer productos} ecológicos.

\begin{tabular}{llrrrr}
\hline & Frecuencia & Porcentaje & $\begin{array}{c}\text { Porcentaje } \\
\text { válido }\end{array}$ & $\begin{array}{r}\text { Porcentaje } \\
\text { acumulado }\end{array}$ \\
\hline \multirow{2}{*}{ Valido } & & & 4.3 & 4.3 \\
& Totalmente en desacuerdo & 16 & 4.3 & 20.5 & 24.8 \\
& En desacuerdo & 77 & 20.5 & 50.1 & 74.9 \\
& Indiferente & 188 & 50.1 & 20.8 & 95.7 \\
& De acuerdo & 78 & 20.8 & 4.3 & 100.0 \\
\cline { 2 - 6 } & Totalmente de acuerdo & 16 & 4.3 & 100.0 & \\
\hline
\end{tabular}

Interpretación: como se observa en la tabla 20 , del total de los clientes el $25.1 \%$ se encuentra totalmente de acuerdo y de acuerdo con la afirmación "Personalmente creo que el hotel intenta ofrecer productos ecológicos", mientras que el $50.1 \%$ se encuentra indiferente, y el $24.8 \%$ se encuentra en desacuerdo y en total desacuerdo. Por lo que se llega a la conclusión que la mayoría no sabe si el hotel intenta ofrecer productos ecológicos.

Tabla 21:

Misión ambiental

\section{RSC17. Personalmente creo que el hotel tiene una misión ambiental}

\begin{tabular}{llrrrr}
\hline & Frecuencia & Porcentaje & $\begin{array}{c}\text { Porcentaje } \\
\text { válido }\end{array}$ & $\begin{array}{c}\text { Porcentaje } \\
\text { acumulado }\end{array}$ \\
\hline \multirow{2}{*}{ Valido } & & & 2.1 & 2.1 & 2.1 \\
& Totalmente en desacuerdo & 8 & 6.1 & 6.1 & 8.3 \\
& En desacuerdo & 23 & 23.7 & 23.7 & 32.0 \\
& Indiferente & 89 & 50.4 & 50.4 & 82.4 \\
& De acuerdo & 189 & 17.6 & 17.6 & 100.0 \\
\cline { 2 - 6 } & Totalmente de acuerdo & 66 & 17.6 & 100.0 & \\
\hline
\end{tabular}

Interpretación: como se observa en la tabla 21, del total de los clientes el $68 \%$ se encuentra totalmente de acuerdo y de acuerdo con la afirmación "Personalmente creo que el hotel tiene una misión ambiental", mientras que el $23.7 \%$ se encuentra indiferente, y el $8.2 \%$ se encuentra en desacuerdo y en total desacuerdo. Por lo que se llega a la conclusión que la mayoría afirma que el hotel si tiene una misión ambiental. 
Tabla 22:

Medio ambiente

\begin{tabular}{|c|c|c|c|c|c|}
\hline & & Frecuencia & Porcentaje & $\begin{array}{c}\text { Porcentaje } \\
\text { válido } \\
\end{array}$ & $\begin{array}{l}\text { Porcentaje } \\
\text { acumulado }\end{array}$ \\
\hline \multirow{6}{*}{ Valido } & Totalmente en desacuerdo & 15 & 4.0 & 4.0 & 4.0 \\
\hline & En desacuerdo & 85 & 22.7 & 22.7 & 26.7 \\
\hline & Indiferente & 200 & 53.3 & 53.3 & 80.0 \\
\hline & De acuerdo & 65 & 17.3 & 17.3 & 97.3 \\
\hline & Totalmente de acuerdo & 10 & 2.7 & 2.7 & 100.0 \\
\hline & Total & 375 & 100.0 & 100.0 & \\
\hline
\end{tabular}

Interpretación: como se observa en la tabla 22, del total de los clientes el $20 \%$ se encuentra totalmente de acuerdo y de acuerdo con la afirmación "Personalmente creo que el hotel realiza esfuerzos concertados para mantener el medio ambiente", mientras que el $53.3 \%$ se encuentra indiferente, y el $26.7 \%$ se encuentra en desacuerdo y en total desacuerdo. Por lo que se llega a la conclusión que la mayoría no sabe si el hotel realiza esfuerzos concertados para mantener el medio ambiente.

Tabla 23:

Problemas de desechos

RSC19. Personalmente creo que el hotel tiene problemas de los desechos sólidos o la basura poco preocupante

\begin{tabular}{llrrrr}
\hline & Frecuencia & Porcentaje & $\begin{array}{c}\text { Porcentaje } \\
\text { válido }\end{array}$ & $\begin{array}{c}\text { Porcentaje } \\
\text { acumulado }\end{array}$ \\
\hline \multirow{3}{*}{ Valido } & & & 3.7 & 3.7 & 3.7 \\
& Totalmente en desacuerdo & 14 & 21.1 & 21.1 & 24.8 \\
& En desacuerdo & 79 & 54.4 & 54.4 & 79.2 \\
& Indiferente & 204 & 18.7 & 18.7 & 97.9 \\
& De acuerdo & 70 & 2.1 & 2.1 & 100.0 \\
\cline { 2 - 6 } & Totalmente de acuerdo & 8 & 100.0 & 100.0 & \\
\hline
\end{tabular}

Interpretación: como se observa en la tabla 23 , del total de los clientes el $20.8 \%$ se encuentra totalmente de acuerdo y de acuerdo con la afirmación "Personalmente creo que el hotel tiene problemas de los desechos sólidos o la basura poco preocupante", mientras que el $54.4 \%$ se encuentra indiferente, y el $24.8 \%$ se encuentra en desacuerdo y en total desacuerdo. Por lo que se llega a la conclusión que la mayoría no sabe si el hotel tiene problemas de los desechos sólidos o la basura poco preocupante. 


\subsubsection{Análisis de los resultados de lealtad del cliente}

Tabla 24:

Seguir usando hotel

\begin{tabular}{llrrrr}
\multicolumn{6}{c}{ L1. Personalmente creo que seguiré utilizando el hotel. } \\
\hline & Frecuencia & Porcentaje & $\begin{array}{c}\text { Porcentaje } \\
\text { válido }\end{array}$ & $\begin{array}{c}\text { Porcentaje } \\
\text { acumulado }\end{array}$ \\
\hline \multirow{2}{*}{ Valido } & 12 & 3.2 & 3.2 & 3.2 \\
& Entalmente en desacuerdo & 36 & 9.6 & 9.6 & 12.8 \\
& Indiferente & 125 & 33.3 & 33.3 & 46.1 \\
& De acuerdo & 188 & 50.1 & 50.1 & 96.3 \\
Totalmente de acuerdo & 14 & 3.7 & 3.7 & 100.0 \\
\cline { 2 - 6 } & Total & 375 & 100.0 & 100.0 & \\
\hline
\end{tabular}

Interpretación: como se observa en la tabla 24 , del total de los clientes el $53.8 \%$ se encuentra totalmente de acuerdo y de acuerdo con la afirmación "Personalmente creo que seguiré utilizando el hotel", mientras que el $33.3 \%$ se encuentra indiferente, y el $12.8 \%$ se encuentra en desacuerdo y en total desacuerdo. Por lo que se llega a la conclusión que la mayoría afirman que seguirán utilizando el hotel.

Tabla 25:

Compra de servicios extras

\section{L2. Personalmente creo que compraré servicios adicionales del hotel.}

\begin{tabular}{llrrrr}
\hline & Frecuencia & Porcentaje & $\begin{array}{c}\text { Porcentaje } \\
\text { válido }\end{array}$ & $\begin{array}{c}\text { Porcentaje } \\
\text { acumulado }\end{array}$ \\
\hline \multirow{2}{*}{ Valido } & & & 3.2 & 3.2 & 3.2 \\
& Totalmente en desacuerdo & 12 & 10.4 & 10.4 & 13.6 \\
& Indiferente & 39 & 29.3 & 29.3 & 42.9 \\
& De acuerdo & 110 & 53.1 & 53.1 & 96.0 \\
Totalmente de acuerdo & 199 & 4.0 & 4.0 & 100.0 \\
\hline Total & 15 & 375 & 100.0 & 100.0 & \\
\hline
\end{tabular}

Interpretación: como se observa en la tabla 25 , del total de los clientes el $57.1 \%$ se encuentra totalmente de acuerdo y de acuerdo con la afirmación "Personalmente creo que compraré servicios adicionales del hotel", mientras que el $29.3 \%$ se encuentra indiferente, y el $13.6 \%$ se encuentra en desacuerdo y en total desacuerdo. Por lo que se llega a la conclusión que la mayoría afirman que compraran servicios adicionales del hotel. 
Tabla 26:

Recomendar hotel a familia y amigos

\begin{tabular}{llrrrr}
\hline L3. Personalmente creo que instaré a los familiares y amigos a usar el hotel. \\
\hline & Frecuencia & Porcentaje & $\begin{array}{c}\text { Porcentaje } \\
\text { válido }\end{array}$ & $\begin{array}{c}\text { Porcentaje } \\
\text { acumulado }\end{array}$ \\
\hline \multirow{4}{*}{ Valido } & & & .3 & .3 & .3 \\
& Totalmente en desacuerdo & 1 & 4.3 & 4.3 & 4.5 \\
& En desacuerdo & 16 & 13.9 & 13.9 & 18.4 \\
& Indiferente & 52 & 30.9 & 30.9 & 49.3 \\
& De acuerdo & 116 & 50.7 & 100.0 \\
Totalmente de acuerdo & 190 & 50.7 & 100.0 & \\
\hline
\end{tabular}

Interpretación: como se observa en la tabla 26 , del total de los clientes el $81.6 \%$ se encuentra totalmente de acuerdo y de acuerdo con la afirmación "Personalmente creo que instaré a los familiares y amigos a usar el hotel", mientras que el $13.9 \%$ se encuentra indiferente, y el $4.5 \%$ se encuentra en desacuerdo y en total desacuerdo. Por lo que se llega a la conclusión que la mayoría afirman que instaran a los familiares y amigos a usar el hotel.

Tabla 27:

Comentarios positivos a otros

\section{L4. Personalmente creo que diré comentarios positivas sobre el hotel a} otros.

\begin{tabular}{|c|c|c|c|c|c|}
\hline & & Frecuencia & Porcentaje & $\begin{array}{c}\text { Porcentaje } \\
\text { válido }\end{array}$ & $\begin{array}{l}\text { Porcentaje } \\
\text { acumulado }\end{array}$ \\
\hline \multirow{6}{*}{ Valido } & Totalmente en desacuerdo & 11 & 2.9 & 2.9 & 2.9 \\
\hline & En desacuerdo & 40 & 10.7 & 10.7 & 13.6 \\
\hline & Indiferente & 115 & 30.7 & 30.7 & 44.3 \\
\hline & De acuerdo & 189 & 50.4 & 50.4 & 94.7 \\
\hline & Totalmente de acuerdo & 20 & 5.3 & 5.3 & 100.0 \\
\hline & Total & 375 & 100.0 & 100.0 & \\
\hline
\end{tabular}

Interpretación: como se observa en la tabla 27 , del total de los clientes el $55.7 \%$ se encuentra totalmente de acuerdo y de acuerdo con la afirmación "Personalmente creo que diré comentarios positivas sobre el hotel a otros", mientras que el $30.7 \%$ se encuentra indiferente, y el $13.6 \%$ se encuentra en desacuerdo y en total desacuerdo. Por lo que se llega a la conclusión que la mayoría afirman que dirán comentarios positivas sobre el hotel a otros. 
Tabla 28:

Recomendar hotel a otros

\section{L5. Personalmente creo que recomendaría el mismo hotel a otros.}

\begin{tabular}{llrrrr}
\hline & Frecuencia & Porcentaje & $\begin{array}{c}\text { Porcentaje } \\
\text { válido }\end{array}$ & $\begin{array}{c}\text { Porcentaje } \\
\text { acumulado }\end{array}$ \\
\hline \multirow{2}{*}{ Valido } & & & 3.2 & 3.2 & 3.2 \\
& Entalmente en desacuerdo & 12 & 9.9 & 9.9 & 13.1 \\
& Indiferente & 37 & 32.8 & 32.8 & 45.9 \\
& De acuerdo & 123 & 50.7 & 50.7 & 96.5 \\
Totalmente de acuerdo & 190 & 3.5 & 3.5 & 100.0 \\
\hline Total & 13 & 375 & 100.0 & 100.0 & \\
\hline
\end{tabular}

Interpretación: como se observa en la tabla 28 , del total de los clientes el $54.2 \%$ se encuentra totalmente de acuerdo y de acuerdo con la afirmación "Personalmente creo que recomendaría el mismo hotel a otros", mientras que el $32.8 \%$ se encuentra indiferente, y el $13.1 \%$ se encuentra en desacuerdo y en total desacuerdo. Por lo que se llega a la conclusión que la mayoría afirman que recomendarían el mismo hotel a otros.

Tabla 29:

Cambio de hotel

\begin{tabular}{|c|c|c|c|c|c|}
\hline \multicolumn{6}{|c|}{$\begin{array}{l}\text { L6. Personalmente creo que no cambiaría a otro hotel, incluso a un costo } \\
\text { menor. }\end{array}$} \\
\hline & & Frecuencia & Porcentaje & $\begin{array}{l}\text { Porcentaje } \\
\text { válido }\end{array}$ & $\begin{array}{l}\text { Porcentaje } \\
\text { acumulado }\end{array}$ \\
\hline \multirow{6}{*}{ Valido } & Totalmente en desacuerdo & 49 & 13.1 & 13.1 & 13.1 \\
\hline & En desacuerdo & 115 & 30.7 & 30.7 & 43.7 \\
\hline & Indiferente & 182 & 48.5 & 48.5 & 92.3 \\
\hline & De acuerdo & 17 & 4.5 & 4.5 & 96.8 \\
\hline & Totalmente de acuerdo & 12 & 3.2 & 3.2 & 100.0 \\
\hline & Total & 375 & 100.0 & 100.0 & \\
\hline
\end{tabular}

Interpretación: como se observa en la tabla 29, del total de los clientes el $7.7 \%$ se encuentra totalmente de acuerdo y de acuerdo con la afirmación "Personalmente creo que no cambiaría a otro hotel, incluso a un costo menor", mientras que el $48.5 \%$ se encuentra indiferente, y el $43.8 \%$ se encuentra en desacuerdo y en total desacuerdo. Por lo que se llega a la conclusión que la mayoría afirman que no saben si cambiarían a otro hotel, incluso a un costo menor. 
Tabla 30:

Consideración del hotel

\begin{tabular}{|c|c|c|c|c|c|}
\hline \multicolumn{6}{|c|}{$\begin{array}{l}\text { L7. Personalmente creo que siempre consideraré el hotel como mi primera } \\
\text { opción para mi viaje futuro. }\end{array}$} \\
\hline & & Frecuencia & Porcentaje & $\begin{array}{l}\text { Porcentaje } \\
\text { válido }\end{array}$ & $\begin{array}{l}\text { Porcentaje } \\
\text { acumulado }\end{array}$ \\
\hline \multirow{6}{*}{ Valido } & Totalmente en desacuerdo & 12 & 3.2 & 3.2 & 3.2 \\
\hline & En desacuerdo & 37 & 9.9 & 9.9 & 13.1 \\
\hline & Indiferente & 115 & 30.7 & 30.7 & 43.7 \\
\hline & De acuerdo & 199 & 53.1 & 53.1 & 96.8 \\
\hline & Totalmente de acuerdo & 12 & 3.2 & 3.2 & 100.0 \\
\hline & Total & 375 & 100.0 & 100.0 & \\
\hline
\end{tabular}

Interpretación: como se observa en la tabla 30 , del total de los clientes el $56.3 \%$ se encuentra totalmente de acuerdo y de acuerdo con la afirmación "Personalmente creo que siempre consideraré el hotel como mi primera opción para mi viaje futuro", mientras que el $30.7 \%$ se encuentra indiferente, y el $13.1 \%$ se encuentra en desacuerdo y en total desacuerdo. Por lo que se llega a la conclusión que la mayoría afirman que siempre consideraran el hotel como su primera opción para un viaje futuro.

\subsection{Contrastación de hipótesis}

\subsubsection{Prueba de normalidad de Kolmogórov-Smirnov}

En la presente investigación se realizó la prueba de Kolmogórov-Smirnov con la finalidad de conocer si los datos reunidos poseen una distribución no paramétrica o paramétrica, en otras palabras, si la distribución de la muestra tiene una relación con la distribución teórica. Como se puede observar en la tabla 31 y 32 , los datos obtenidos de los cuestionarios que se han aplicado no tienen distribución normal ya que su significancia es de $0.000<0.05$ por lo tanto, se llega a la conclusión que la distribución es no normal y por ende su distribución es no paramétrica.

Tabla 31:

Prueba de normalidad Kolmogórov-Smirnov RSC

\begin{tabular}{lllllll}
\hline \multicolumn{5}{c}{ Pruebas de normalidad } \\
\hline & Kolmogorov-Smirnova & \multicolumn{3}{c}{ Shapiro-Wilk } \\
\hline & Estadística & df & Sig. & Estadística & df & Sig. \\
\hline $\begin{array}{l}\text { RSC1. Personalmente creo que el hotel obtiene las mayores } \\
\text { ganancias potenciales }\end{array}$ & .189 & 375 & .000 & .898 & 375 & .000
\end{tabular}


RSC2. Personalmente creo que el hotel intenta lograr el éxito a largo plazo.

\begin{tabular}{|c|c|c|c|c|c|}
\hline .194 & 375 & .000 & .885 & 375 & .000 \\
\hline .214 & 375 & .000 & .863 & 375 & .000 \\
\hline .203 & 375 & .000 & .856 & 375 & .000 \\
\hline .244 & 375 & .000 & .854 & 375 & .000 \\
\hline .264 & 375 & .000 & .797 & 375 & .000 \\
\hline .242 & 375 & .000 & .852 & 375 & .000 \\
\hline .243 & 375 & .000 & .881 & 375 & .000 \\
\hline .253 & 375 & .000 & .866 & 375 & .000 \\
\hline .253 & 375 & .000 & .802 & 375 & .000 \\
\hline .318 & 375 & .000 & .795 & 375 & .000 \\
\hline .300 & 375 & .000 & .833 & 375 & .000 \\
\hline .282 & 375 & .000 & .755 & 375 & .000 \\
\hline .299 & 375 & .000 & .741 & 375 & .000 \\
\hline .284 & 375 & .000 & .842 & 375 & .000 \\
\hline .251 & 375 & .000 & .883 & 375 & .000 \\
\hline .290 & 375 & .000 & .852 & 375 & .000 \\
\hline .272 & 375 & .000 & .866 & 375 & .000 \\
\hline .280 & 375 & .000 & .860 & 375 & .000 \\
\hline
\end{tabular}

RSC3. Personalmente creo que el hotel mejora el desempeño económico.

RSC4.Personalmente creo que el hotel asegura una

supervivencia y éxito en el tiempo.

RSC5. Personalmente creo que el hotel ayuda a resolver

problemas de la comunidad.

RSC6. Personalmente creo que el hotel tiene un fuerte sentido

de responsabilidad social corporativa (RSC)

RSC7. Personalmente creo que el hotel proporciona

contribuciones suficientes a las sociedades.

RSC8. Personalmente creo que el hotel asigna recursos a

actividades filantrópicas.

RSC9. Personalmente creo que el hotel tiene un papel en la

sociedad que va más allá de la generación de ganancias.

RSC10. Personalmente creo que el hotel motiva a los

empleados a contribuir en acciones voluntarias.

RSC11. Personalmente creo que el hotel destaca la importancia de la RSC para los empleados

RSC12. Personalmente creo que el hotel organiza programas de capacitación en ética para empleados.

RSC13. Personalmente creo que el hotel proporciona

información precisa a todos los clientes.

RSC14.Personalmente creo que el hotel tiene un código de

conducta integral

RSC15.Personalmente creo que el hotel es reconocido como

una compañía confiable

RSC16. Personalmente creo que el hotel intenta ofrecer

productos ecológicos.

RSC17. Personalmente creo que el hotel tiene una misión

ambiental

RSC18. Personalmente creo que el hotel realiza esfuerzos

concertados para mantener el medio ambiente.

RSC19. Personalmente creo que el hotel tiene problemas de los desechos sólidos o la basura poco preocupante

Elaboración: Calderón y Chico (2020) - Extraído del SPSS (2020) 
Tabla 32:

Prueba de normalidad Kolmogorov-Smirnov Lealtad del cliente

\begin{tabular}{|c|c|c|c|c|c|c|}
\hline \multicolumn{7}{|c|}{ Pruebas de normalidad } \\
\hline & \multicolumn{3}{|c|}{ Kolmogorov-Smirnov ${ }^{a}$} & \multicolumn{3}{|c|}{ Shapiro-Wilk } \\
\hline & Estadística & df & Sig. & Estadística & df & Sig. \\
\hline L1. Personalmente creo que seguiré utilizando el hotel. & 296 & 375 & .000 & .822 & 375 & .000 \\
\hline $\begin{array}{l}\text { L2. Personalmente creo que compraré servicios adicionales del } \\
\text { hotel. }\end{array}$ & 314 & 375 & .000 & .813 & 375 & .000 \\
\hline $\begin{array}{l}\text { L3. Personalmente creo que instaré a los familiares y amigos a } \\
\text { usar el hotel. }\end{array}$ & .303 & 375 & .000 & .773 & 375 & .000 \\
\hline $\begin{array}{l}\text { L4. Personalmente creo que diré comentarios positivos sobre el } \\
\text { hotel a otros. }\end{array}$ & 297 & 375 & .000 & .836 & 375 & .000 \\
\hline $\begin{array}{l}\text { L5. Personalmente creo que recomendaría el mismo hotel a } \\
\text { otros. }\end{array}$ & 299 & 375 & .000 & .818 & 375 & .000 \\
\hline $\begin{array}{l}\text { L6. Personalmente creo que no cambiaría a otro hotel, incluso a } \\
\text { un costo menor. }\end{array}$ & 259 & 375 & .000 & .855 & 375 & .000 \\
\hline $\begin{array}{l}\text { L7. Personalmente creo que siempre consideraré el hotel como } \\
\text { mi primera opción para mi viaje futuro. }\end{array}$ & 314 & 375 & .000 & .805 & 375 & .000 \\
\hline
\end{tabular}

Elaboración: Calderón y Chico (2020) - Extraído del SPSS (2020)

\subsubsection{Análisis factorial (validación del constructo)}

Para ratificar las dimensiones de las dos variables en estudio, así como de los ítems de los dos cuestionarios se usó para el análisis factorial exploratorio el método Varimax para la rotación y el método de componentes principales para la extracción. Los resultados que se lograron alcanzar para la variable de responsabilidad social corporativa son: 0.830 en el estadístico Kaiser-Meyer-Olkin (KMO), 5184.774 aproximadamente en el Chi-cuadrado y 0.000 en la significancia (tabla 33). Por tal motivo se observa un buen ajuste factorial en base a la aplicación del estadístico KMO, llegando a obtener 4 dimensiones o factores que explican el $72.414 \%$ de la varianza total y la matriz de componente (tabla 34 ).

Tabla 33:

Prueba de KMO, Bartlett y método de extracción

\begin{tabular}{|c|c|c|}
\hline \multicolumn{3}{|c|}{ Prueba de KMO y Bartlett } \\
\hline \multicolumn{2}{|c|}{ Medida Kaiser-Meyer-Olkin de adecuación de muestreo. } & .830 \\
\hline \multirow[t]{3}{*}{ Prueba de esfericidad de Bartlett } & Aprox. Chi-cuadrado & 5184.774 \\
\hline & Df & 171 \\
\hline & Sig. & .000 \\
\hline
\end{tabular}

Elaboración: Calderón y Chico (2020) - Extraído del SPSS (2020) 
El primer factor es la dimensión "responsabilidades filantrópicas" y posee una varianza de $25.736 \%$, el segundo factor es la dimensión "responsabilidades ambientales" y posee una varianza de $17.872 \%$, el tercer factor es la dimensión "responsabilidades económicas" y posee una varianza de $15.198 \%$ y el cuarto factor es la dimensión "responsabilidades éticas" y posee una varianza de $13.608 \%$.

Tabla 34:

Varianza total explicada - Responsabilidad social corporativa

\begin{tabular}{|c|c|c|c|c|c|c|c|c|c|}
\hline \multicolumn{10}{|c|}{ Varianza total explicada } \\
\hline \multirow[t]{2}{*}{ Componente } & \multicolumn{3}{|c|}{ Valores propios iniciales } & \multicolumn{3}{|c|}{$\begin{array}{l}\text { Sumas de rotación de cargas al } \\
\text { cuadrado }\end{array}$} & \multicolumn{3}{|c|}{$\begin{array}{l}\text { Sumas de rotación de cargas al } \\
\text { cuadrado }\end{array}$} \\
\hline & Total & $\begin{array}{c}\% \text { de } \\
\text { varianza }\end{array}$ & $\begin{array}{c}\% \\
\text { acumulado }\end{array}$ & Total & $\begin{array}{c}\% \text { de } \\
\text { varianza }\end{array}$ & $\begin{array}{c}\% \\
\text { acumulado }\end{array}$ & Total & $\begin{array}{c}\% \text { de } \\
\text { varianza }\end{array}$ & $\begin{array}{c}\% \\
\text { acumulado }\end{array}$ \\
\hline 1 & 4.890 & 25.736 & 25.736 & 4.890 & 25.736 & 25.736 & 4.008 & 21.097 & 21.097 \\
\hline 2 & 3.396 & 17.872 & 43.608 & 3.396 & 17.872 & 43.608 & 3.424 & 18.019 & 39.116 \\
\hline 3 & 2.888 & 15.198 & 58.806 & 2.888 & 15.198 & 58.806 & 3.229 & 16.996 & 56.111 \\
\hline 4 & 2.586 & 13.608 & 72.414 & 2.586 & 13.608 & 72.414 & 3.098 & 16.303 & 72.414 \\
\hline
\end{tabular}

Elaboración: Calderón y Chico (2020) - Extraído del SPSS (2020)

Según el método Varimax, el cual se utiliza para poder disminuir la expresión del subespacio determinado en componentes importantes, con normalidad Kaiser, el primer factor en la matriz de componente es la dimensión "responsabilidades filantrópicas" y se encuentra entre los ítems 5 y 10, el segundo factor en la matriz de componente es la dimensión "responsabilidades ambientales" y se encuentra entre los ítems 16 y 19, el tercer factor en la matriz de componente es la dimensión "responsabilidades económicas" y se encuentra entre los ítems 1 y 4 y el cuarto factor en la matriz de componente es la dimensión "responsabilidades éticas" y se encuentra entre los ítems 11 y 15.

Tabla 35:

Matriz de componente rotado de gestión del conocimiento - Método de rotación Varimax con normalización Kaiser

Matriz de componente rotado

\begin{tabular}{l}
\hline \\
\cline { 2 - 2 } Componente \\
\cline { 2 - 3 }
\end{tabular}

RSC7. Personalmente creo que el hotel proporciona contribuciones suficientes a las sociedades.

RSC10. Personalmente creo que el hotel motiva a los empleados a contribuir en acciones voluntarias. 
RSC5. Personalmente creo que el hotel ayuda a resolver problemas de la comunidad.

.854

RSC9. Personalmente creo que el hotel tiene un papel en la sociedad que va más allá de la generación de ganancias.

RSC6. Personalmente creo que el hotel tiene un fuerte sentido de responsabilidad social corporativa (RSC)

RSC8. Personalmente creo que el hotel asigna recursos a actividades filantrópicas.

RSC19. Personalmente creo que el hotel tiene problemas de los desechos sólidos o la basura poco preocupante

RSC18. Personalmente creo que el hotel realiza esfuerzos concertados para mantener el medio ambiente.

RSC16. Personalmente creo que el hotel intenta ofrecer productos ecológicos.

RSC17. Personalmente creo que el hotel tiene una misión ambiental

RSC2. Personalmente creo que el hotel intenta lograr el éxito a largo plazo.

RSC1. Personalmente creo que el hotel obtiene las mayores ganancias potenciales

RSC3. Personalmente creo que el hotel mejora el desempeño económico.

RSC4.Personalmente creo que el hotel asegura una supervivencia y éxito en el tiempo.

RSC11. Personalmente creo que el hotel destaca la importancia de la RSC para los empleados

RSC12. Personalmente creo que el hotel organiza programas de capacitación en ética para empleados.

RSC15.Personalmente creo que el hotel es reconocido como una compañía confiable

RSC14.Personalmente creo que el hotel tiene un código de conducta integral

RSC13. Personalmente creo que el hotel proporciona información precisa a todos los clientes.

Elaboración: Calderón y Chico (2020) - Extraído del SPSS (2020)

Los resultados que se lograron alcanzar para la variable de lealtad del cliente son: 0.933 en el estadístico Kaiser-Meyer-Olkin (KMO), 5061.660 aproximadamente en el Chi-cuadrado y 0.000 en la significancia (tabla 36). Por tal motivo se observa un buen ajuste factorial en base a la aplicación del estadístico KMO, llegando a obtener una sola dimensión o factor que explica el $88.806 \%$ de la varianza total y la matriz de componente (tabla 37 ).

Tabla 36:

Prueba de KMO, Bartlett y método de extracción

\begin{tabular}{|c|c|c|}
\hline \multicolumn{3}{|c|}{ Prueba de KMO y Bartlett } \\
\hline \multicolumn{2}{|c|}{ Medida Kaiser-Meyer-Olkin de adecuación de muestreo. } & .933 \\
\hline \multirow[t]{3}{*}{ Prueba de esfericidad de Bartlett } & Aprox. Chi-cuadrado & 5061.660 \\
\hline & Df & 21 \\
\hline & Sig. & .000 \\
\hline
\end{tabular}

Elaboración: Calderón y Chico (2020) - Extraído del SPSS (2020) 
Tabla 37:

Varianza total explicada - Lealtad del cliente

\begin{tabular}{ccccccc}
\hline & \multicolumn{5}{c}{ Varianza total explicada } \\
\hline \multirow{2}{*}{ Componente } & \multicolumn{5}{c}{ Valores propios iniciales } & \multicolumn{2}{c}{ Sumas de rotación de cargas al cuadrado } \\
\cline { 2 - 6 } & Total & \% de varianza & \% acumulado & Total & \% de varianza & \% acumulado \\
\hline 1 & 6.216 & 88.806 & 88.806 & 6.216 & 88.806 & 88.806 \\
\hline
\end{tabular}

Elaboración: Calderón y Chico (2020) - Extraído del SPSS (2020)

Según el método Varimax, el cual se utiliza para poder disminuir la expresión del subespacio determinado en componentes importantes, con normalidad Kaiser, la única dimensión de la lealtad del cliente se encuentra entre los ítems 1 y 7.

Tabla 38:

Matriz de componente - Lealtad del cliente

\section{Matriz de componente}

Componente

1

L7. Personalmente creo que siempre consideraré el hotel como mi primera opción para mi viaje futuro.

L5. Personalmente creo que recomendaría el mismo hotel a otros.

L2. Personalmente creo que compraré servicios adicionales del hotel.

L1. Personalmente creo que seguiré utilizando el hotel.

L4. Personalmente creo que diré comentarios positivos sobre el hotel a otros.

L6. Personalmente creo que no cambiaría a otro hotel, incluso a un costo menor.

L3. Personalmente creo que instaré a los familiares y amigos a usar el hotel. .863

Elaboración: Calderón y Chico (2020) - Extraído del SPSS (2020) 


\subsubsection{Correlaciones Rho de Spearman}

En base a los resultados alcanzados basados en los dos cuestionarios aplicados a los clientes corporativos del hotel Palmetto en San Borja, se llega a mostrar las relaciones encontradas entre la responsabilidad social corporativa y la lealtad de los clientes.

Tabla 39:

Correlación Rho Spearman

\begin{tabular}{|c|c|c|c|c|c|c|c|}
\hline \multicolumn{8}{|c|}{ Correlación Rho Spearman } \\
\hline & & & Resp_eco & Resp_filan & Resp_etic & Resp_amb & Lealtad \\
\hline & & Coeficiente de correlación & 1.000 & $.188^{* \star}$ & $.174^{* *}$ & $.130^{\star}$ & $.445^{* \star}$ \\
\hline & Resp_eco & Sig. (2-tailed) & . & .000 & .001 & .011 & .000 \\
\hline & & $\mathrm{N}$ & 375 & 375 & 375 & 375 & 375 \\
\hline & & Coeficiente de correlación & $.188^{* *}$ & 1.000 & $.131^{*}$ & .048 & $.309^{* *}$ \\
\hline & Resp_filan & Sig. (2-tailed) & .000 & . & .011 & .351 & .000 \\
\hline & & $\mathrm{N}$ & 375 & 375 & 375 & 375 & 375 \\
\hline & & Coeficiente de correlación & $.174^{* *}$ & $.131^{*}$ & 1.000 & .086 & $.275^{* *}$ \\
\hline \multirow[t]{8}{*}{ Spearman's rho } & Resp_etic & Sig. (2-tailed) & .001 & .011 & . & .096 & .000 \\
\hline & & $\mathrm{N}$ & 375 & 375 & 375 & 375 & 375 \\
\hline & & Coeficiente de correlación & $.130^{*}$ & .048 & .086 & 1.000 & $.208^{* *}$ \\
\hline & Resp_amb & Sig. (2-tailed) & .011 & .351 & .096 & . & .000 \\
\hline & & $\mathrm{N}$ & 375 & 375 & 375 & 375 & 375 \\
\hline & & Coeficiente de correlación & $.445^{\star *}$ & $.309^{* \star}$ & $.275^{\star *}$ & $.208^{* *}$ & 1.000 \\
\hline & Lealtad & Sig. (2-tailed) & .000 & .000 & .000 & .000 & . \\
\hline & & $\mathrm{N}$ & 375 & 375 & 375 & 375 & 375 \\
\hline
\end{tabular}

**. La correlación es significativa en el nivel 0.01 (bilateral); *. La correlación es significativa en el nivel 0,05 (bilateral).

Elaboración: Calderón y Chico (2020) - Extraído del SPSS (2020) 


\subsubsection{Contrastación de las hipótesis}

Las hipótesis que se plantean se corroboran por medio de la prueba Rho de Spearman, la cual se usó para poder reunir datos exactos, como a continuación se muestra.

\subsubsection{Hipótesis general.}

La responsabilidad social corporativa se relaciona positivamente con la lealtad de los clientes corporativos en el hotel Palmetto en San Borja 2020.

\section{i. Planteamiento de las hipótesis}

Ho: $\rho=0$, (La responsabilidad social corporativa NO se relaciona positivamente con la lealtad de los clientes corporativos en el hotel Palmetto en San Borja 2020)

$H 1: \rho \neq 0$, (La responsabilidad social corporativa SI se relaciona positivamente con la lealtad de los clientes corporativos en el hotel Palmetto en San Borja 2020)

\section{ii. Nivel de significancia ( $\alpha)$}

El nivel de significancia que se considera es de $\alpha=0.05$

\section{iii. Cálculo del estadístico de prueba:}

Tabla 40:

Resultado de Rho de Spearman - Hipótesis general

\begin{tabular}{|c|c|c|c|}
\hline & & & Lealtad \\
\hline \multirow{3}{*}{ Spearman's rho } & \multirow{3}{*}{ RSC } & Coeficiente de correlación & $.533^{* *}$ \\
\hline & & Sig. (2-tailed) & .000 \\
\hline & & $N$ & 375 \\
\hline
\end{tabular}

Elaboración: Calderón y Chico (2020) - Extraído del SPSS (2020)

\section{iv. Toma de decisiones}

Existe evidencia estadística para $\mathrm{RH}$, ya que se muestra un nivel de significancia de menor a 0.05 ( $r=0.533$; p_valor $=0.000<0.05)$, por lo que se llega a afirmar que la responsabilidad social corporativa si se relaciona con la lealtad de los clientes corporativos en el hotel Palmetto en San Borja 2020. 


\subsubsection{Primera hipótesis específica.}

Las responsabilidades económicas se relacionan positivamente con la lealtad de los clientes corporativos en el hotel Palmetto en San Borja 2020.

\section{i. Planteamiento de las hipótesis}

Ho: $\rho=0$, (Las responsabilidades económicas NO se relaciona positivamente con la lealtad de los clientes corporativos en el hotel Palmetto en San Borja 2020)

H1: $\rho \neq 0$, (Las responsabilidades económicas SI se relaciona positivamente con la lealtad de los clientes corporativos en el hotel Palmetto en San Borja 2020)

\section{ii. $\quad$ Nivel de significancia $(\alpha)$}

El nivel de significancia que se considera es de $\alpha=0.05$

\section{iii. Cálculo del estadístico de prueba:}

Tabla 41:

Resultado de Rho de Spearman - Primera hipótesis específica

\begin{tabular}{lcccc}
\hline PRUEBA ESTADÍSTICA & $\begin{array}{c}\text { NIVEL DE } \\
\text { SIGNIFICANCIA }\end{array}$ & SIGNIFICANCIA & $\begin{array}{c}\text { COEFICIENTE } \\
\text { DE } \\
\text { CORRELACION }\end{array}$ & CONCLUSIÓN \\
\hline Rho de Spearman & 0.05 & 0.000 & 0.445 & $\begin{array}{c}<5 \% \text { se rechaza } \\
\text { la hipótesis nula }\end{array}$ \\
\hline
\end{tabular}

Elaboración: Calderón y Chico (2020) - Extraído del SPSS (2020)

\section{iv. Toma de decisiones}

Existe evidencia estadística para $\mathrm{RH}$, ya que se muestra un nivel de significancia de menor a 0.05 ( $r=0.445$; p_valor $=0.000<0.05)$, por lo que se llega a afirmar que las responsabilidades económicas si se relacionan con la lealtad de los clientes corporativos en el hotel Palmetto en San Borja 2020. 


\subsubsection{Segunda hipótesis específica.}

Las responsabilidades filantrópicas se relacionan positivamente con la lealtad de los clientes corporativos en el hotel Palmetto en San Borja 2020.

\section{i. Planteamiento de las hipótesis}

Ho: $\rho=0$, (Las responsabilidades filantrópicas NO se relacionan positivamente con la lealtad de los clientes corporativos en el hotel Palmetto en San Borja 2020)

H1: $\rho \neq 0$, (Las responsabilidades filantrópicas SI se relacionan positivamente con la lealtad de los clientes corporativos en el hotel Palmetto en San Borja 2020)

\section{ii. $\quad$ Nivel de significancia $(\alpha)$}

El nivel de significancia que se considera es de $\alpha=0.05$

\section{iii. Cálculo del estadístico de prueba:}

Tabla 42:

Resultado de Rho de Spearman - Segunda hipótesis específica

\begin{tabular}{lcccc}
\hline PRUEBA ESTADÍSTICA & $\begin{array}{c}\text { NIVEL DE } \\
\text { SIGNIFICANCIA }\end{array}$ & SIGNIFICANCIA & $\begin{array}{c}\text { COEFICIENTE } \\
\text { DE } \\
\text { CORRELACION }\end{array}$ & CONCLUSIÓN \\
\hline Rho de Spearman & 0.05 & 0.000 & 0.309 & $\begin{array}{c}<5 \% \text { se rechaza } \\
\text { la hipótesis nula }\end{array}$ \\
\hline
\end{tabular}

Elaboración: Calderón y Chico (2020) - Extraído del SPSS (2020)

\section{iv. Toma de decisiones}

Existe evidencia estadística para $\mathrm{RH}$, ya que se muestra un nivel de significancia de menor a 0.05 ( $r=0.309$; p_valor $=0.000<0.05)$, por lo que se llega a afirmar que las responsabilidades filantrópicas si se relacionan con la lealtad de los clientes corporativos en el hotel Palmetto en San Borja 2020. 


\subsubsection{Tercera hipótesis específica.}

Las responsabilidades éticas se relacionan positivamente con la lealtad de los clientes corporativos en el hotel Palmetto en San Borja 2020.

\section{i. Planteamiento de las hipótesis}

Ho: $\rho=0$, (Las responsabilidades éticas NO se relacionan positivamente con la lealtad de los clientes corporativos en el hotel Palmetto en San Borja 2020)

H1: $\rho \neq 0$, (Las responsabilidades éticas SI se relacionan positivamente con la lealtad de los clientes corporativos en el hotel Palmetto en San Borja 2020)

\section{ii. $\quad$ Nivel de significancia $(\alpha)$}

El nivel de significancia que se considera es de $\alpha=0.05$

\section{iii. Cálculo del estadístico de prueba:}

Tabla 43:

Resultado de Rho de Spearman - Tercera hipótesis específica

\begin{tabular}{lcccc}
\hline PRUEBA ESTADísticA & $\begin{array}{c}\text { NIVEL DE } \\
\text { SIGNIFICANCIA }\end{array}$ & SIGNIFICANCIA & $\begin{array}{c}\text { COEFICIENTE } \\
\text { DE } \\
\text { CORRELACION }\end{array}$ & CONCLUSIÓN \\
\hline Rho de Spearman & 0.05 & 0.000 & 0.275 & $\begin{array}{c}<5 \% \text { se rechaza } \\
\text { la hipótesis nula }\end{array}$ \\
\hline
\end{tabular}

Elaboración: Calderón y Chico (2020) - Extraído del SPSS (2020)

\section{iv. Toma de decisiones}

Existe evidencia estadística para $\mathrm{RH}$, ya que se muestra un nivel de significancia de menor a 0.05 ( $r=0.275$; p_valor $=0.000<0.05)$, por lo que se llega a afirmar que las responsabilidades éticas si se relacionan con la lealtad de los clientes corporativos en el hotel Palmetto en San Borja 2020. 


\subsubsection{Cuarta hipótesis específica.}

Las responsabilidades ambientales se relacionan positivamente con la lealtad de los clientes corporativos en el hotel Palmetto en San Borja 2020.

\section{i. Planteamiento de las hipótesis}

Ho: $\rho=0$, (Las responsabilidades ambientales NO se relacionan positivamente con la lealtad de los clientes corporativos en el hotel Palmetto en San Borja 2020)

$\mathrm{H} 1: \rho \neq 0$, (Las responsabilidades ambientales SI se relacionan positivamente con la lealtad de los clientes corporativos en el hotel Palmetto en San Borja 2020)

\section{ii. $\quad$ Nivel de significancia $(\alpha)$}

El nivel de significancia que se considera es de $\alpha=0.05$.

\section{iii. Cálculo del estadístico de prueba:}

Tabla 44:

Resultado de Rho de Spearman - Cuarta hipótesis específica

\begin{tabular}{lcccc}
\hline PRUEBA ESTADístiCA & $\begin{array}{c}\text { NIVEL DE } \\
\text { SIGNIFICANCIA }\end{array}$ & SIGNIFICANCIA & $\begin{array}{c}\text { COEFICIENTE } \\
\text { DE } \\
\text { CORRELACION }\end{array}$ & CONCLUSIÓN \\
\hline Rho de Spearman & 0.05 & 0.000 & 0.208 & $\begin{array}{c}<5 \% \text { se rechaza } \\
\text { la hipótesis nula }\end{array}$ \\
\hline
\end{tabular}

Elaboración: Calderón y Chico (2020) - Extraído del SPSS (2020)

\section{iv. Toma de decisiones}

Existe evidencia estadística para $\mathrm{RH}$, ya que se muestra un nivel de significancia de menor a 0.05 ( $r=0.208$; p_valor $=0.000<0.05)$, por lo que se llega a afirmar que las responsabilidades ambientales si se relacionan con la lealtad de los clientes corporativos en el hotel Palmetto en San Borja 2020. 


\subsection{Discusión}

En la presente investigación titulada "Relación de la responsabilidad social corporativa y la lealtad de clientes en el hotel Palmetto de San Borja 2020" fueron desarrollados dos cuestionarios, los mismos que se aplicaron a los clientes del hotel Palmetto en San Borja, en cuanto a la relación entre las variables que se estudian en esta investigación: el cuestionario de responsabilidad social corporativa de los investigadores Puriwat, W. y Tripopsakul, S. (2018) y el cuestionario de lealtad de clientes de los investigadores Seyedhossein N., Harihodin B., Rasimah Ch. y Mohsen M. (2017). Los mismos que se utilizaron con la finalidad de analizar la relación entre las variables en estudio. Los resultados que se lograron obtener basados en los cuestionarios muestran semejanza con resultados de otros investigadores, como se presentan a continuación.

\section{Hipótesis general}

Según los resultados que se han presentado en la presente investigación, la hipótesis general "La responsabilidad social corporativa se relaciona positivamente con la lealtad de los clientes corporativos en el hotel Palmetto en San Borja 2020" es aprobada, en base en que la responsabilidad social corporativa tiene un coeficiente de correlación Rho de Spearman de $r$ $=0.533 ;$ p_valor $=0.000<0.05$, por lo que la responsabilidad social corporativa si se relaciona con la lealtad de los clientes corporativos en el hotel Palmetto en San Borja, y por tal la hipótesis planteada es aprobada. En seguida se realiza la comparación con investigaciones que alcanzaron el mismo resultado, como en la investigación de Martínez, P. \& del Bosque, I. R. (2013) quienes consiguieron el mismo resultado, haciendo énfasis en que la responsabilidad social corporativa se relaciona con la lealtad de los clientes.

\section{Primera hipótesis específica}

Según los resultados que se han presentado en la presente investigación, la primera hipótesis específica "Las responsabilidades económicas se relacionan positivamente con la lealtad de los clientes corporativos en el hotel Palmetto en San Borja 2020" es aprobada, en base en que las responsabilidades económicas tienen un coeficiente de correlación Rho de Spearman de $r=0.445$; $p \_v a l o r=0.000<0.05$, por lo que las responsabilidades económicas si se relacionan con la lealtad de los clientes corporativos en el hotel Palmetto en San Borja, y por tal la hipótesis planteada es aprobada. En seguida se realiza la comparación con investigaciones que alcanzaron el mismo resultado, como en la investigación de Gürlek, M., 
Düzgün, E., \& Meydan, S. (2017) quienes consiguieron el mismo resultado, haciendo énfasis en que las responsabilidades económicas se relaciona con la lealtad de los clientes.

\section{Segunda hipótesis específica}

Según los resultados que se han presentado en la presente investigación, la segunda hipótesis específica "Las responsabilidades filantrópicas se relacionan positivamente con la lealtad de los clientes corporativos en el hotel Palmetto en San Borja 2020" es aprobada, en base en que las responsabilidades filantrópicas tienen un coeficiente de correlación Rho de Spearman de $r=0.309$; p_valor $=0.000<0.05$, por lo que las responsabilidades filantrópicas si se relacionan con la lealtad de los clientes corporativos en el hotel Palmetto en San Borja, y por tal la hipótesis planteada es aprobada. En seguida se realiza la comparación con investigaciones que alcanzaron el mismo resultado, como en la investigación de Irshad, A., Rahim, A., Khan, M. F., \& Khan, M. M. (2017) quienes consiguieron el mismo resultado, haciendo énfasis en que las responsabilidades filantrópicas se relaciona con la lealtad de los clientes.

\section{Tercera hipótesis específica}

Según los resultados que se han presentado en la presente investigación, la tercera hipótesis específica "Las responsabilidades éticas se relacionan positivamente con la lealtad de los clientes corporativos en el hotel Palmetto en San Borja 2020" es aprobada, en base en que las responsabilidades éticas tienen un coeficiente de correlación Rho de Spearman de $r=$ 0.275 ; p_valor $=0.000<0.05$, por lo que las responsabilidades éticas si se relaciona con la lealtad de los clientes corporativos en el hotel Palmetto en San Borja, y por tal la hipótesis planteada es aprobada. En seguida se realiza la comparación con investigaciones que alcanzaron el mismo resultado, como en la investigación de Shahril, A., Ashaari, N., Hamid, R., Bachok, S. \& Baba, N. (2017) quienes consiguieron el mismo resultado, haciendo énfasis en que las responsabilidades éticas se relaciona con la lealtad de los clientes.

\section{Cuarta hipótesis específica}

Según los resultados que se han presentado en la presente investigación, la cuarta hipótesis específica "Las responsabilidades ambientales se relacionan positivamente con la lealtad de los clientes corporativos en el hotel Palmetto en San Borja 2020" es aprobada, en base en que las responsabilidades ambientales tienen un coeficiente de correlación Rho de 
Spearman de $r=0.208 ; p \_$valor $=0.000<0.05$, por lo que las responsabilidades ambientales si se relacionan con la lealtad de los clientes corporativos en el hotel Palmetto en San Borja, y por tal la hipótesis planteada es aprobada. En seguida se realiza la comparación con investigaciones que alcanzaron el mismo resultado, como en la investigación de Puriwat, W. \& Tripopsakul, S. (2018) quienes consiguieron el mismo resultado, haciendo énfasis en que las responsabilidades ambientales se relaciona con la lealtad de los clientes.

\subsection{Conclusiones}

Según los resultados conseguidos en este trabajo de investigación basados en los cuestionarios de responsabilidad social corporativa y la lealtad de los clientes, se llega a las siguientes conclusiones:

1) La responsabilidad social corporativa es un elemento importante para los clientes corporativos del hotel Palmetto en San Borja sean cada más leales al hotel. Por tal razón, en la presente investigación se asevera que la responsabilidad social corporativa si se relaciona con la lealtad de los clientes corporativos del mismo hotel; con lo que se puede afirmar que, si se implementase adecuadamente la responsabilidad social corporativa, la lealtad de los clientes corporativos aumentaría de manera considerable. En base a la información de los cuestionarios, y alcanzando los resultados por medio del coeficiente de correlación Rho de Spearman, se ratifica que entre la responsabilidad social corporativa y la lealtad de los clientes existe una relación positiva, por tal, se confirma la hipótesis que se plantea.

2) Las responsabilidades económicas son un factor importante para que los clientes corporativos del hotel Palmetto en San Borja sean cada más leales al hotel. Por tal razón, en la presente investigación se asevera que las responsabilidades económicas si se relacionan con la lealtad de los clientes corporativos del mismo hotel; con lo que se puede afirmar que, si el hotel obtiene un beneficio aceptable tomando en cuenta la mejora en la producción de bienes y servicios que los consumidores necesitan, la lealtad de los clientes corporativos aumentaría de manera considerable. En base a la información de los cuestionarios, y alcanzando los resultados por medio del coeficiente de correlación Rho de Spearman, se ratifica que entre las responsabilidades económicas y la lealtad de los clientes existe una relación positiva, por tal, se confirma la hipótesis que se plantea. 
3) Las responsabilidades filantrópicas son un componente importante para los clientes corporativos del hotel Palmetto en San Borja sean cada más leales al hotel. Por tal razón, en la presente investigación se asevera que las responsabilidades filantrópicas si se relacionan con la lealtad de los clientes corporativos del mismo hotel; con lo que se puede afirmar que, si el hotel de manera voluntaria contribuyese con las expectativas caritativas de la sociedad y los proyectos que mejoran la calidad de vida de una comunidad, la lealtad de los clientes corporativos aumentaría de manera considerable. En base a la información de los cuestionarios, y alcanzando los resultados por medio del coeficiente de correlación Rho de Spearman, se ratifica que entre las responsabilidades filantrópicas y la lealtad de los clientes existe una relación positiva, por tal, se confirma la hipótesis que se plantea.

4) Las responsabilidades éticas son un elemento importante para los clientes corporativos del hotel Palmetto en San Borja sean cada más leales al hotel. Por tal razón, en la presente investigación se asevera que las responsabilidades éticas si se relacionan con la lealtad de los clientes corporativos del mismo hotel; con lo que se puede afirmar que, si el hotel lograra mejorar los estándares, normas o expectativas reflejados en la preocupación por los clientes, empleados y lo que la comunidad considera justo en relación a la protección y respeto de los derechos morales, la lealtad de los clientes corporativos aumentaría de manera considerable. En base a la información de los cuestionarios, y alcanzando los resultados por medio del coeficiente de correlación Rho de Spearman, se ratifica que entre las responsabilidades éticas y la lealtad de los clientes existe una relación positiva, por tal, se confirma la hipótesis que se plantea.

5) Las responsabilidades ambientales son un componente importante para los clientes corporativos del hotel Palmetto en San Borja sean cada más leales al hotel. Por tal razón, en la presente investigación se asevera que las responsabilidades ambientales si se relacionan con la lealtad de los clientes corporativos del mismo hotel; con lo que se puede afirmar que, si el hotel se preocupara más por el medio ambiente y disminuyeran los impactos negativos sobre por el medio ambiente, la lealtad de los clientes corporativos aumentaría de manera considerable. En base a la información de los cuestionarios, y alcanzando los resultados por medio del coeficiente de correlación Rho de Spearman, se ratifica que entre las responsabilidades ambientales y la lealtad de los clientes existe una relación positiva, por tal, se confirma la hipótesis que se plantea. 


\subsection{Recomendaciones}

1) Se les recomienda implementar la responsabilidad social corporativa (RSC) en la empresa, involucrando a todas las áreas existentes, para esto deberán de formar un área que se encargue especialmente de la responsabilidad social corporativa y que a su vez se encuentre conformada por trabajadores de las diferentes áreas para que cada uno haga contribuciones. Así como le recomiendan Shahril, A. M., Ashaari, N. A., Hamid, R., Bachok, S., \& Baba, N. (2017) en su trabajo sobre la responsabilidad social corporativa en empresas de Malasia, donde se recomendó que las empresas involucren a todas las áreas de la empresa en la implementación de la RSC, logrando que sus clientes sean leales.

2) Se les recomienda darle más prioridad a la inversión que realizan, dado que la continua toma de decisiones que se genera a diario en una empresa debe equilibrar acciones de corto y de largo recorrido, para esto deberán de implementar nuevos sistemas informáticos que faciliten la gestión, como los programas ERP que son programas informáticos en los que se integran todos los procesos e informaciones de una empresa y que todas las funciones de un negocio se automatizan, quedando integradas en un sistema que tiene una única base de datos compartida y así generar acciones que contribuyan a generar dinámicas positivas que repercuten directamente en sus clientes. Incorporar soluciones de gestión ERP mejora la automatización de procesos, disponibilidad de información en tiempo real así como sus procesos internos, ahorra tiempo, y costes generales. Una alternativa de ERP que se recomienda es SMARTSYSTEM, cuyo costo de implementación es de USD 1297 (+igv) /pago único). Así como en la investigación de Rivera, J. J., Bigne, E., \& Curras-Perez, R. (2019) en empresas brasileñas donde se recomendó que las empresas prioricen su inversión implementando nuevos sistemas informáticos para facilitar la gestión logrando repercutir en la lealtad de sus clientes.

3) Se les recomienda implementar políticas de RSC para poder planificar estrategias de gestión responsable (es una apuesta por la excelencia que redunda en la mejora del posicionamiento de la organización en el mercado, en su productividad y su rentabilidad) que desarrollen iniciativas e inversiones que logren contribuir tanto a la sustentabilidad como al crecimiento de la empresa. Para esto deberán de tener claro desde el principio cuáles son los fundamentos básicos que dirigirán su estrategia de RSC y cómo gestionarán sus nuevas prácticas. Como en la investigación de Sekulić, 
V., \& Pavlović, M. (2018) en empresas de Serbia, donde recomendaron que se implemente políticas acerca de RSC, teniendo que tomar claramente cuáles son sus principios fundamentales para dirigir la empresa.

4) Se les recomienda establecer una actitud asumida voluntariamente con la finalidad de contribuir al desarrollo social y al mejoramiento medioambiental, para esto deberán de ser conscientes de lo importante que son en la sociedad y de la repercusión de sus actos, promoviendo acciones de responsabilidad social (mecanismo para extender responsabilidad sobre administradores que generen daños a la sociedad, socios 0 terceros) y que beneficien a la sociedad para poder eliminar o minimizar las consecuencias negativas que pueda ocasionar su actividad, invirtiendo parte de sus beneficios para la realización de proyectos y campañas diversas. Como lo recomienda Muñoz-Martín, J. (2013) en su investigación sobre la ética en la responsabilidad social corporativa en empresas de España, quien recomendó que las empresas tomen conciencia de la importancia que tienen para la sociedad donde se encuentran y asuman una actitud para la contribución del desarrollo social y a mejorar el medioambiente, logrando que las empresas muestren una ética ante la sociedad, así como la lealtad de sus clientes.

5) Se les recomienda disminuir su huella ambiental, es decir, disminuir el impacto ambiental, creando programas o prácticas que fomenten el reciclaje, para esto deberán de instalar basureros dedicados en especial al reciclaje y otros donde se pueda separar la basura que sea orgánica de la inorgánica, así como recomendar a los trabajadores evadir las impresiones que no sean necesarias y a utilizar siempre que sea posible comprobantes digitales. Así como le recomiendan Chaudary, S., Zahid, Z., Shahid, S., Khan, S. N., \& Azar, S. (2016) en su trabajo sobre la responsabilidad social corporativa en el medioambiente en Canadá, donde se recomendó que las empresas disminuyan el impacto ambiental por medio de prácticas como la implementación de basureros especiales para el reciclaje.

6) Se les recomienda a futuras investigaciones que decidan desarrollar las variables de responsabilidad social corporativa y lealtad del cliente, que se enfoquen en las demás partes interesadas como empleados, los clientes, las organizaciones comunitarias locales, que son elementos que pueden influir en los resultados de la empresa. 


\section{Referencias bibliográficas}

Abbas, J., Mahmood, S., Ali, H., Raza, M. A., Ali, G., Aman, J., ... \& Nurunnabi, M. (2019). The Effects of Corporate Social Responsibility Practices and Environmental Factors through a Moderating Role of Social Media Marketing on Sustainable Performance of Firms' Operating in Multan, Pakistan. Sustainability, 11(12), 3434.

Abu-Alhaija, A. S., Yusof, R. N. R., Hashim, H., \& Jaharuddin, N. S. (2018). Determinants of customer loyalty: a review and future directions. Australian Journal of Basic and Applied Sciences, 12(7), 106-111.

Ajzen, I. (1992). Persuasive communication theory in social psychology: A historical perspective, in "Influencing Human Behavior: Theory and Applications in Recreation, Tourism, and Natural Ž. Ž. Resource Management'MJ Manfredo, Ed. MJ Manfredo (1992), Champaign, IL: Sagamore Publishing.

Amponsah, M. (2015). Corporate Social Responsibility and Competitive Advantage: A Comparative Study Across Selected Ghanaian Industries (Doctoral dissertation, University of Ghana).

Anastassova, L. (2015). Online reporting of corporate social responsibility of the hotels in Bulgaria: Current situation and marketing implications. In DIEM: Dubrovnik International Economic Meeting (Vol. 2, No. 1, pp. 87-99). Sveučilište u Dubrovniku.

Bruns, A. S. (2017). Determinants of corporate social responsibility: Empirical evidence from the Netherlands (Master's thesis, University of Twente).

Camayo Vivanco, J. L. (2015). Responsabilidad social corporativa de las empresas de la Región Callao en el año 2014.

Carroll, A. B. (2015). Corporate social responsibility (CSR) is on a sustainable trajectory. Journal of Defense Management, 5(2), 2167-0374.

Chaudary, S., Zahid, Z., Shahid, S., Khan, S. N., \& Azar, S. (2016). Customer perception of CSR initiatives: its antecedents and consequences. Social Responsibility Journal.

Coila Quispe, D. (2014). Responsabilidad social en la sociedad stakeholders en agencias de viajes y turismo de la ciudad de Puno 2012. 
Cubillos, C. H., Montealegre, J. V., \& Delgado, A. (2016). Responsabilidad social empresarial y stakeholders en organizaciones de tamaños y actividades diferentes.

De Bracamonte Huere, M. D. P., Moran, R., \& Levis, K. (2016). La Responsabilidad Social corporativa en la Empresa Hotelera SUNSET BAY COLAN SCRL y su contribucion al desarrollo Turistico sostenible en el Distrito de Colan de la Provincia de Paita del Departamento de Piura en el año 2016.

Debreu, G. (1959). Theory of value: An axiomatic analysis of economic equilibrium (No. 17). Yale University Press.

Doob, L. W. (1947). The behavior of attitudes. Psychological review, 54(3), 135.

Fishbein, M. (1963). An investigation of the relationships between beliefs about an object and the attitude toward that object. Human relations, 16(3), 233-239.

Fraile, E. B. (2018). La gestión de la responsabilidad social corporativa: Propuesta de un modelo teórico. Questiones publicitarias, 1(22), 59-68.

Gürlek, M., Düzgün, E., \& Meydan Uygur, S. (2017). How does corporate social responsibility create customer loyalty? The role of corporate image. Social Responsibility Journal, 13(3), 409-427.

Hernández, J. (2019). "Responsabilidad social empresarial: ¿cómo está Perú en la divulgación de logros?". Recuperado de: http://udep.edu.pe/hoy/2019/responsabilidad-socialempresarial-como-esta-peru-en-la-divulgacion-de-logros/.

Hernández, R., Fernández, C., \& Baptista, L. (2014). Metodología de la investigación. Sexta edición por McGRAW-HILL.

Hovland, C. I., Janis, I. L., \& Kelley, H. H. (1953). Communication and persuasion.

latridis, K. (2011). The influence of corporate social responsibility on business practice: The case of international certifiable management standards (Doctoral dissertation, University of Central Lancashire).

Irshad, A., Rahim, A., Khan, M. F., \& Khan, M. M. (2017). The impact of corporate social responsibility on customer satisfaction and customer loyalty, moderating effect of corporate image. City University Research Journal, 1, 63-73. 
Johnson, H. G. (1958). Demand theory further revised or goods are goods. Economica, 25(98), 149-149.

Khadka, K., \& Maharjan, S. (2017). Customer satisfaction and customer loyalty: Case trivsel städtjänster (trivsel siivouspalvelut).

Kim, S. B., \& Kim, D. Y. (2016a). The impacts of corporate social responsibility, service quality, and transparency on relationship quality and customer loyalty in the hotel industry. Asian Journal of Sustainability and Social Responsibility, 1(1), 39.

Kim, S. B., \& Kim, D. Y. (2016b). The influence of corporate social responsibility, ability, reputation, and transparency on hotel customer loyalty in the US: a gender-based approach. SpringerPlus, 5(1), 1537.

Loo, C. H. (2015). Factors Affect the Customer Loyalty Towards Business Event: Book Fair Industry (Doctoral dissertation, Universiti Sains Malaysia).

Marium, M., \& Younas, S. (2017). The Impact of corporate social responsibility (CSR) and relationship marketing on relationship maintainer and customer loyalty by mediating role of customer satisfaction. Journal of Management Info, 4(4), 19-24.

Martínez, P., \& del Bosque, I. R. (2013). CSR and customer loyalty: The roles of trust, customer identification with the company and satisfaction. International Journal of Hospitality Management, 35, 89-99.

Muñoz-Martín, J. (2013). Ética empresarial, Responsabilidad Social Corporativa (RSC) y Creación de Valor Compartido (CVC). Globalización, Competitividad y Gobernabilidad de Georgetown/Universia, 7(3).

Nemec Rudež, H. (2010). Integration of corporate social responsibility into loyalty programs in the tourism industry. Tourism and Hospitality Management, 16(1), 101-108.

Peralta, J. B., Rossi, E. L., \& Álvarez, M. N. (2019). Responsabilidad Social Empresarial de los servicios hoteleros: Valoración de los consumidores. RAN: Revista Academia \& Negocios, 4(2), 107-114.

Petty, R. E., \& Cacioppo, J. T. (1986). The elaboration likelihood model of persuasion. In Communication and persuasion (pp. 1-24). Springer, New York, NY. 
Puriwat, W., \& Tripopsakul, S. (2018). The Impact of Corporate Social Responsibility on Customer Satisfaction and Loyalty: A Case Study of the Hotel Industry in Thailand. Asia-Pacific Social Science Review, 18(2), 347-355.

Rivera, J. J., Bigne, E., \& Curras-Perez, R. (2019). Effects of Corporate Social Responsibility on consumer brand loyalty. Revista Brasileira de Gestão de Negócios, 21(3), 395-415.

Saleem, F., \& Gopinath, C. (2015). Corporate Social Responsibility and Customer Behavior: A Developing Country Perspective.

Sánchez, H., \& Reyes, C. (2000). Método Científico. Planificación de la investigación. Diseños de Investigación, 157-162.

Sekulić, V., \& Pavlović, M. (2018). Corporate social responsibility in relations with social community: Determinants, development, management aspects. Ekonomika, 64(4), 5969.

Seyedhossein Nikou, Harihodin Bin Selamat, Rasimah Che Mohd Yusoff, Mohsen Malekalketab Khiabani. (2017). IDENTIFYING THE IMPACT OF HOTEL IMAGE ON CUSTOMER LOYALTY: A CASE STUDY FROM FOUR-STAR HOTELS IN KUALA LUMPUR, MALAYSIA. International Journal of Social Science and Economic Research.

Shahril, A. M., Ashaari, N. A., Hamid, R., Bachok, S., \& Baba, N. (2017). The Effect of Perceived Corporate Social Responsibility Initiatives Towards Loyalty Intention Among Four and Five Star Hotels in Malaysia: The Mediating Effect of Brand Preference. Advanced Science Letters, 23(11), 10761-10764.

Singal, M., \& Rhou, Y. (2017). Corporate Social Responsibility in the Hospitality Sector. Boston Hospitality Review.

Srivastava, M., \& Kaul, D. (2016). Exploring the link between customer experience-loyaltyconsumer spend. Journal of Retailing and Consumer Services, 31, 277-286.

Staats, A. W., \& Staats, C. K. (1958). Attitudes established by classical conditioning. The Journal of Abnormal and Social Psychology, 57(1), 37.

Tilakasiri, K. K. (2012). Corporate social responsibility and company performance: evidence from Sri Lanka (Doctoral dissertation, Victoria University). 
Uzawa, H. (1960). Preference and rational choice in the theory of consumption. Palo Alto: Stanford University Press.

Vásquez López, A. M., \& Maldonado Fernández, P. F. (2017). Responsabilidad social interna y ventaja competitiva del capital humano en el sector hotelero de 3 y 4 estrellas de la ciudad de Cajamarca.

Ventura, J. (2019). “¿La responsabilidad social corporativa es solo para empresas grandes?”. Recuperado de: https://www.esan.edu.pe/apuntes-empresariales/2019/08/laresponsabilidad-social-corporativa-es-solo-para-empresas-grandes/. 


\section{Anexos}

\section{Anexo 1. Matriz de consistencia}

Tabla 45:

Matriz de consistencia

\begin{tabular}{|c|c|c|c|c|}
\hline PROBLEMA & OBJETIVOS & HIPOTESIS & ES & LLOGIA \\
\hline $\begin{array}{l}\text { Problema general } \\
\text { ¿Existe relación entre la } \\
\text { responsabilidad social } \\
\text { corporativa y la lealtad de los } \\
\text { clientes en el hotel Palmetto } \\
\text { en San Borja 2020? } \\
\text { Problemas específicos } \\
\text { ¿Existe relación entre las } \\
\text { responsabilidades } \\
\text { económicas y la lealtad de los } \\
\text { clientes en el hotel Palmetto } \\
\text { en San Borja } 2020 ? \\
\text { ¿Existe relación entre las } \\
\text { responsabilidades } \\
\text { filantrópicas y la lealtad de los } \\
\text { clientes en el hotel Palmetto } \\
\text { en San Borja } 2020 ? \\
\text { ¿Existe relación entre las } \\
\text { responsabilidades éticas y la } \\
\text { lealtad de los clientes en el } \\
\text { hotel Palmetto en San Borja } \\
2020 ? \\
\text { ¿Existe relación entre las } \\
\text { responsabilidades } \\
\text { ambientales y la lealtad de los } \\
\text { clientes en el hotel Palmetto } \\
\text { en San Borja } 2020 ?\end{array}$ & $\begin{array}{l}\text { Objetivo general } \\
\text { Analizar si existe relación } \\
\text { entre la responsabilidad } \\
\text { social corporativa y la lealtad } \\
\text { de los clientes en el hotel } \\
\text { Palmetto en San Borja } 2020 . \\
\text { Objetivos específicos } \\
\text { Analizar si existe relación } \\
\text { entre las responsabilidades } \\
\text { económicas y la lealtad de } \\
\text { los clientes en el hotel } \\
\text { Palmetto en San Borja } 2020 . \\
\text { Analizar si existe relación } \\
\text { entre las responsabilidades } \\
\text { filantrópicas y la lealtad de } \\
\text { los clientes en el hotel } \\
\text { Palmetto en San Borja } 2020 . \\
\text { Analizar si existe relación } \\
\text { entre las responsabilidades } \\
\text { éticas y la lealtad de los } \\
\text { clientes en el hotel Palmetto } \\
\text { en San Borja } 2020 . \\
\text { Analizar si existe relación } \\
\text { entre las responsabilidades } \\
\text { ambientales y la lealtad de } \\
\text { los clientes en el hotel } \\
\text { Palmetto en San Borja } 2020 .\end{array}$ & $\begin{array}{l}\text { Hipótesis general } \\
\text { La responsabilidad social } \\
\text { corporativa se relaciona } \\
\text { positivamente con la lealtad } \\
\text { de los clientes en el hotel } \\
\text { Palmetto en San Borja } 2020 . \\
\text { Hipótesis especificas } \\
\text { Las responsabilidades } \\
\text { económicas se relacionan } \\
\text { positivamente con la lealtad } \\
\text { de los clientes en el hotel } \\
\text { Palmetto en San Borja } 2020 . \\
\text { Las responsabilidades } \\
\text { filantrópicas se relacionan } \\
\text { positivamente con la lealtad } \\
\text { de los clientes en el hotel } \\
\text { Palmetto en San Borja } 2020 . \\
\text { Las responsabilidades éticas } \\
\text { se relacionan positivamente } \\
\text { con la lealtad de los clientes } \\
\text { en el hotel Palmetto en San } \\
\text { Borja } 2020 . \\
\text { Las responsabilidades } \\
\text { ambientales se relacionan } \\
\text { positivamente con la lealtad } \\
\text { de los clientes en el hotel } \\
\text { Palmetto en San Borja } 2020 .\end{array}$ & $\begin{array}{l}\text { X1: Responsabilidad } \\
\text { social corporativa. } \\
\text { X1A: Responsabilidades } \\
\text { económicas, } \\
\text { X1B: Responsabilidades } \\
\text { filantrópicas, } \\
\text { X1C: Responsabilidades } \\
\text { éticas, y } \\
\text { X1D: Responsabilidades } \\
\text { ambientales. }\end{array}$ & 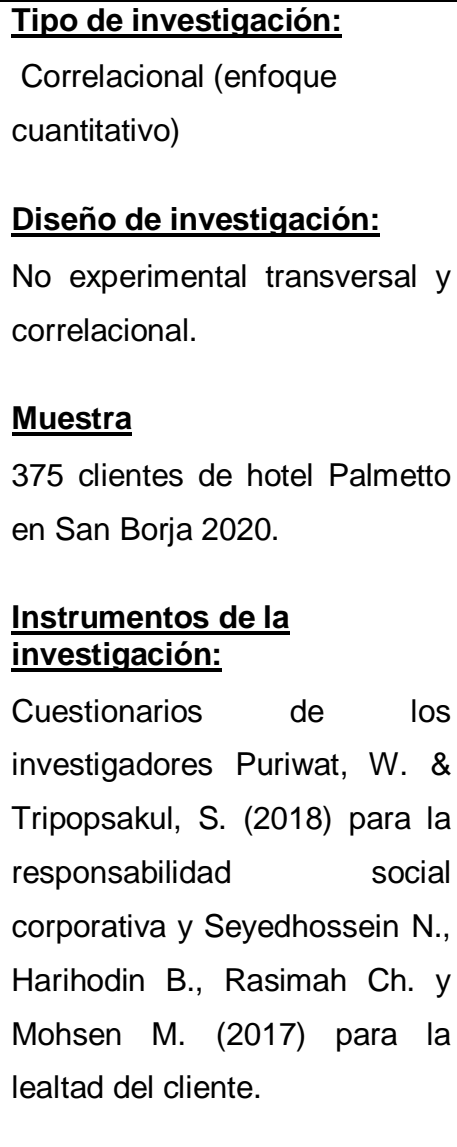 \\
\hline
\end{tabular}




\section{Anexo 2. Cuestionarios}

Tabla 46:

Cuestionario responsabilidad social corporativa

UNIVERSIDAD SAN IGNACIO DE LOYOLA

CARRERA: ADMINISTRACION

Tema: "Relación de responsabilidad social corporativa y lealtad de clientes corporativos en el Hotel Palmetto de San Borja 2020"

VARIABLE: responsabilidad social corporativa

Instrucción:

A continuación, se presenta una serie de ítems para que sean respondidos por usted. Lea detenidamente cada enunciado, marque una sola alternativa con un $X$ en la casilla correspondiente al enunciado elegido. Es fundamental su absoluta sinceridad dentro de las respuestas, pues de ellas depende el éxito de la presente investigación.

NOTA: Para cada pregunta se considera la escala de 1 a 5 donde:

\begin{tabular}{|c|c|c|c|c|}
\hline 1 & 2 & 3 & 4 & 5 \\
\hline $\begin{array}{c}\text { totalmente } \\
\text { en } \\
\text { desacuerdo }\end{array}$ & $\begin{array}{c}\text { en } \\
\text { desacuerdo }\end{array}$ & indiferente & $\begin{array}{c}\text { de } \\
\text { acuerdo }\end{array}$ & $\begin{array}{c}\text { totalmente } \\
\text { de } \\
\text { acuerdo }\end{array}$ \\
\hline
\end{tabular}

\begin{tabular}{|c|c|c|c|c|c|c|}
\hline Número & ITEM & 1 & 2 & 3 & 4 & 5 \\
\hline \multicolumn{7}{|c|}{ ECONÓMICO } \\
\hline 1 & $\begin{array}{l}\text { Personalmente creo que el hotel obtiene las } \\
\text { mayores ganancias potenciales }\end{array}$ & & & & & \\
\hline 2 & $\begin{array}{l}\text { Personalmente creo que el hotel intenta } \\
\text { lograr el éxito a largo plazo. }\end{array}$ & & & & & \\
\hline 3 & $\begin{array}{l}\text { Personalmente creo que el hotel mejora el } \\
\text { desempeño económico. }\end{array}$ & & & & & \\
\hline 4 & $\begin{array}{l}\text { Personalmente creo que el hotel asegura una } \\
\text { supervivencia y éxito en el tiempo. }\end{array}$ & & & & & \\
\hline \multicolumn{7}{|c|}{ FILANTRÓPICO } \\
\hline 5 & $\begin{array}{l}\text { Personalmente creo que el hotel ayuda a } \\
\text { resolver problemas de la comunidad. }\end{array}$ & & & & & \\
\hline 6 & $\begin{array}{l}\text { Personalmente creo que el hotel tiene un } \\
\text { fuerte sentido de responsabilidad social } \\
\text { corporativa (RSC) }\end{array}$ & & & & & \\
\hline 7 & $\begin{array}{l}\text { Personalmente creo que el hotel proporciona } \\
\text { contribuciones suficientes a las sociedades. }\end{array}$ & & & & & \\
\hline 8 & $\begin{array}{l}\text { Personalmente creo que el hotel asigna } \\
\text { recursos a actividades filantrópicas. }\end{array}$ & & & & & \\
\hline
\end{tabular}







Tabla 47:

Cuestionario lealtad del cliente

UNIVERSIDAD SAN IGNACIO DE LOYOLA

CARRERA: ADMINISTRACION

Tema: "Relación de responsabilidad social corporativa y lealtad de clientes corporativos en el Hotel Palmetto de San Borja 2020"

VARIABLE: lealtad de clientes

Instrucción:

A continuación, se presenta una serie de ítems para que sean respondidos por usted. Lea detenidamente cada enunciado, marque una sola alternativa con un $X$ en la casilla correspondiente al enunciado elegido. Es fundamental su absoluta sinceridad dentro de las respuestas, pues de ellas depende el éxito de la presente investigación.

NOTA: Para cada pregunta se considera la escala de 1 a 5 donde:

\begin{tabular}{|c|c|c|c|c|}
\hline 1 & 2 & 3 & 4 & 5 \\
\hline $\begin{array}{c}\text { totalmente } \\
\text { en } \\
\text { desacuerdo }\end{array}$ & $\begin{array}{c}\text { en } \\
\text { desacuerdo }\end{array}$ & indiferente & $\begin{array}{c}\text { de } \\
\text { acuerdo }\end{array}$ & $\begin{array}{c}\text { totalmente } \\
\text { de } \\
\text { acuerdo }\end{array}$ \\
\hline
\end{tabular}

\begin{tabular}{|c|c|c|c|c|c|c|}
\hline Número & ITEM & 1 & 2 & 3 & 4 & 5 \\
\hline 1 & $\begin{array}{l}\text { Personalmente creo que seguiré utilizando el } \\
\text { hotel. }\end{array}$ & & & & & \\
\hline 2 & $\begin{array}{l}\text { Personalmente creo que compraré servicios } \\
\text { adicionales del hotel. }\end{array}$ & & & & & \\
\hline 3 & $\begin{array}{l}\text { Personalmente creo que instaré a los } \\
\text { familiares y amigos a usar el hotel. }\end{array}$ & & & & & \\
\hline 4 & $\begin{array}{l}\text { Personalmente creo que diré comentarios } \\
\text { positivos sobre el hotel a otros. }\end{array}$ & & & & & \\
\hline 5 & $\begin{array}{l}\text { Personalmente creo que recomendaría el } \\
\text { mismo hotel a otros. }\end{array}$ & & & & & \\
\hline 6 & $\begin{array}{l}\text { Personalmente creo que no cambiaría a otro } \\
\text { hotel, incluso a un costo menor. }\end{array}$ & & & & & \\
\hline 7 & $\begin{array}{l}\text { Personalmente creo que siempre } \\
\text { consideraré el hotel como mi primera opción } \\
\text { para mi viaje futuro. }\end{array}$ & & & & & \\
\hline
\end{tabular}




\section{Anexo 3. Alfa de Cronbach}

\section{Responsabilidades económicas}

\begin{tabular}{llr|r}
\multicolumn{3}{c}{ Case Processing Summary } \\
& \multicolumn{1}{c}{$\mathrm{N}$} & \multicolumn{1}{c}{$\%$} \\
\hline \multirow{3}{*}{ Cases } & Valid & 375 & 100.0 \\
\cline { 2 - 4 } & Excluded & 0 & .0 \\
\cline { 2 - 4 } & Total & 375 & 100.0 \\
\hline
\end{tabular}

a. Listwise deletion based on all variables in the procedure.

\section{Reliability Statistics}

\begin{tabular}{r|r} 
Cronbach's Alpha & N of Items \\
\hline .919 & 4 \\
\hline
\end{tabular}

\begin{tabular}{|c|c|c|c|c|}
\hline \multicolumn{5}{|c|}{ Item-Total Statistics } \\
\hline & $\begin{array}{c}\text { Scale Mean if Item } \\
\text { Deleted }\end{array}$ & $\begin{array}{l}\text { Scale Variance if } \\
\text { Item Deleted }\end{array}$ & $\begin{array}{l}\text { Corrected Item- } \\
\text { Total Correlation } \\
\end{array}$ & $\begin{array}{l}\text { Cronbach's Alpha } \\
\text { if Item Deleted } \\
\end{array}$ \\
\hline $\begin{array}{l}\text { RSC1. Personalmente creo que } \\
\text { el hotel obtiene las mayores } \\
\text { ganancias potenciales }\end{array}$ & 9.22 & 5.993 & .865 & .877 \\
\hline $\begin{array}{l}\text { RSC2. Personalmente creo que } \\
\text { el hotel intenta lograr el éxito a } \\
\text { largo plazo. }\end{array}$ & 9.19 & 6.245 & .881 & 872 \\
\hline $\begin{array}{l}\text { RSC3. Personalmente creo que } \\
\text { el hotel mejora el desempeño } \\
\text { económico. }\end{array}$ & 10.06 & 6.710 & .761 & .912 \\
\hline $\begin{array}{l}\text { RSC4.Personalmente creo que } \\
\text { el hotel asegura una } \\
\text { supervivencia y éxito en el } \\
\text { tiempo. }\end{array}$ & 8.37 & 6.366 & .755 & .916 \\
\hline
\end{tabular}




\section{Responsabilidades filantrópicas}

\section{Case Processing Summary}

\begin{tabular}{llr|r} 
& & \multicolumn{1}{c|}{$\mathrm{N}$} & \multicolumn{1}{c}{$\%$} \\
\hline \multirow{3}{*}{ Cases } & Valid & 375 & 100.0 \\
\cline { 2 - 4 } & Excluded $^{\mathrm{a}}$ & 0 & .0 \\
\cline { 2 - 4 } & Total & 375 & 100.0 \\
\hline
\end{tabular}

a. Listwise deletion based on all variables in the procedure.

\section{Reliability Statistics}

\begin{tabular}{r|r} 
Cronbach's Alpha & N of Items \\
\hline .895 & 6 \\
\hline
\end{tabular}

\begin{tabular}{|c|c|c|c|c|}
\hline \multicolumn{5}{|c|}{ Item-Total Statistics } \\
\hline & $\begin{array}{l}\text { Scale Mean } \\
\text { if Item } \\
\text { Deleted } \\
\end{array}$ & $\begin{array}{c}\text { Scale } \\
\text { Variance if } \\
\text { Item Deleted }\end{array}$ & $\begin{array}{l}\text { Corrected Item- } \\
\text { Total Correlation }\end{array}$ & $\begin{array}{c}\text { Cronbach's } \\
\text { Alpha if Item } \\
\text { Deleted } \\
\end{array}$ \\
\hline $\begin{array}{l}\text { RSC5. Personalmente creo que el hotel } \\
\text { ayuda a resolver problemas de la } \\
\text { comunidad. }\end{array}$ & 13.45 & 10.746 & .783 & .866 \\
\hline $\begin{array}{l}\text { RSC6. Personalmente creo que el hotel } \\
\text { tiene un fuerte sentido de responsabilidad } \\
\text { social corporativa (RSC) }\end{array}$ & 14.30 & 11.231 & .639 & .889 \\
\hline $\begin{array}{l}\text { RSC7. Personalmente creo que el hotel } \\
\text { proporciona contribuciones suficientes a las } \\
\text { sociedades. }\end{array}$ & 13.41 & 10.568 & .844 & .857 \\
\hline $\begin{array}{l}\text { RSC8. Personalmente creo que el hotel } \\
\text { asigna recursos a actividades filantrópicas. }\end{array}$ & 12.63 & 10.999 & .620 & .894 \\
\hline $\begin{array}{l}\text { RSC9. Personalmente creo que el hotel } \\
\text { tiene un papel en la sociedad que va más } \\
\text { allá de la generación de ganancias. }\end{array}$ & 12.58 & 11.249 & .653 & .886 \\
\hline $\begin{array}{l}\text { RSC10. Personalmente creo que el hotel } \\
\text { motiva a los empleados a contribuir en } \\
\text { acciones voluntarias. }\end{array}$ & 14.33 & 11.077 & .802 & .865 \\
\hline
\end{tabular}




\section{Responsabilidades éticas}

\section{Case Processing Summary}

\begin{tabular}{|c|c|c|c|}
\hline & & & $\%$ \\
\hline \multirow{3}{*}{ Cases } & Valid & 375 & 100.0 \\
\hline & Excluded $^{\mathrm{a}}$ & 0 & .0 \\
\hline & Total & 375 & 100.0 \\
\hline
\end{tabular}

a. Listwise deletion based on all variables in the procedure.

\section{Reliability Statistics}

\begin{tabular}{r|r} 
Cronbach's Alpha & N of Items \\
\hline .832 & 5 \\
\hline
\end{tabular}

\section{Item-Total Statistics}

\begin{tabular}{|c|c|c|c|c|}
\hline & $\begin{array}{c}\text { Scale Mean } \\
\text { if Item } \\
\text { Deleted } \\
\end{array}$ & $\begin{array}{c}\text { Scale } \\
\text { Variance if } \\
\text { Item Deleted }\end{array}$ & $\begin{array}{l}\text { Corrected Item- } \\
\text { Total Correlation }\end{array}$ & $\begin{array}{l}\text { Cronbach's } \\
\text { Alpha if Item } \\
\text { Deleted }\end{array}$ \\
\hline $\begin{array}{l}\text { RSC11. Personalmente creo que el hotel } \\
\text { destaca la importancia de la RSC para los } \\
\text { empleados }\end{array}$ & 10.10 & 7.102 & .736 & .769 \\
\hline $\begin{array}{l}\text { RSC12. Personalmente creo que el hotel } \\
\text { organiza programas de capacitación en } \\
\text { ética para empleados. }\end{array}$ & 9.28 & 7.428 & .708 & .780 \\
\hline $\begin{array}{l}\text { RSC13. Personalmente creo que el hotel } \\
\text { proporciona información precisa a todos los } \\
\text { clientes. }\end{array}$ & 10.84 & 7.352 & .509 & .838 \\
\hline $\begin{array}{l}\text { RSC14.Personalmente creo que el hotel } \\
\text { tiene un código de conducta integral }\end{array}$ & 10.90 & 7.198 & .582 & .813 \\
\hline $\begin{array}{l}\text { RSC15.Personalmente creo que el hotel es } \\
\text { reconocido como una compañía confiable }\end{array}$ & 9.31 & 7.400 & .663 & .790 \\
\hline
\end{tabular}




\section{Responsabilidades ambientales}

\section{Case Processing Summary}

\begin{tabular}{llr|r} 
& & \multicolumn{1}{c|}{$\mathrm{N}$} & \multicolumn{1}{c}{$\%$} \\
\hline \multirow{3}{*}{ Cases } & Valid & 375 & 100.0 \\
\cline { 2 - 4 } & Excluded $^{\mathrm{a}}$ & 0 & .0 \\
\cline { 2 - 4 } & Total & 375 & 100.0 \\
\hline
\end{tabular}

a. Listwise deletion based on all variables in the procedure.

\section{Reliability Statistics}

\begin{tabular}{r|r} 
Cronbach's Alpha & N of Items \\
\hline .937 & 4 \\
\hline
\end{tabular}

\section{Item-Total Statistics}

\begin{tabular}{l|r|r|r|r} 
& $\begin{array}{c}\text { Scale Mean } \\
\text { if Item } \\
\text { Deleted }\end{array}$ & $\begin{array}{r}\text { Scale } \\
\text { Variance if } \\
\text { Item Deleted }\end{array}$ & $\begin{array}{c}\text { Corrected Item- } \\
\text { Total Correlation }\end{array}$ & $\begin{array}{r}\text { Cronbach's } \\
\text { Alpha if Item } \\
\text { Deleted }\end{array}$ \\
\hline $\begin{array}{l}\text { RSC16. Personalmente creo que el hotel } \\
\text { intenta ofrecer productos ecológicos. }\end{array}$ & 9.62 & 5.430 & .833 & .924 \\
\hline $\begin{array}{l}\text { RSC17. Personalmente creo que el hotel } \\
\text { tiene una misión ambiental }\end{array}$ & 8.87 & 5.517 & .779 & .943 \\
\hline $\begin{array}{l}\text { RSC18. Personalmente creo que el hotel } \\
\text { realiza esfuerzos concertados para } \\
\text { mantener el medio ambiente. }\end{array}$ & 9.70 & 5.500 & .891 & .906 \\
\hline $\begin{array}{l}\text { RSC19. Personalmente creo que el hotel } \\
\text { tiene problemas de los desechos sólidos 0 } \\
\text { la basura poco preocupante }\end{array}$ & 9.67 & 5.520 & & .915 \\
\hline
\end{tabular}




\section{Lealtad}

\begin{tabular}{|c|c|c|c|}
\hline \multicolumn{4}{|c|}{ Case Processing Summary } \\
\hline & & $\mathrm{N}$ & $\%$ \\
\hline \multirow{3}{*}{ Cases } & Valid & 375 & 100.0 \\
\hline & Excluded $^{a}$ & 0 & .0 \\
\hline & Total & 375 & 100.0 \\
\hline
\end{tabular}

a. Listwise deletion based on all variables in the procedure.

\section{Reliability Statistics}

\begin{tabular}{r|r} 
Cronbach's Alpha & N of Items \\
\hline .978 & 7 \\
\hline
\end{tabular}

\section{Item-Total Statistics}

\begin{tabular}{l|r|r|r|r} 
& $\begin{array}{c}\text { Scale Mean } \\
\text { if Item } \\
\text { Deleted }\end{array}$ & $\begin{array}{c}\text { Scale Variance } \\
\text { if Item Deleted }\end{array}$ & $\begin{array}{c}\text { Corrected Item- } \\
\text { Total Correlation }\end{array}$ & $\begin{array}{c}\text { Cronbach's Alpha } \\
\text { if Item Deleted }\end{array}$ \\
\hline $\begin{array}{l}\text { L1. Personalmente creo que seguiré } \\
\text { utilizando el hotel. }\end{array}$ & 20.55 & 23.441 & .944 & .973 \\
\hline $\begin{array}{l}\text { L2. Personalmente creo que compraré } \\
\text { servicios adicionales del hotel. }\end{array}$ & 20.52 & 23.149 & .966 & .971 \\
\hline $\begin{array}{l}\text { L3. Personalmente creo que instaré a los } \\
\text { familiares y amigos a usar el hotel. }\end{array}$ & 19.69 & 24.011 & .820 & .981 \\
\hline $\begin{array}{l}\text { L4. Personalmente creo que diré } \\
\text { comentarios positivos sobre el hotel a } \\
\text { otros. }\end{array}$ & 20.52 & 23.550 & .976 \\
\hline $\begin{array}{l}\text { L5. Personalmente creo que } \\
\text { recomendaría el mismo hotel a otros. }\end{array}$ & 20.55 & 23.253 & & .972 \\
\hline $\begin{array}{l}\text { L6. Personalmente creo que no } \\
\text { cambiaría a otro hotel, incluso a un costo } \\
\text { menor. }\end{array}$
\end{tabular}




\section{Anexo 4. Análisis factorial}

\section{Responsabilidad social corporativa}

\begin{tabular}{llr}
\multicolumn{3}{c}{ KMO and Bartlett's Test } \\
Kaiser-Meyer-Olkin Measure of Sampling Adequacy. & .830 \\
\hline & Approx. Chi-Square & 5184.774 \\
\cline { 2 - 3 } Bartlett's Test of Sphericity & df & 171 \\
\cline { 2 - 3 } & Sig. & .000 \\
\hline
\end{tabular}

\section{Communalities}

Initial Extraction

\begin{tabular}{ll|l}
\hline RSC1. Personalmente creo que el hotel obtiene las mayores ganancias potenciales & 1.000 & .867 \\
\hline RSC2. Personalmente creo que el hotel intenta lograr el éxito a largo plazo. & 1.000 & .883 \\
\hline RSC3. Personalmente creo que el hotel mejora el desempeño económico. & 1.000 & .747 \\
\hline RSC4.Personalmente creo que el hotel asegura una supervivencia y éxito en el tiempo. & 1.000 & .738 \\
\hline RSC5. Personalmente creo que el hotel ayuda a resolver problemas de la comunidad. & 1.000 & .751 \\
\hline $\begin{array}{l}\text { RSC6. Personalmente creo que el hotel tiene un fuerte sentido de responsabilidad social } \\
\text { corporativa (RSC) }\end{array}$ & 1.000 & .564 \\
\hline $\begin{array}{l}\text { RSC7. Personalmente creo que el hotel proporciona contribuciones suficientes a las } \\
\text { sociedades. }\end{array}$ & 1.000 & .838 \\
\hline RSC8. Personalmente creo que el hotel asigna recursos a actividades filantrópicas. & 1.000 & .528 \\
\hline RSC9. Personalmente creo que el hotel tiene un papel en la sociedad que va más allá de la & 1.000 & .582 \\
\hline $\begin{array}{l}\text { generación de ganancias. } \\
\text { RSC10. Personalmente creo que el hotel motiva a los empleados a contribuir en acciones } \\
\text { voluntarias. }\end{array}$ & 1.000 & .784 \\
\hline $\begin{array}{l}\text { RSC11. Personalmente creo que el hotel destaca la importancia de la RSC para los } \\
\text { empleados }\end{array}$ & 1.000 & .740 \\
\hline $\begin{array}{l}\text { RSC12. Personalmente creo que el hotel organiza programas de capacitación en ética para } \\
\text { empleados. }\end{array}$ & 1.000 & .712 \\
\hline $\begin{array}{l}\text { RSC13. Personalmente creo que el hotel proporciona información precisa a todos los } \\
\text { clientes. }\end{array}$ & 1.000 & .431 \\
\hline RSC14.Personalmente creo que el hotel tiene un código de conducta integral & 1.000 & .534 \\
\hline RSC15.Personalmente creo que el hotel es reconocido como una compañía confiable & 1.000 & .675 \\
\hline RSC16. Personalmente creo que el hotel intenta ofrecer productos ecológicos. & 1.000 & .823 \\
\hline RSC17. Personalmente creo que el hotel tiene una misión ambiental & 1.000 & .758 \\
\hline $\begin{array}{l}\text { RSC18. Personalmente creo que el hotel realiza esfuerzos concertados para mantener el } \\
\text { medio ambiente. }\end{array}$ & 1.000 & .890 \\
\hline
\end{tabular}


RSC19. Personalmente creo que el hotel tiene problemas de los desechos sólidos o la basura poco preocupante

Extraction Method: Principal Component Analysis.

\section{Lealtad de clientes}

\section{KMO and Bartlett's Test}

Kaiser-Meyer-Olkin Measure of Sampling Adequacy. .933

Approx. Chi-Square 5061.660

Bartlett's Test of Sphericity

df

Sig. .000

\section{Communalities}

Initial Extraction

L1. Personalmente creo que seguiré utilizando el hotel. $1.000 \quad .924$

L2. Personalmente creo que compraré servicios adicionales del hotel.

$1.000 \quad .955$

L3. Personalmente creo que instaré a los familiares y amigos a usar el hotel.

1.000

.746

L4. Personalmente creo que diré comentarios positivos sobre el hotel a otros. 1.000 .857

L5. Personalmente creo que recomendaría el mismo hotel a otros. 1.000 .962

L6. Personalmente creo que no cambiaría a otro hotel, incluso a un costo menor. 1.000 .791

L7. Personalmente creo que siempre consideraré el hotel como mi primera opción para mi viaje futuro.

Extraction Method: Principal Component Analysis. 
Anexo 5. Coeficiente de Aiken

Responsabilidad social corporativa

\begin{tabular}{|c|c|c|c|c|c|c|c|c|c|c|c|c|c|c|}
\hline \multirow{2}{*}{$\begin{array}{l}\text { JUECES } \\
\text { ITEM }\end{array}$} & \multicolumn{4}{|c|}{ JUEZ 1} & \multicolumn{4}{|c|}{ JUEZ 2} & \multicolumn{4}{|c|}{ JUEZ 3} & \multirow[b]{2}{*}{ SUMA } & \multirow[b]{2}{*}{ V AIKEN } \\
\hline & $C$ & $\mathrm{CO}$ & CON & $D C$ & $\mathrm{C}$ & $\mathrm{CO}$ & CON & $\mathrm{DC}$ & C & $\mathrm{CO}$ & CON & $\mathrm{DC}$ & & \\
\hline RSC1 & 5 & 5 & 5 & 5 & 4 & 4 & 4 & 4 & 4 & 4 & 4 & 4 & 52.00 & 0.87 \\
\hline $\mathrm{RSC2}$ & 5 & 5 & 5 & 5 & 4 & 4 & 4 & 4 & 4 & 4 & 4 & 4 & 52.00 & 0.87 \\
\hline $\mathrm{RSC3}$ & 5 & 5 & 5 & 5 & 5 & 4 & 4 & 4 & 4 & 4 & 4 & 4 & 53.00 & 0.88 \\
\hline RSC4 & 5 & 5 & 5 & 5 & 5 & 5 & 4 & 4 & 4 & 4 & 4 & 4 & 54.00 & 0.90 \\
\hline RSC5 & 5 & 5 & 5 & 5 & 3 & 4 & 4 & 3 & 5 & 5 & 5 & 5 & 54.00 & 0.90 \\
\hline RSC6 & 5 & 5 & 5 & 5 & 3 & 3 & 3 & 3 & 5 & 5 & 5 & 5 & 52.00 & 0.87 \\
\hline RSC7 & 5 & 5 & 5 & 5 & 3 & 4 & 4 & 3 & 4 & 5 & 5 & 5 & 53.00 & 0.88 \\
\hline $\mathrm{RSC} 8$ & 5 & 5 & 5 & 5 & 5 & 5 & 5 & 5 & 4 & 4 & 4 & 4 & 56.00 & 0.93 \\
\hline RSC9 & 5 & 5 & 5 & 5 & 3 & 3 & 3 & 3 & 4 & 4 & 4 & 4 & 48.00 & 0.80 \\
\hline RSC10 & 5 & 5 & 5 & 5 & 5 & 5 & 5 & 5 & 4 & 4 & 4 & 4 & 56.00 & 0.93 \\
\hline RSC11 & 5 & 5 & 5 & 5 & 4 & 3 & 4 & 4 & 4 & 4 & 4 & 4 & 51.00 & 0.85 \\
\hline $\mathrm{RSC} 12$ & 5 & 5 & 5 & 5 & 3 & 3 & 3 & 3 & 4 & 4 & 4 & 4 & 48.00 & 0.80 \\
\hline $\mathrm{RSC} 13$ & 5 & 5 & 5 & 5 & 5 & 5 & 5 & 5 & 4 & 5 & 5 & 5 & 59.00 & 0.98 \\
\hline RSC14 & 5 & 5 & 5 & 5 & 5 & 5 & 5 & 5 & 4 & 4 & 4 & 4 & 56.00 & 0.93 \\
\hline RSC15 & 5 & 5 & 5 & 5 & 5 & 5 & 5 & 5 & 5 & 4 & 5 & 5 & 59.00 & 0.98 \\
\hline $\mathrm{RSC} 16$ & 5 & 5 & 5 & 5 & 3 & 4 & 4 & 3 & 4 & 4 & 5 & 5 & 52.00 & 0.87 \\
\hline $\mathrm{RSC} 17$ & 5 & 5 & 5 & 5 & 4 & 5 & 5 & 5 & 4 & 4 & 5 & 5 & 57.00 & 0.95 \\
\hline RSC18 & 5 & 5 & 5 & 5 & 5 & 5 & 5 & 5 & 5 & 4 & 5 & 5 & 59.00 & 0.98 \\
\hline $\mathrm{RSC} 19$ & 5 & 5 & 5 & 5 & 5 & 5 & 5 & 5 & 4 & 5 & 4 & 4 & 57.00 & 0.95 \\
\hline \multicolumn{14}{|c|}{ V AIKEN } & 0.90 \\
\hline
\end{tabular}

CLARIDAD = C; CONGRUENCIA = CO; CONTEXTO = CON; DOMINIO DE CONSTRUCTO = DC 


\section{Lealtad del cliente}

\begin{tabular}{|c|c|c|c|c|c|c|c|c|c|c|c|c|c|c|}
\hline \multirow{2}{*}{$\begin{array}{l}\text { JUECES } \\
\text { ITEM }\end{array}$} & \multicolumn{4}{|c|}{ JUEZ 1} & \multicolumn{4}{|c|}{ JUEZ 2} & \multicolumn{4}{|c|}{ JUEZ 3} & \multirow[b]{2}{*}{ SUMA } & \multirow[b]{2}{*}{ V AIKEN } \\
\hline & $\mathrm{C}$ & $\mathrm{CO}$ & CON & DC & C & $\mathrm{CO}$ & CON & $\mathrm{DC}$ & $\mathrm{C}$ & $\mathrm{CO}$ & CON & $\mathrm{DC}$ & & \\
\hline L1 & 5 & 5 & 5 & 5 & 5 & 5 & 5 & 5 & 5 & 4 & 4 & 5 & 58.00 & 0.97 \\
\hline L2 & 5 & 5 & 5 & 5 & 4 & 4 & 3 & 4 & 5 & 5 & 5 & 5 & 55.00 & 0.92 \\
\hline L3 & 5 & 5 & 5 & 5 & 5 & 5 & 4 & 4 & 4 & 4 & 4 & 4 & 54.00 & 0.90 \\
\hline L4 & 5 & 5 & 5 & 5 & 5 & 5 & 5 & 5 & 4 & 4 & 4 & 4 & 56.00 & 0.93 \\
\hline $\mathrm{L} 5$ & 5 & 5 & 5 & 5 & 5 & 5 & 5 & 5 & 5 & 5 & 5 & 5 & 60.00 & 1.00 \\
\hline L6 & 5 & 5 & 5 & 5 & 4 & 4 & 3 & 4 & 4 & 4 & 4 & 4 & 51.00 & 0.85 \\
\hline $\mathrm{L} 7$ & 5 & 5 & 5 & 5 & 4 & 4 & 4 & 4 & 5 & 5 & 5 & 5 & 56.00 & 0.93 \\
\hline \multicolumn{14}{|c|}{ VALOR DE AIKEN } & 0.93 \\
\hline
\end{tabular}

CLARIDAD = C; CONGRUENCIA = CO; CONTEXTO = CON; DOMINIO DE CONSTRUCTO = DC 


\title{
Anexo 6. Validación de jueces
}

Juez $N^{\circ} 1$

\section{INSTRUMENTO PARA LA VALIDEZ DE CONTENIDO \\ (JUICIO DE EXPERTOS)}

\begin{abstract}
El presente documento tiene como finalidad validar el cuestionario de responsabilidad social corporativa, el mismo que será aplicado a los clientes corporativos del Hotel Palmetto que forman parte del estudio "Relación de responsabilidad social corporativa y lealtad de clientes corporativos en hotel Palmetto de San Borja 2020", que corresponde a un diseño correlacional no experimental transversal.
\end{abstract}

\section{Instrucciones}

La evaluación requiere de la lectura detallada y completa de cada uno de los ítems propuestos a fin de cotejarlos de manera cualitativa con los criterios propuestos relativos a: Claridad de la redacción, congruencia con el contenido, contexto correcto del ítem y dominio del constructo. Para ello deberá asignar una valoración si el ítem presenta o no los criterios propuestos, y en caso necesario se ofrecen un espacio para las observaciones si hubiera.

Juez $\mathrm{N}^{0}$ :

Fecha actual: 20Abr20

Nombres y Apellidos: BRAGGI A. BAMBERGER VARGAS

Institución donde labora: FINANCE CONSULT

Años de experiencia profesional o científica: 20 AÑOS

Grado de Instrucción: DOCTOR EN CONTABILIDAD Y FINANZAS

Profesión: ADMINISTRADOR

Puesto que desempeña: CONSULTOR FINANCIERO

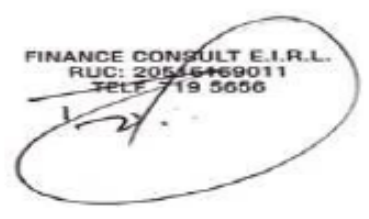

Firma y Sello 


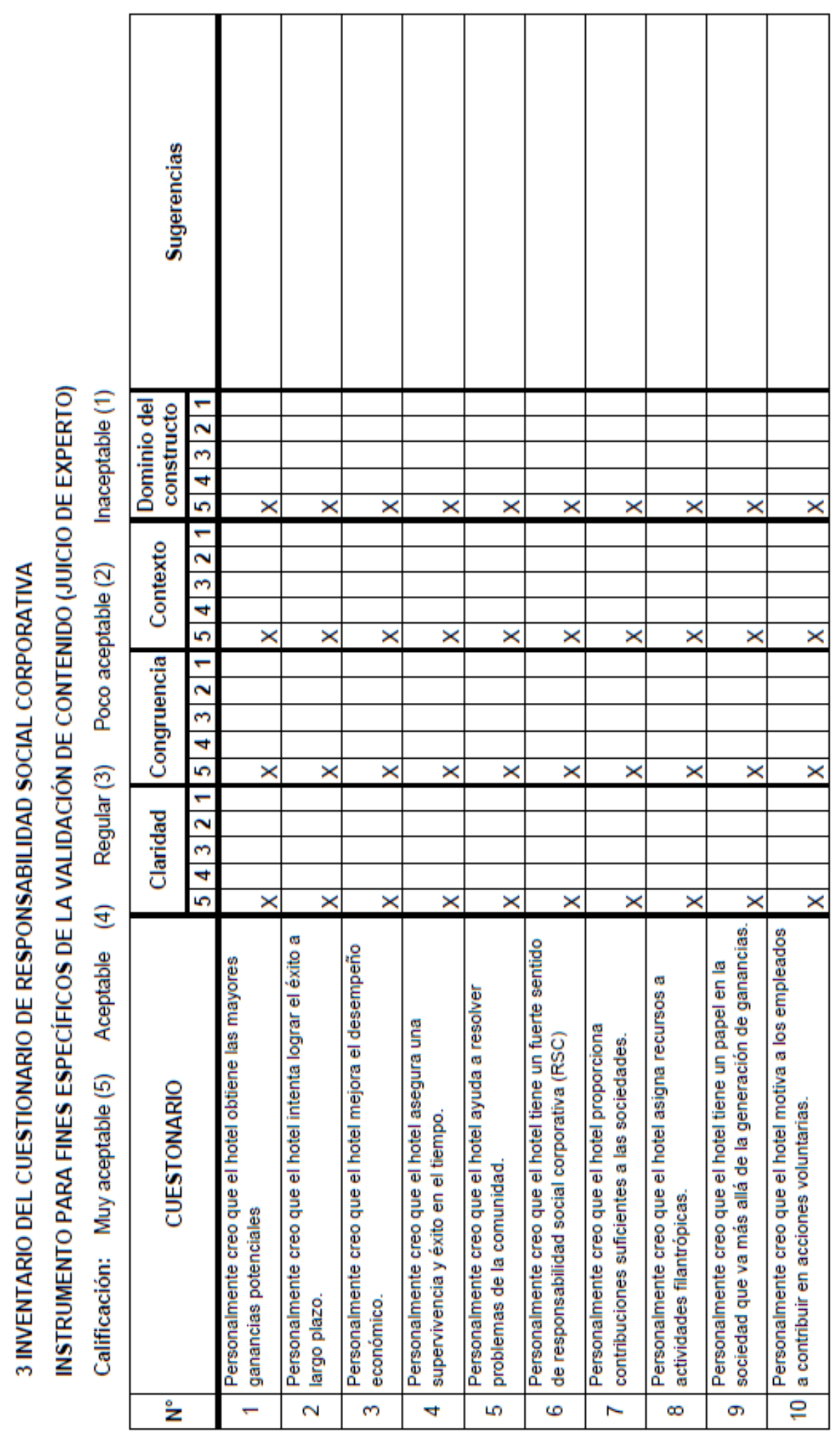




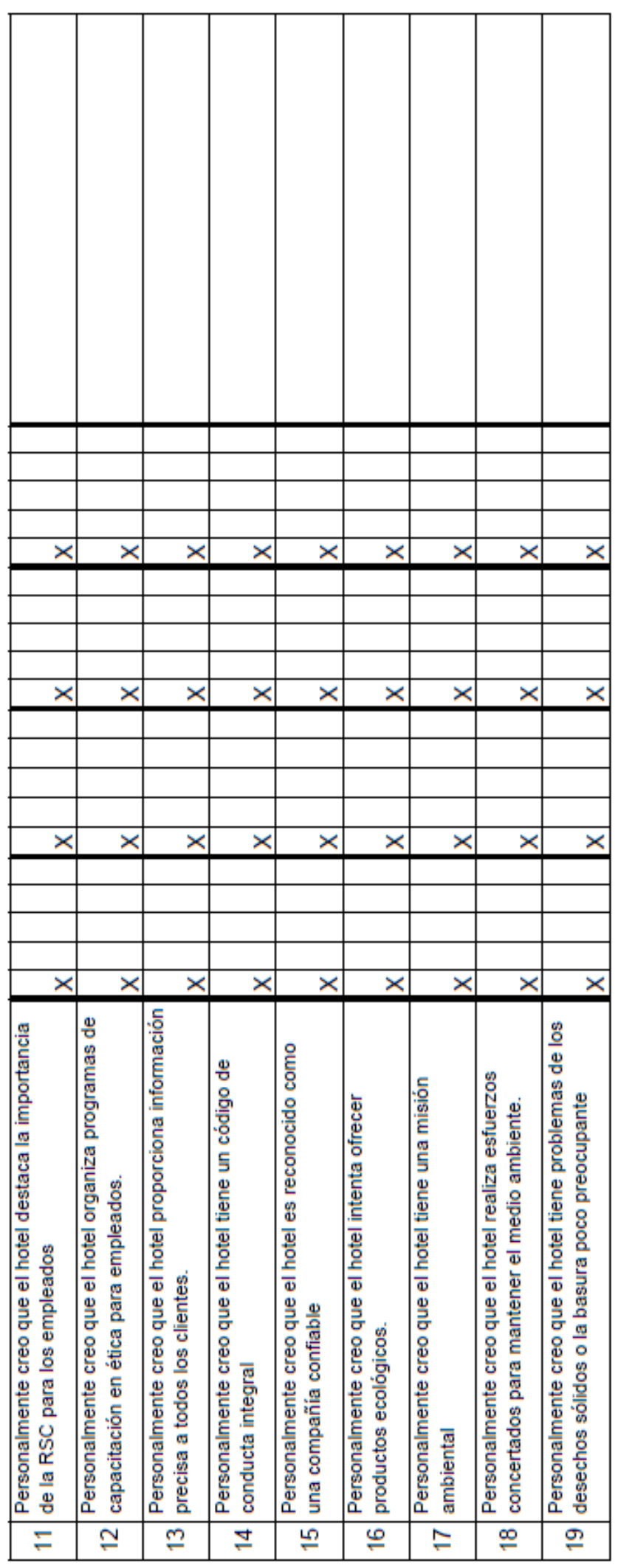




\section{INSTRUMENTO PARA LA VALIDEZ DE CONTENIDO (JUICIO DE EXPERTOS)}

El presente documento tiene como finalidad validar el cuestionario de lealtad del cliente, el mismo que será aplicado a los clientes corporativos del Hotel Palmetto que forman parte del estudio "Relación de responsabilidad social corporativa y lealtad de clientes corporativos en hotel Palmetto de San Borja 2020", que corresponde a un diseño correlacional no experimental transversal.

\section{Instrucciones}

La evaluación requiere de la lectura detallada y completa de cada uno de los ítems propuestos a fin de cotejarlos de manera cualitativa con los criterios propuestos relativos a: Claridad de la redacción, congruencia con el contenido, contexto correcto del item y dominio del constructo. Para ello deberá asignar una valoración si el ítem presenta o no los criterios propuestos, y en caso necesario se ofrecen un espacio para las observaciones si hubiera.

Juez $\mathrm{N}^{0}$ :

1

Fecha actual: $20 \mathrm{Abr} 20$

Nombres y Apellidos: BRAGGI A. BAMBERGER VARGAS

Institución donde labora: FINANCE CONSULT

Años de experiencia profesional o cientifica: 20 AÑOS

Grado de Instrucción: DOCTOR EN CONTABILIDAD Y FINANZAS

Profesión: ADMINISTRADOR

Puesto que desempeña: CONSULTOR FINANCIERO

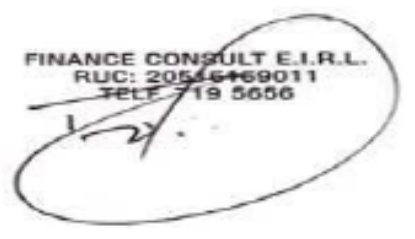

Firma y Sello 


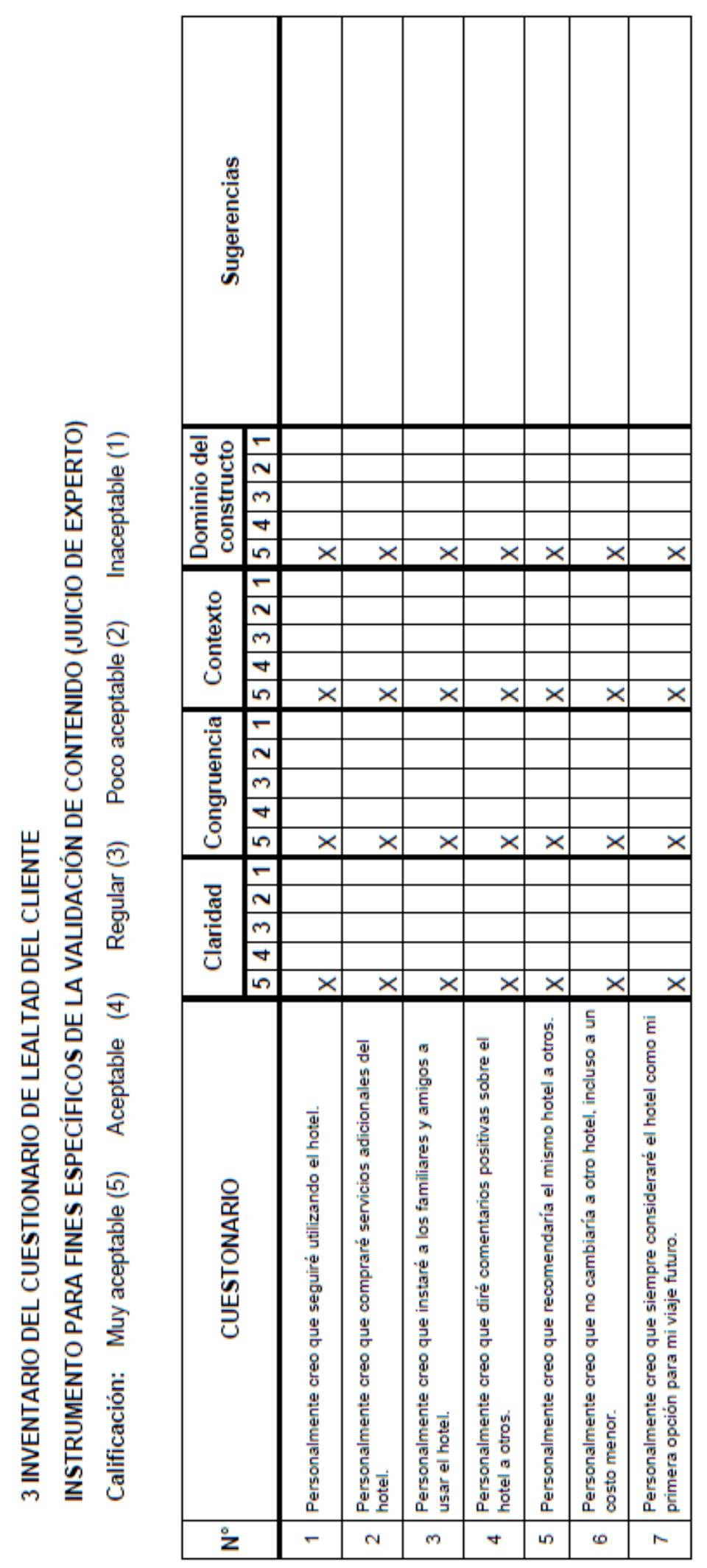




\section{INSTRUMENTO PARA LA VALIDEZ DE CONTENIDO}

\section{(JUICIO DE EXPERTOS)}

El presente documento tiene como finalidad validar el cuestionario de responsabilidad social corporativa, el mismo que será aplicado a los clientes corporativos del Hotel Palmetto que forman parte del estudio "Relación de responsabilidad social corporativa y lealtad de clientes corporativos en hotel Palmetto de San Borja 2020", que corresponde a un diseño correlacional no experimental transversal.

\section{Instrucciones}

La evaluación requiere de la lectura detallada y completa de cada uno de los ítems propuestos a fin de cotejarlos de manera cualitativa con los criterios propuestos relativos a: Claridad de la redacción, congruencia con el contenido, contexto correcto del item y dominio del constructo. Para ello deberá asignar una valoración si el ítem presenta o no los criterios propuestos, y en caso necesario se ofrecen un espacio para las observaciones si hubiera.

Juez $\mathrm{N}^{0}$ : 2

Fecha actual: 20/04/2020

Nombres y Apellidos: Zaida Katherine Rivera Nalvarte

Institución donde labora: MOCA Platform

Años de experiencia profesional o cientifica: 9

Grado de Instrucción: Máster

Profesión: Administración

Puesto que desempeña: HR Business Partner

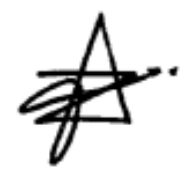

Firma y Sello 


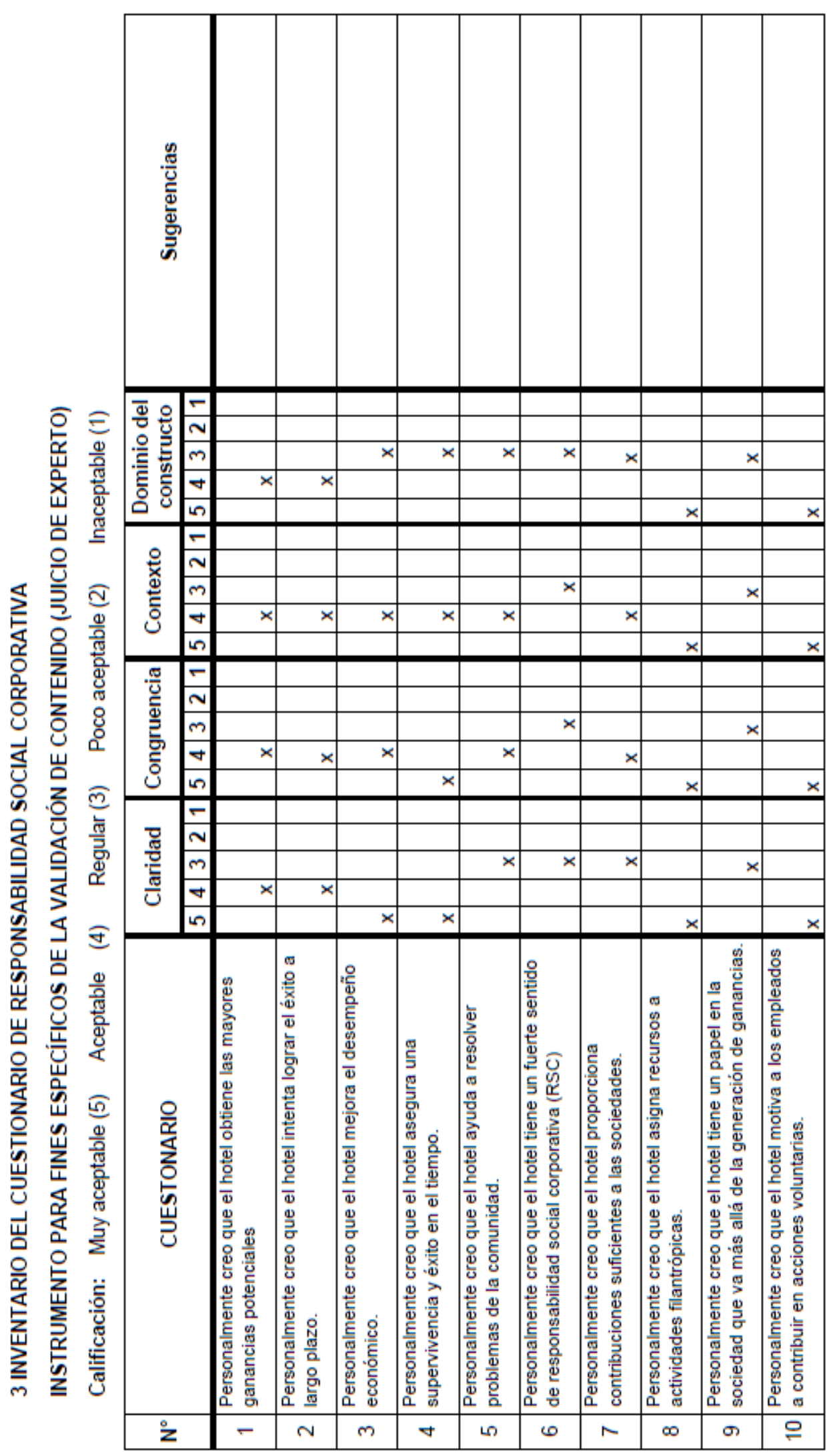




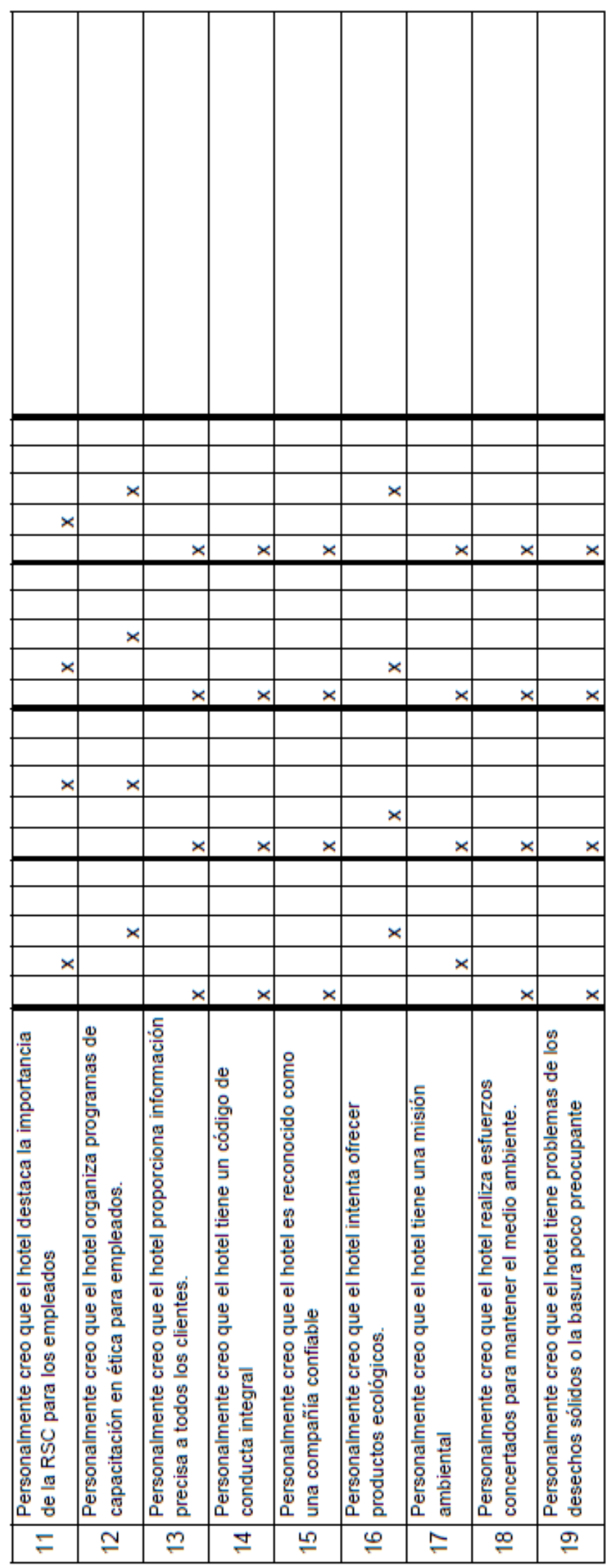




\section{INSTRUMENTO PARA LA VALIDEZ DE CONTENIDO (JUICIO DE EXPERTOS)}

El presente documento tiene como finalidad validar el cuestionario de lealtad del cliente, el mismo que será aplicado a los clientes corporativos del Hotel Palmetto que forman parte del estudio "Relación de responsabilidad social corporativa y lealtad de clientes corporativos en hotel Palmetto de San Borja 2020", que corresponde a un diseño correlacional no experimental transversal.

\section{Instrucciones}

La evaluación requiere de la lectura detallada y completa de cada uno de los items propuestos a fin de cotejarlos de manera cualitativa con los criterios propuestos relativos a: Claridad de la redacción, congruencia con el contenido, contexto correcto del ítem y dominio del constructo. Para ello deberá asignar una valoración si el ítem presenta o no los criterios propuestos, y en caso necesario se ofrecen un espacio para las observaciones si hubiera.

Juez $\mathrm{N}^{0}$ : 2

Fecha actual: 20/04/2020

Nombres y Apellidos: Zaida Katherine Rivera Nalvarte

Institución donde labora: MOCA Platform

Años de experiencia profesional o cientifica: 9

Grado de Instrucción: Máster

Profesión: Administración

Puesto que desempeña: HR Business partner

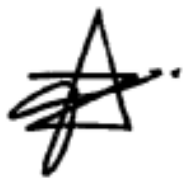

Firma y Sello 


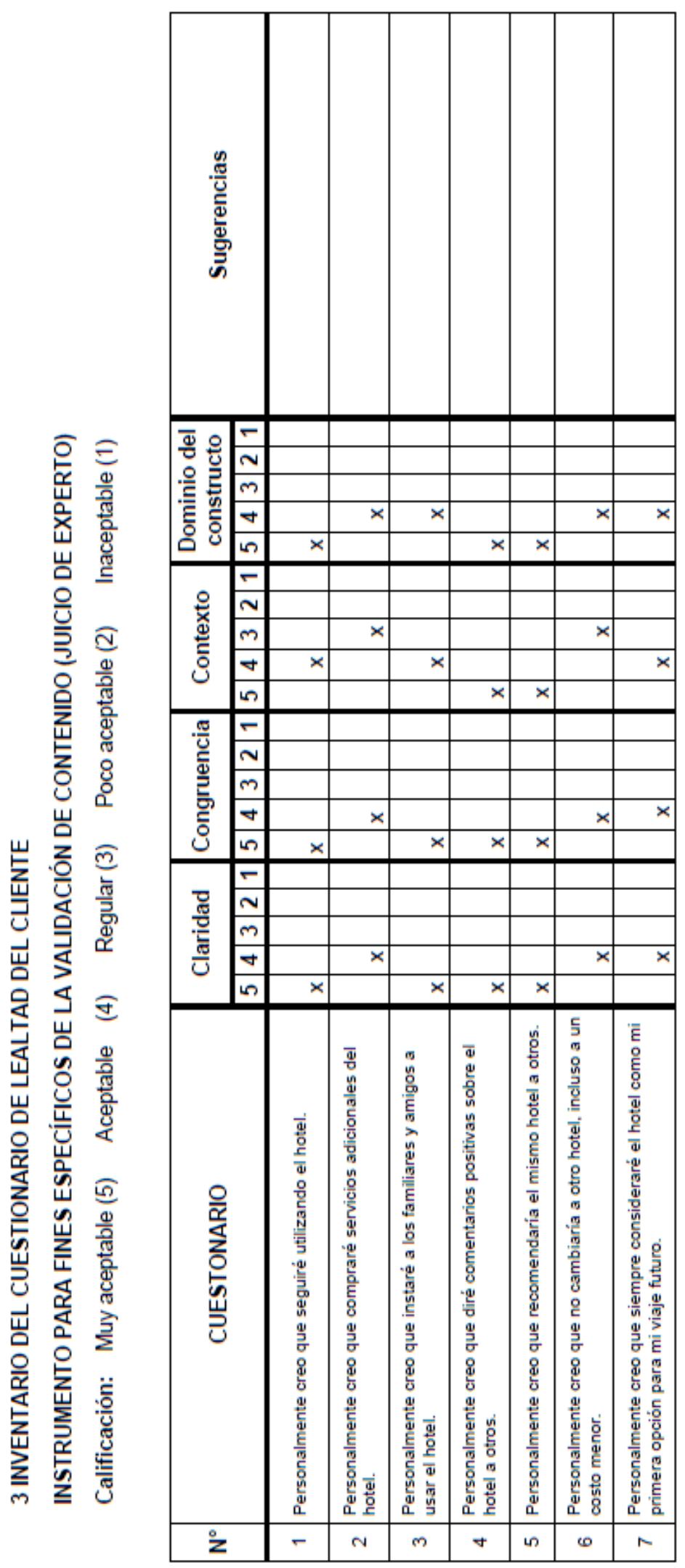




\section{INSTRUMENTO PARA LA VALIDEZ DE CONTENIDO}

\section{(JUICIO DE EXPERTOS)}

El presente documento tiene como finalidad validar el cuestionario de responsabilidad social corporativa, el mismo que será aplicado a los clientes corporativos del Hotel Palmetto que forman parte del estudio "Relación de responsabilidad social corporativa y lealtad de clientes corporativos en hotel Palmetto de San Borja 2020", que corresponde a un diseño correlacional no experimental transversal.

\section{Instrucciones}

La evaluación requiere de la lectura detallada y completa de cada uno de los ítems propuestos a fin de cotejarlos de manera cualitativa con los criterios propuestos relativos a: Claridad de la redacción, congruencia con el contenido, contexto correcto del ítem y dominio del constructo. Para ello deberá asignar una valoración si el ítem presenta o no los criterios propuestos, y en caso necesario se ofrecen un espacio para las observaciones si hubiera.

Juez $\mathrm{N}^{0}$ : 3

Fecha actual: 27 DE ABRIL DE 2020

Nombres y Apellidos: MYRIAM SILVY D ALESSIO

Institución donde labora: UPC, USIL

Años de experiencia profesional o cientifica: _25 PROFESIONAL 15

DOCENCIA

Grado de Instrucción: DOCTORANDA

Profesión: _ADMINISTRADORA DE EMPRESAS

Puesto que desempeña:__DOCENTE Y CONSULTORA

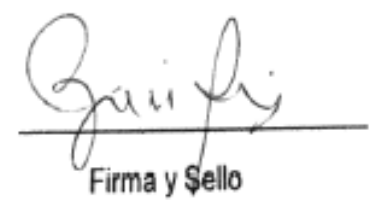




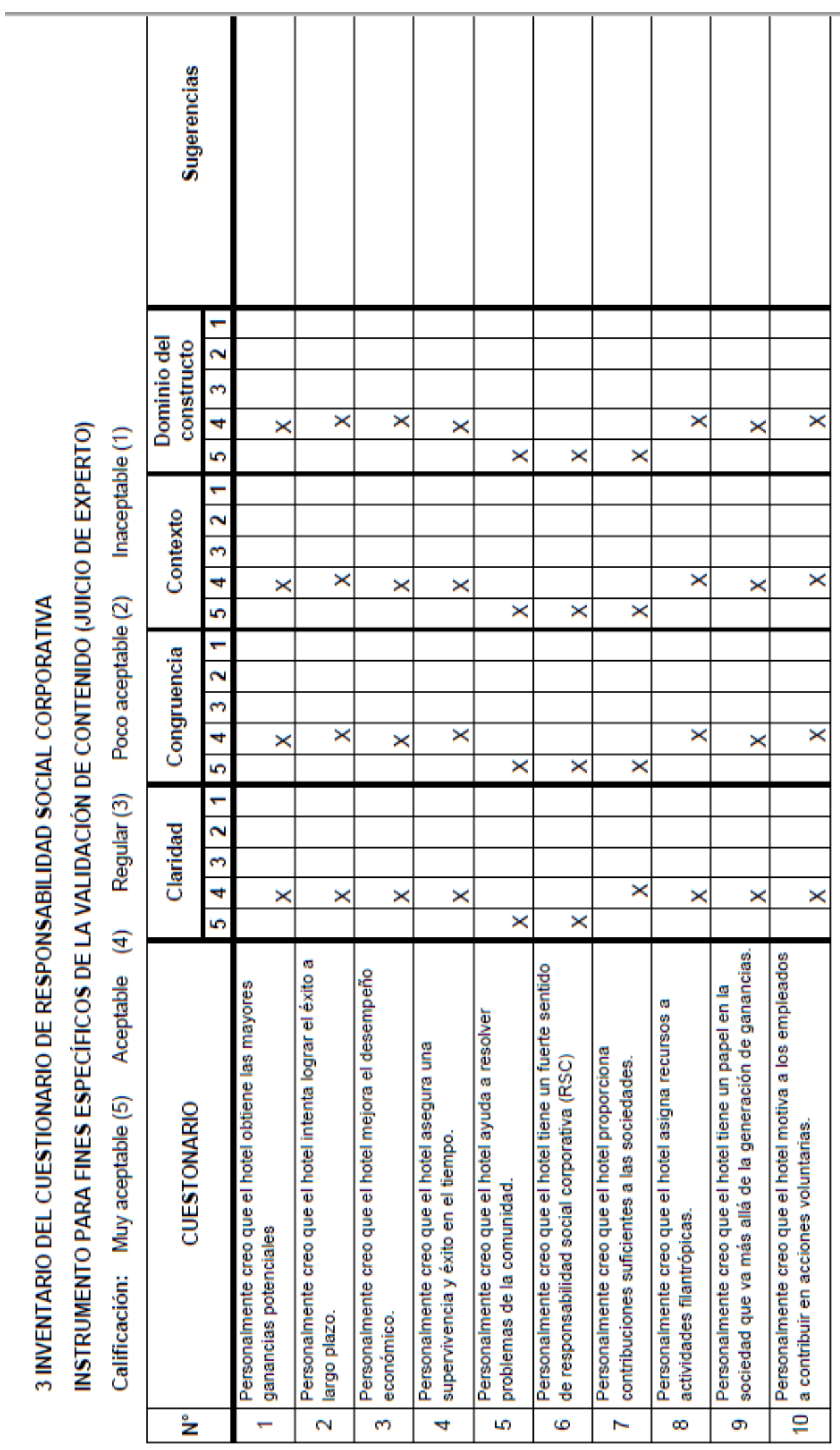









\section{INSTRUMENTO PARA LA VALIDEZ DE CONTENIDO (JUICIO DE EXPERTOS)}

El presente documento tiene como finalidad validar el cuestionario de lealtad del cliente, el mismo que será aplicado a los clientes corporativos del Hotel Palmetto que forman parte del estudio "Relación de responsabilidad social corporativa y lealtad de clientes corporativos en hotel Palmetto de San Borja 2020", que corresponde a un diseño correlacional no experimental transversal.

\section{Instrucciones}

La evaluación requiere de la lectura detallada y completa de cada uno de los ítems propuestos a fin de cotejarlos de manera cualitativa con los criterios propuestos relativos a: Claridad de la redacción, congruencia con el contenido, contexto correcto del item y dominio del constructo. Para ello deberá asignar una valoración si el ítem presenta o no los criterios propuestos, y en caso necesario se ofrecen un espacio para las observaciones si hubiera.

Juez $\mathrm{N}^{\mathrm{0}}$ : 3

Fecha actual: 27 de abril de 2020

Nombres y Apellidos: _MYRIAM SILW D'ALESSIO

Institución donde labora: __UPC y USIL

Años de experiencia profesional o científica: _25 PROFESIONAL Y 15 DOCENCIA

Grado de Instrucción: __ DOCTORANDA

Profesión: _ ADMINISTRADORA DE EMPRESAS

Puesto que desempeña: DOCENTE Y CONSULTORA

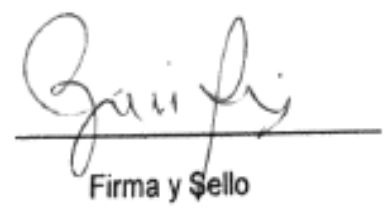




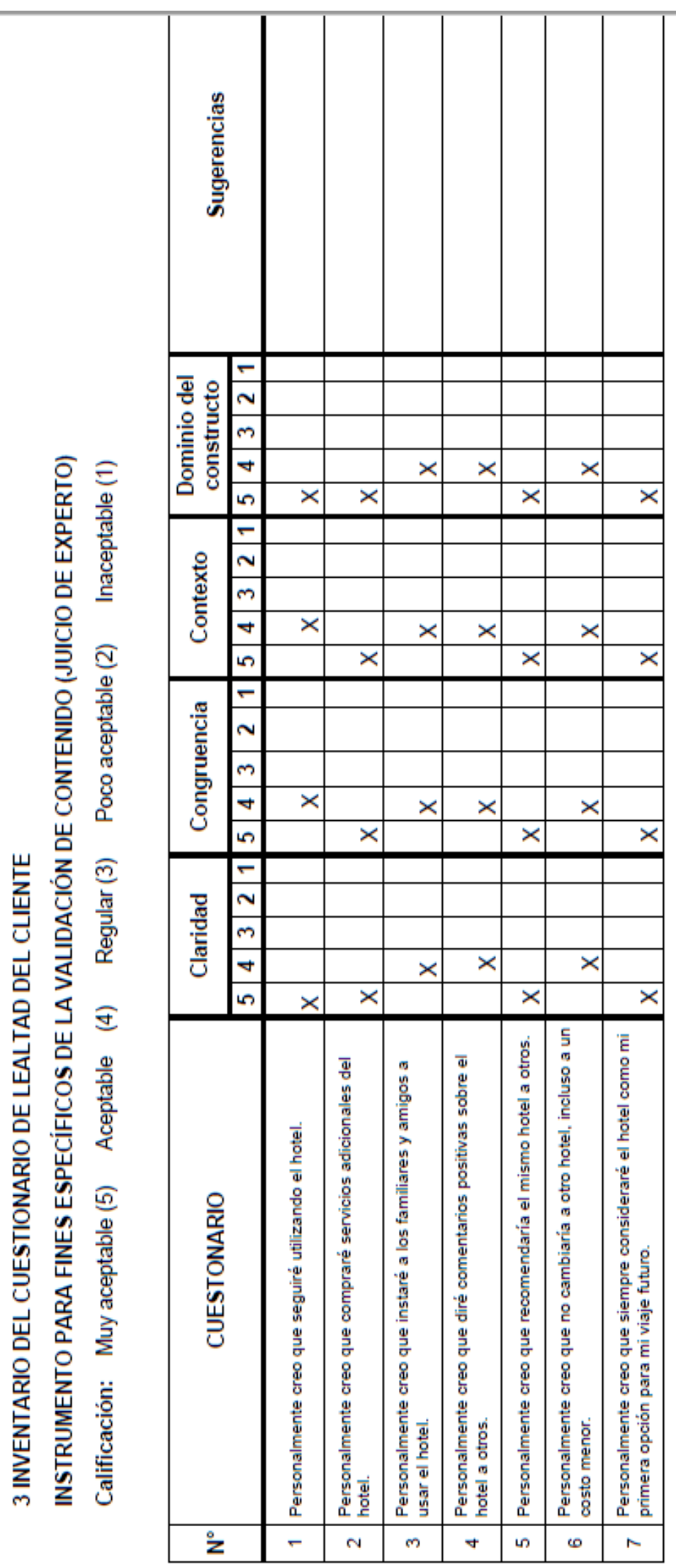




\section{Anexo 7. Consentimiento informado}

\section{CONSENTIMIENTO INFORMADO}

Estimado(a) participante le pedimos el apoyo respectivo para desarrollar los cuestionarios efectuados por Victor Enrique Calderón Reyna y Walther Jorginho Chico López, bachilleres de la carrera de administración de empresas de la Universidad San Ignacio de Loyola. Este trabajo de investigación tiene como principal objetivo analizar la relación entre la responsabilidad social corporativa y la lealtad de clientes en hotel Palmetto de San Borja. Si usted consiente a participar en este estudio, se le pedirá completar dos cuestionarios, los mismos que tendrán una duración de aproximadamente 15 a 20 minutos (cada cuestionario) de su tiempo. La participación en este trabajo de investigación será de manera confidencial y voluntaria y se utiliza con fines netamente académicos. Las respuestas que usted de se recogerán anónimamente y no se expondrá su identidad. Si existiera duda alguna sobre la investigación, se le solicita comunicarse a los siguientes correos electrónicos:

victorircalderon@gmail.com

jorginho.jchl@gmail.com

De antemano se agradece su participación.

Acepto las condiciones descritas anteriormente

Si, acepto

No, acepto 